\title{
USERS GUIDE FOR THE WATER RESOURCES DIVISION BIBLIOGRAPHIC RETRIEVAL AND REPORT GENERATION SYSTEM
}

By Nora Tamberg

U.S. GEOLOGICAL SURVEY

Open-File Report 83-691

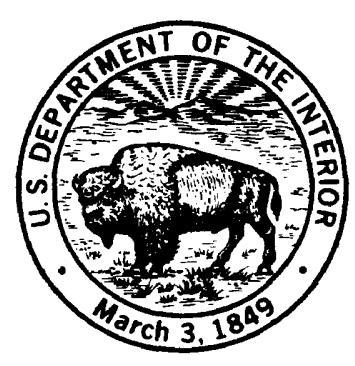




\section{UNITED STATES DEPARTMENT OF THE INTERIOR \\ JAMES G. WATT, Secretary \\ GEOLOGICAL SURVEY \\ Dallas L. Peck, Director}

For additional information

write to:

Chief, Hydrologic Information Unit U.S. Geological Survey 420 National Center 12201 Sunrise Valley Drive Reston, Virginia 22092
Copies of this report can be purchased from:

Open-File Services Section Western Distribution Branch Box 25425, Federal Center Denver, Colorado 80225 (Telephone: (3ก3) 234-5888) 


\section{CONTENTS}

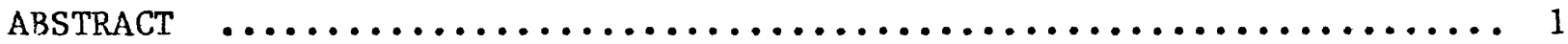

\section{SECTION I}

GENERAL INFORLATION

A. INTRODUCTION TO USERS GUIDE $\ldots \ldots \ldots \ldots \ldots \ldots \ldots \ldots \ldots \ldots \ldots \ldots \ldots \ldots \ldots$

A.1. Objectives $\ldots \ldots \ldots \ldots \ldots \ldots \ldots \ldots \ldots \ldots \ldots \ldots \ldots \ldots \ldots \ldots \ldots$ I 1

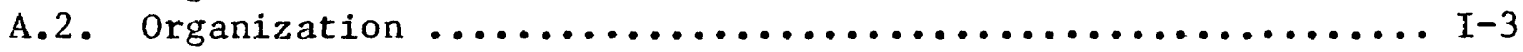

A.3. How to use Users Guide $\ldots \ldots \ldots \ldots \ldots \ldots \ldots \ldots \ldots \ldots \ldots \ldots \ldots \ldots$

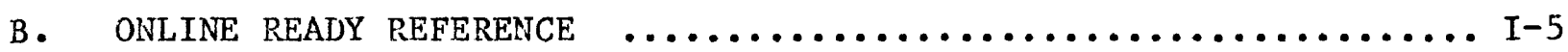

B.1. Online Ready Reference: "WBsum.info" ................. I-5

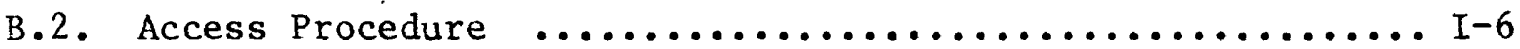

B.3. Contents of "WBsum.info" segment $\ldots \ldots \ldots \ldots \ldots \ldots \ldots \ldots \ldots \ldots$ I -7

C. SCHEMATIC OVERVIEN OF WRDBIB SYSTFM.................... I-8

C.1. Schematic Overview $\ldots \ldots \ldots \ldots \ldots \ldots \ldots \ldots \ldots \ldots \ldots \ldots \ldots \ldots$

C.2. Program Execution Checklist $\ldots \ldots \ldots \ldots \ldots \ldots \ldots \ldots \ldots \ldots \ldots$ I-9

C.3. Entry Conventions ............................ I-10

C.4. Use Multics editor $\ldots \ldots \ldots \ldots \ldots \ldots \ldots \ldots \ldots \ldots \ldots \ldots \ldots \ldots \ldots \ldots$ I 11

C.5. Essentials of File Management $\ldots \ldots \ldots \ldots \ldots \ldots \ldots \ldots \ldots \ldots \ldots$ I 12

D. LISTING OF MULTICS READY_REFERENCE SECTIONS $\ldots \ldots \ldots \ldots \ldots \ldots \ldots \ldots$

\section{SECTIOIJ II}

INTRODUCTION TO WRDBIB FEATURES

A. PROGRAM EXECUTION OVERVIEW

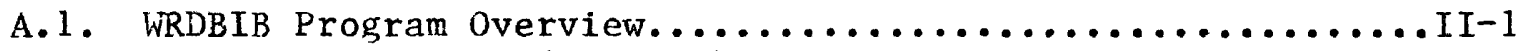

A.2. Program Statement (Command)..................... II

A.3. Systems Features.............................. II

A.4. Systems Responses.............................

A.5. Program Execution Example....................... II -5

A.6. Custom Report Format............................ II 6 
B. WRDBIB FILES AND STATEMENTS

B.1. WRDBIB Files Required for Program Execution.............. II-7

B.2. Data Dictionary.............................. II -8

B.2.1 Dictionary Created in Multics Text Editor..............

B.2.2 Dictionary Created During Creation Program............II-10

B.3. Creating a WRDBIB Program (Compiling).................II-11

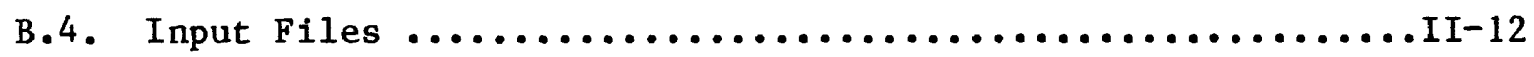

B.4.1 WRDBIB Input Files.......................... II-12

B.4.2 Altering Input Files During Program Execution.........II-13

B.5. Defining Program Variables ........................II-14

B.5.1 Checking Internal Program Dictionary................II-14

B.5.2 Declaring Numeric Variables......................II-15

B.6. Retrieval statement............................II-16

B.6.1 How to Formulate Your Retrieval Statement............II-16

B.6.2 Retrieval Relational Operators................... II 16

B.6.3 Examples ................................ II 17

B.6.4 Compound $($ Logic) Operators....................... II-18

B.7. Response File................................II-19

B.7.1 Response File Function .........................

B.7.2 Altering Response File During Program Execution........II-19

B.7.3 Example of Response File ....................... II-20

C. OUTPUT FEATURES

C.1. Sorting...................................II-21

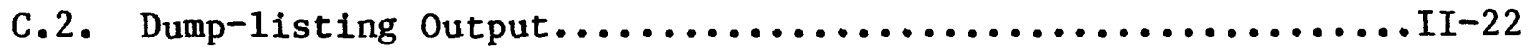

C.2.1 "Dump-11sting" Procedure....................... II 22

C.2.2 Retrieval Program Using "Dump-1isting" Option.........II-23

C.2.3 Example of "Dump-Listing" Output.................II-24

C.3. Creating Standard Report.........................II-25

C.3.1 Creating a "Standard MT" Report.....................

C.3.2 Standard Report Generation Procedure................II-26

C.3.3 "Standard_MT" Response File.....................II-27

C.4. Creating a Custom Report.........................II-28

C.4.1 Report Format Specifications.....................

C.4.2 Header Lines and Detail Record Lines................. II-28

C.4.3 Printing Wraparound...........................

C.4.4 Using Key-Words..............................II-29

C.4.5 Key-Words Prompting User Interaction ...............II-29

C.5. Selected Key-Word List.......................... II-30 
WRDBIB PROGRAM EXECUTION PROCEDURES

A. RETRIEVAL: EXECUTING W/USER-SUPPLIED RESPONSES

A.1. Overview: Program Statement (Command)................ III-1

A.2. Overview: Retrieval Request Structure................. III-3

A.3. Retrieval Program Execution:

A.3.1 Procedure_A: How to Execute a Retrieval Program.......III-4

A.3.2 Program Ex̃ecution: EXAMPLE.................... II -5

A.4. Retrieval Output:

A.4.1 Retrieval Response File "RETR.response"..............III-6

A.4.2 Data Segment..............................III-6

B. RETRIEVAL AND REPORT GENERATION USING CONTROL ARGUMENTS

B.1. Procedure_B: Using -rsp $\langle$ path $\rangle-$ chg $\langle 1 i s t\rangle \ldots \ldots \ldots \ldots \ldots \ldots . . .1 I I-7$

B.2. Retrieval Program: Using - rsp RETR -chg mc

EXAMPLE .................................

B.3. Retrieval and Report Generation Program:

B.3.1 Response File "newpr.response" ....................II-10

B.3.2 Program Execution: Using - rsp newpr -chg in,mc

EXAMPLE ...................................

C. REPORT GENERATION USING CONTROL ARGUMENTS

C.1. Reformatting Previously Retrieved Data:

C.1.1 Procedure C: Using -rsp 〈path〉-chg $\langle 1$ ist $\rangle \ldots \ldots \ldots \ldots$...III-12

C.1.2 Response $\overline{\text { File }}$ "FORM. response" ....................III-13

C.2. Custom Report Generation: Using - rsp FORM - chg in

C.2.1 Reformatting Program: EXAMPLE ................... III 14

C.2.2 Custom Report (C1tations)..................... III 15

C.3. Report Generation w/Descriptors: Using - rsp newpr -chg in,mc

C.3.1 Reformatting Program: EXAMPLE .................. III-16

C.3.2 Custom Report w/Descriptors.....................III-17

C.4. Index Report Generation: Using -rsp AUT -chg in

C.4.1 Response File: AUT.response ....................II-18

C.4.2 Generating Author Index: EXAMPLE ................... III-19

C.4.3 Author Index Report..........................III-20

C.5. Numeric Index Report Generation: Using - rsp AUT -chg in, sc

C.5.1 Generating Numeric Sort.......................III-21

C.5.2 Numeric Index Report..........................III-22

D. DIRECTORY CHECK ................................... III 23 


\section{APPENDIX I :}

\section{ACCESS AND LISTING PROCEDURES}

A. WRDBIB DATA BASE ACCESS $\ldots \ldots \ldots \ldots \ldots \ldots \ldots \ldots \ldots \ldots \ldots \ldots \ldots \ldots$ APP_I-1

A.1. Checklist: Access Procedures .................. APP_I-1

A.2. How to Establish Communication with Multics ......... APP_I-2 A.2.1 Dial_up Procedure ..................... APP_I-2

A 2.2 Login Procedure ..................... APP_I-2

A.3. Access to "Working Directory" $\ldots \ldots \ldots \ldots \ldots \ldots \ldots \ldots \ldots \ldots \ldots$ APP I-3

A.3.1 Working Directory ">IO" ................. APP_I-3

A. 3.2 WRDBIB. ec Command $\ldots \ldots \ldots \ldots \ldots \ldots \ldots \ldots \ldots \ldots \ldots$ APP_I-4

B. WORKING DIRECTORY AND WRDBIB FILES $\ldots \ldots \ldots \ldots \ldots \ldots \ldots \ldots \ldots \ldots \ldots \ldots$ APP I-5

B.1. Listing Procedures: Working Directory ............ APP_I-5

B.2. Listing Procedures: Programs and Dictionaries ........ APP_I-6

B.3. Listing Procedures: Input Files $\ldots \ldots \ldots \ldots \ldots \ldots \ldots \ldots \ldots \ldots$ APP_I

B.4. Tape-archived Input Files .................... APP I-8

B.4.1 To List Contents of "master.ta"............. APP I-8

B.4.2 To Extract Tape-archived Segments ..................

B.5. Listing Procedures: Response Files ................. APP I-9

B.5.1 Response Files ......................... APP I-9

B.5.2 Response File Archive .................... APP I-9

B.5.3 Editing Response File $\ldots \ldots \ldots \ldots \ldots \ldots \ldots \ldots \ldots \ldots$ APP_I 10

B.6. Listing Procedures: Output Files $\ldots \ldots \ldots \ldots \ldots \ldots \ldots \ldots \ldots$ APP_I -11

APPENDIX_II

GLOSSARY OF SELECTED TERMS 
Step_1: FORMULATE SEARCH STRATEGY $\ldots \ldots \ldots \ldots \ldots \ldots \ldots \ldots \ldots \ldots \ldots \ldots \ldots$ APP_III 1

Step_2: FORMULATE RETRIEVAL STATEMENT $\ldots \ldots \ldots \ldots \ldots \ldots \ldots \ldots \ldots \ldots \ldots \ldots$ APP_III-2 Print Data Dictionary ............................

Step_3: SELECT CUSTOM PROGRAM \& COMPATIBLE INPUT FILES .......... APP III-4 Check Program Dictionary ..................... APP_III-4

Step_4: ENTER A CUSTOM PROGRAM STATEMENT w/CONTROL ARGUMENTS ...... APP_III-5 Select Response Argument --

Response File: "FORM.response" ............................... III-5

Enter Program Statement for Index Report ................. APP III

Response File: "AUT.response" ........................ APP_III-8

FIRST RETRIEVAL RUN $: \ldots \ldots \ldots \ldots \ldots \ldots \ldots \ldots \ldots \ldots \ldots \ldots \ldots \ldots \ldots \ldots \ldots \ldots \ldots \ldots$ APP III -9

Step_5: EXECUTE INITIAI RETRIEVAL PROGRAM .................. APP_III-9 (Step 1 of Two-step Procedure and Example)

Step_5A: EXECUTE (OPTIONAL) REPORT GENERATION PROGRAM ........... APP_III-11 (Optional Step 2 of Two-step Procedure)

Step_6: EXECUTE ALTERNATE RETRIEVAL \& REPORT-GENERATION PROGRAM ... APP_III-12 (One-step Procedure and Example)

Step_7: EXECUTE (OPTIONAL) AUTHOR INDEX PROGRAM APP_III-14 (Procedure and Example)

SECOND RETRIEVAL RUN:

APP_III- 16

Step_8: EXECUTE SECOND RETRIEVAL \& REPORT GENERATION PROGRAM APP III -17 (One-step Procedure and Example)

Step 8A: EXECUTE ALTERNATE REPORT GENERATION PROGRAM (Procedure) ... APP III-19 Response File: "newpr.response" .................... APP III-20 Reformat Final Report to Include Descriptors (Example) .... APP III-2I

Step_9: EXECUTE FINAL AUTHOR INDEX PROGRAM ..................APP_III-22 (Procedure and Example)

Step_10: CHECK WORKING DIRECTORY \& LOGOUT ....................APP_III-24

EXAMPLES $\quad$ CUSTOLI REPORT ..............................APP_III-25 AUTHOR INDEX REPORT $\ldots \ldots \ldots \ldots \ldots \ldots \ldots \ldots \ldots \ldots \ldots \ldots \ldots \ldots \ldots$ APP_III 26 


\section{ILLUSTRATIONS}

Figure I-1.-- CUSTOM-FORMATTED RECORD........................ I-2

Figure I-2.-- LISTING OF WBsum. info HEADER LINES $\ldots \ldots \ldots \ldots \ldots \ldots \ldots \ldots \ldots \ldots \ldots$ I-6

Figure II-1.-- PROGRAM EXECUTION USING CONTROL ARGUMENTS............... II-5

Figure II-2a.--A TYPICAL CUSTOM REPORT: POST's GLACIER REPORTS........... II-6

Figure II-2b.--CUSTOM REPORT WITH DESCRIPTORS: POST'S GLACIER REPORTS....... II-6

Figure II-3.-- DATA DICTIONARY DESCRIPTION: "extdict" ................ II-8

Figure II-4.-- DICTIONARY INPUT DURING PROGRAM CREATION $\ldots \ldots \ldots \ldots \ldots \ldots \ldots \ldots \ldots$ II-10

Figure II-5.-- CREATING A CUSTOM PROGRAM USING A WRDBIB DICTIONARY ........ II-11

Figure II-6.-- CHECKING PROGRAM DICTIONARY FOR VARIABLE DEFINITION ......... II-14

Figure II-7.-- TYPICAL RESPONSE FILE SPECIFIES A CUSTOM REPORT FORMAT ...... II-20

Figure II-8.-- RETRIEVAL PROGRAM EXECUTION: DUMP-LISTING OUTPUT ......... II-23

Figure II-9.-- DUMP-LISTING OUTPUT: ONE SAMPLE RECORD AT THE TERMINAL ...... II-24

Figure II-10.--STANDARD REPORT RESPONSE FILE: "STD.response" $\ldots \ldots \ldots \ldots \ldots \ldots$ II-27

Figure II-11.--CUSTOM-FORMATTED RECORD: Example of wrap-around printing .... II-29

Figure III-1.--RETRIEVAL PROGRAM EXECUTION: Creating RESPONSE File ........ III-4

Figure III-2.--RETRIEVAL RESPONSE FILE: "RETR.response" $\ldots \ldots \ldots \ldots \ldots \ldots \ldots \ldots \ldots$. ....

Figure III-3.--RETRIEVAL PROGRAM EXECUTION USING CONTROL ARGUMENTS .........III-7

FIgure III-4.--RESPONSE FILE: "newpr.response" w/Report Format ...........III-8

Figure III-5.--TYPICAL ONE-STEP RETRIEVAL AND REPORT GENERATION PROGRAM ..... III-9

Figure III-6.--RESPONSE FILE: "FORM.response" w/Report Format ...........III-11

Figure III-7.--REFORMATTING PREVIOUSLY RETRIEVED DATA: Using FORM.response..III-12

Figure III-8.--CUSTOM REPORT: BIBLIOGRAPHIC CITATIONS ONLY ............ III-13

Figure III-9.--CUSTOM REPORT GENERATION: Reformatting Data Segment .........III-14

Figure III-10.--CUSTOM REPORT W/DESCRIPTORS GENERATED BY "newpr.response" ...III-15

Figure III-11.--RESPONSE FILE "AUT.response" : INDEX REPORT Format .........III-16

Figure III-12.--REPORT GENERATION PROGRAM: Creating AUTHOR INDEX .........III-17

Figure III-13.--AUTHOR INDEX REPORT TO RETRIEVED WATER SUPPLY PAPERS ....... III-18

Figure III-14.--NUMERIC INDEX REPORT TO RETRIEVED WATER SUPPLY PAPERS ......III-20 
USERS GUIDE FOR THE WATER RESOURCES DIVISION BIBLIOGRAPHIC

RETRIEVAL AND REPORT GENERATION SYSTEM

ABSTRACT

The Water Resources Division maintains a bibliographic reports data base (WRDBIB) using WRSIC* tapes as input. The WRDBIB data base includes some 8700 WRD report citations and is updated quarterly. (The annual update volume is ca. 700 titles.) The data base contains bibliographic data elements and key-words descriptive of WRD reports released for publication or open-filed during the period 1968 to present. The data base is resident in the Multics computer in Reston and may be accessed by registered Multics users in the field.

A RETRIEVAL AND REPORT GENERATION system has been developed by applying Multi_trieve (MT-) Retrieval and Report-generation software to bibliographic data files. Users may search WRD reports derived from WRSIC tapes on the following bibliographic and subject data fields: authors, organizational source, title, citation, descriptors, and WRSIC (accession) number. The USERS GUIDE is intended to assist the user in selecting and executing retrieval and report generation procedures.

A GENERAL INTRODUCTION describes the organization of the USERS GUIDE and the online READY REFERENCE feature: WBsum.info. A schematic overview of the WRDBIB Retrieval and Report generation system and of WRDBIB files required for program execution is given at this point. Section_II: INTRODUCTION TO WRDBIB provides a description of Multi_trieve features from PROGRAM CREATION to REPORT GENERATION as applied to WRDBIB programs. Section III: WRDBIB PROGRAM EXECUTION describes the actual RETRIEVAL and/or REPORT GENERATION PROCEDURES providing detailed instructions and program execution examples. Three APPENDICES include detailed instructions on how to access Multics and the WRDRIB data base (APPENDIX I); a Glossary of Selected Terms used by the Multi_trieve system (APPENDIXIII), and procedures illustrating how to execute a fairly complex RETRIEVAT and REPORT GENERATION SESSION in ten steps (APPENDIX III)-- beginning with problem definition to creating custom REPORTS and INDEX $\bar{X} E$.

The User will learn to describe his INPUT record in terms of a DATA DICTIONARY, and use it to create a custom WRDBIB PROGRAM. The user will learn to formulate a PROGRAM STATENENT (command) appropriate to his/her RETRIEVAL and/or REPORT GENERATION problem: He/she may execute exploratory RETRIEVAL runs supplying all responses which may be stored as RESPONSE files for future similar retrievals. 
To execute RETRIEVAL and REPORT GENERATION PROGRAMS the user will formulate PROGRAM STATEMENTS which will include control arguments. The user may wish to use the "response" argument together with the "change_list" argument. This will allow him/her to recall a WRDBIB RESPONSE file with custom REPORT specifications and to interactively alter certain parameters as designated by the "change_list": For example, INPUT files, selection (MATCH) criteria, and SORT criterīa.

The user will learn to translate his retrieval problem into RETRIEVAL STATEMENTS. These selection criteria are designed to match expected values of DICTIONARY elements against character strings found in a given INPUT record. Use of relational operators (partial name, equal to, greater than, less than, range) and of BOOLEAN "AND/OR" logic is illustrated.

Finally, the user will learn to create custom REPORTS using various WRDBIB RESPONSE files with detailed format specifications. Interactive entry of REPORT elements in response to system's prompts is illustrated. Examples are, entry of the REPORT "title", or of "descriptors" as additional print element. The user will use various output options for his OUTPUT files. Detailed file manipulation procedures, as well as the use of Multics text editor "ted", are are given in APPENDIX_I: WRDBIB DIRECTORY AND WRDBIB FILES.

The USERS GUIDE supplements the basic MULTI TRIEVE Users Manual (CCD 1980).

Available online are fifteen selected topics of the USERS GUIDE in form of "info" segments labelled "WBsum.info" which may be accessed with the "help" command. The "info" segments are designed as "ready_reference" and complement the information in the USERS GUIDE.

* WRSIC: Dept. of Interior. Water Resources Scientific Information Center. 


\section{SECTION I. \\ GENERAL INFORMATION}

A. INTRODUCTION TO USERS GUIDE

B. ONLINE READY_REFERENCE: WBsum.info

C. WRDBIB SYSTEM: SCHEMATIC OVERVIEW

D. LISTING OF MULTICS READY_REFERENCE SECTIONS 


\section{GENERAL INFORMATION}

\section{A. INTRODUCTION TO USERS GUIDE}

A.1. Objectives:

The Users Guide is intended to provide ready reference information to users of the WRDBIB RETRIEVAL and REPORT GENERATION system as applied to searching bibliographic data. The aim is to make Water Resources Division reports generally accessible to users in Reston and in the field for browsing and retrieval on user-specified search criteria, or by types of materials (all maps, Water Supply Papers, Open-File Reports, specific journal articles, etc.), and to enable users to prepare their own custom reports and indexes.

The WRDBIB data base has been compiled from extracts of WRSIC* bibliographic tapes covering the WRSIC accession period: 1968 to present. The data base includes $8500+$ WRD report citations. (The annual update volume is about 700 titles.) The "Master" file (7407 records) is tape-archived, while the "Current" files (1200 records) are accessible online. Users may search the following variable fields: Author, publication year, source organization, title, citation, descriptor/identifier, and WRSIC (accession) number. The record fields are described in the DATA DICTIONARY.

The Users Guide is conceived to compliment the Multi trieve Manual.** To aid the user WRDBIB programs operate in a tutorial mode. Thus upon mastering the elementary Multics command language at the systems and the editor levels,*** the user may apply "custorn" (user-formatted) retrieval and report generation PROGRAMS to interactive searching of WRDBIB files.

The Users Guide provides information on data elements and their formats as represented in the DATA DICTIONARY. It describes WRDBIB INPUT (data) files and PROGRAMS which must conform to the DATA DICTIONARY format. It teaches how to execute RETRIEVAL AND/OR REPORT GENERATION PROGRAMS using WRDBIB RESPONSE files as the major control argument, together with "change list" arguments which allow to interactively change INPUT files, MATCHING and SORT criteria during program execution. The syntax of the PROGRAM command is fully described:

$\langle$ PROGRAM NAME [-response 〈path>] [-change 〈change_list>]

where "change_list" may designate: "in" (INPUT file); "mc" (MATCHING criteria); and "sc" SORT criteria in any combination.

\footnotetext{
* WRSIC: Water Resources Scientific Information Center. Dept. of Interior.

** See: MULTI_TRIEVE [Manual]. U.S. Geological Survey. CCD. (1980)

*** It is assumed the user has a working knowledge of Multics command language, editing techniques, and basic skills in file manipulation as learned in the course: Introduction to Multics. For ready reference see Introductory Multics Handbook. USGS CCD (1980).
} 
The Users Guide suggests retrieval strategies and translates them into RETRIEVAL STATEMENTS using relational operators and Boolean ("AND/OR") logic.

The Users Guide introduces various REPORT generation options. The user may specify a "standard MT" REPORT format or create a custom REPORT by choosing a RESPONSE file with appropriate format specifications. The user may direct his REPORT output to the terminal or to a remote printer. Instructions are given how to obtain a sample "dump" of one or more records at the terminal and how to retrieve and store a data (OUTPUT) file for use as INPUT in other searches. A discussion of reformatting procedures and the creation of AUTHOR INDEXES is included. A custom formatted report record is shown in figure $I-1$ below.

The generated bibliographic citations may be sorted alphabetically by author or numerically by the WRSIC number. A sort by the WRSIC (accession) number will enable the user to tie into the published Selected Water Resources Abstracts (SWRA) and to read the abstracts of cited reports.

\footnotetext{
Author(s)

WOLANSKY, R. M.; MILLS, L. R.; WOODHAM, W. M.; $1979 \longleftrightarrow \cdots$ Publn.year AND LAUGHLIN, C. P.;

POTENTIOMETRIC SURFACE OF FLORIDAN AQUIFER, SOUTIWEST <-FLORIDA WATER MANAGEMENT DISTRICT AND ADJACEIT AREAS, MAY 1979,

GEOLOGICAL SURVEY OPEN-FILE REPORT 79-1255, 1979.

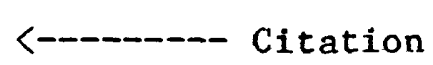
1 SHEET.

*IAAPS, *AQUIFERS, *WATER LEVELS, *POTENTIOMETRIC LEVEL, <---- Descriptors *FLORIDA, WATER WELLS, WATER UTILIZATION, IRRIGATION, WATER LEVEL FLUCTUATIONS, *FLORIDAN AQUIFER, SOUTHWEST FLORIDA, WATER MANAGEMENT .

$$
\text { 81-00141 - - WRSIC no. }
$$
}

Figure I-1.--CUSTOM-FORMATTED RECORD: Includes Variable Field Designation. 
Section I: General Information begins with an Introduction to the Users Guide stating its objectives and outlining its organization. This is followed by a section suggesting how to use this Users Guide. A brief description of the online ready_reference feature: WBsum.info is given. A Schematic Overview of the WRDB IB System and its auxiliary procedures follows. A Listing of Multics Ready Reference Sections is appended here.

Section II. Introduction to WRDBIB Features provides a Program Execution Overview with illustrations (section II.A.) This is followed by section II.B. WRDBIB Files and Statements with a description of Multi trieve features from Program creation to Report generation as applied to WRDBIB programs. Section II.C. covers available Output Features.

Section_III: WRDBIB Program Execution describes the actual retrieval and/or report generation processes providing detailed instructions and program execution examples.

Three Appendices include detailed instructions as outlined below:

APPENDIX_I of the Users Guide contains access procedures to the working directory and its files. It details listing and printing procedures for WRDBIB files using commands at the Multics command and the editor levels. Use of online (storage) archives as well as tape archives is illustrated.

APPENDIX_II includes a Glossary of Selected Terms that have a special meaning in applied Multi trieve programs. Since users will be familiar with the majority of terms in Multics parlance, only the usage of selected Multics terms has been redefined here in relation to the WRDBIB program.

APPENDIX III includes a sample Retrieval Session with step-by-step instructions and examples illustrating user/computer interaction during program execution while searching the Water Resources Division bibliographic (WRDBIB) reports data base. 
A.3. How to use this Users Guide:

Depending on the user's proficiency level in using Multics commands and editor features, the user may select any one of the following approaches:

(1) Glance over section I: GENERAL INFORMATION. If you are at ease with Multics, you might prefer to consult online "help" segments for additional information.

-- Go to section I.B. Online Ready Reference: "WBsum.info" and check out the information segment using the "help" command. For more detailed access procedures to the working directory and its files see APPENDIX I.

-- To get a feel for the system look at section I.C. Schematic Overview of of the WRDBIB System and its components.

(2) Begin with section I: GENERAL INFORMATION. Study section I.C. Schematic Overview of WRDBIB System.

-- Proceed to section II.A. Program Execution Overview. This will tell you on four pages and in three figures all you need to know about executing a WRDBIB retrieval and report generation program.

-- Do you understand the PROGRAM STATEMENT entry? (See section II.A.2.)

-- Do you understand what the RESPONSE file is all about? (See section II.B.7.) Print the two referenced RESPONSE files and compare format specifications! (See APPENDIX I for procedures listing and printing library files.)

-- Do you understand how to formulate your RETRIEVAL STATEMENT? (See II.B.6.)

NOTE: FOR A DESCRIPTION OF WRDBIB FILES AND INPUT/OUTPUT PROCEDURES SEE SECTIONS II.B AND II.C.

(3) Skim the introductory section I and study Schematic Overview in I.C.

-- Go to section III: WRDBIB PROGRAM EXECUTION PROCEDURES. Read the two Overview sections III.A.1. and III.A.2.

-- Select PROCEDURE_A: Retrieval Program--you provide the responses! (See EXAMPLE in fig. III-1.)

or PROCEDURE_B : Retrieval and/or Report Generation Procedure using WRDBIB library files (in argument form).

-- List and select your INPUT file(s) and, optionally, your RESPONSE file. RESPONSE files are printed in figs. III-2, III-4, III-6, III-12. (See use of editor commands in APPENDIX_I.)

-- Execute: See EXAMPLES in figs. III-3, III-5, III-7, III-9, and III-11. Custom REPORTS are printed in figs. III-8, III-10, and III-13.

NOTE: In any case study APPENDIX III. A WRDBIB RETRIEVAL \& REPORT GENERATION SESSION in ten detailed steps--beginning with the search strategy! 
B.1. "WBsum.info":

WRDBIB RETRIEVAL and REPORT GENERATION procedures are available online in form of "info" segments which may be accessed randomly with the "help" command. The "WBsum.info" file consists of fifteen parts which address WRDBIB program functions and provide examples of program execution. Using "help" responses the user may obtain as much or as little information as he/she desires on topics such as: The program command, file input, retrieval statements, response file, and report generation.

To list the various segments of "WBsum.info", link to the master file in the >IO directory and enter the list command. (User entries follow ":")

: $1 k>$ udd $>$ Wrdbib $>$ NTamberg $>$ IO $>$ WB sum. info

: 1 s WBsum.info

or : 1 s <path>WBsum, info

The system will print all add names which are indicative of their contents. Use "help" command to recall desired "info" sections!

: 1 s WBsum.info

Segments $=1$, Lengths $=15$

rew 15 WBsum.info

WBintro.info

INPUT.info

RETRs tmt . info

RETRpr.ec.info

RESPONSE . info

REPgen. info

PROG.ex.info

PROG.ec.info

GWpr.ec.info

REFORM. ec. info

INDEX.ec.info

DICT.ec.info

CoMPdict.info

C+E/STDrep.ec.info

The access procedure using the exec_com WRDBIB.ec is listed in APPENDIX_I, section A. 3 .

A brief outline describing use of WBsum.info units in conjunction with the "help" command is given below. For more detail see online info segment WBhelp.info. 


\section{B.2. Access Procedure:}

(1) Establish links to WRDBIB files and programs by linking to WRDBIB.ec. This is a one-time step. (Check link in your home directory!)

: $\quad 1 \mathrm{k}>\mathrm{udd}>$ Wrdbib $>$ NT amberg $>$ IO $>$ WRDBIB. ec

Add search path to "working directory" at the beginning of session in in order not to use the "-pn" (pathname) argument:

: asp -wd (Add search_path of the >IO working_dir)

\section{(2) Execute--}

: ec WRDBIB

(This will place you into the Wrdbib>IO subdirectory and list all units of the WBsum.info segment. Then it will start reading the first info.section which describes the general procedure of using "help" commands!)

(3) Use "help" command to read "info" segments--*

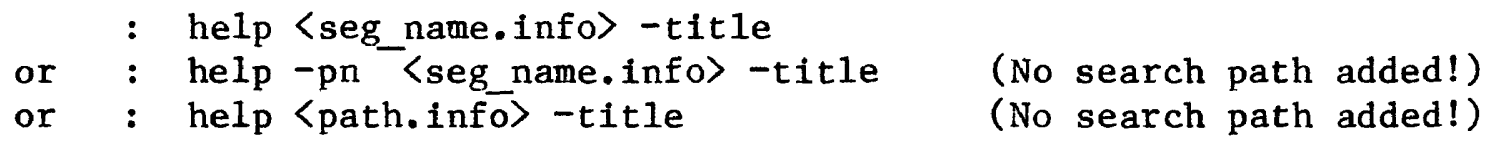

NOTE: The argument "-title" will print all section titles within a given "info" segment for the user to access.

To list user responses for selective reading of "info" segments enter at section break of any info segment: "?"

The system will print responses and usage.

(4) Examples--

: help WBintro-title

(Recalls the WBintro.info segment for your information and list its section titles.)

: help PROG.ex PROG.ec -title (These segments show how to enter input in form of statements to the system. PROG.ec shows actual program execution.)

* To learn about the "help" command enter

: help help.info or help help (You may disregard the info suffix!)

The system will start printing the info segment. 
B.3. Contents of "WBsum.info":

A listing of individual WBsum.info segments is given in figure I-2 below. Select label following the ":Info:" designation for your "help" command:

Ex.: $\quad$ help WBintro -title

NOTE: The argument "-title" will list the section titles of any referenced info unit.

For prompts on expected user responses enter "?" at any section break.

:Info: WBsum: 08/04/82 Introduction to WBsum.info segments.

:Info: WBintro: WB: 08/05/82 WRDBIB PROGRAM Functions \& Statements

:Info: INPUT: Input: 07/06/82 INPUT.info

:Info: RETRstmt: 07/11/82 RETRIEVAL STATEMENT \& OPER.CONDITIONS

:Info: RETRpr.ec: 08/05/82 Executing RETRIEVAL PROGRAM ("Creation" Program)

:Info: RESPONSE: 07/28/82 RESPONSE file.info

:Info: C+E/STDrep.ec: C+E.ec: 08/05/82 Comp\&Exec.; DUMP \& STAND_MT_Rep_gen.

:Info: REPgen: 07/11/82 Creating CUSTOM_REPORT_format (RESPONSE.file)

:Info: PROG.ex: 07/14/82 HOW TO ENTER STATEMENTS INTO PROGRAM (Exercise)

:Info: PROG.ec: 07/14/82 PROG.exec with chg_mc argument (AND_logic)

:Info: GWpr.ec: 07/11/82 PROG.exec with chg_in,mc args (OR_logic)

:Info: REFORM.ec: 07/11/82 PROG.exec--Reformatting_data (REPORT_GEN.)

:Info: INDEX,ec: AUX: 08/01/82 creating AUTHOR INDEX and Exercise

:Info: DICT.ec: 07/14/82 Creating custom PROGRAM with DATA DICTIONARY

:Info: COMPdict: 07/28/82 PROGRAM_compilation using "extdict"

Figure I-2.-- LISTING OF WBsum.info HEADER LINES. 
C. SCHEMATIC OVERVIEW OF WRDBIB SYSTEM

C.1. SCHEMATIC OVERVIEW: To search the WRD reports data base using Multi trieve (MT-) RETRIEVAL AND REPORT GENERATION software and WRDBIB data and programs the user needs access to the Reston Multics computer and to the "Working Directory" containing WRDBIB files (1968 to date: 8600 records) and procedures listed below. Your working directory is: (For Access procedures see APPENDIX_I.)

$>$ udd $>$ Wrdbib $>$ NTamberg $>$ IO

ACCESS MULTI TRIEVE \&

WORKING DIRECTORY >IO

Containing :

(1) WRDBIB DATA DICTIONARY

(2) WRDBIB PROGRAMS

(3) WRDBIB INPUT Files (DATA)

(4) WRDBIB RESPONSE Files

(5) ONLINE READY REFERENCE:

WBsum.info fíles

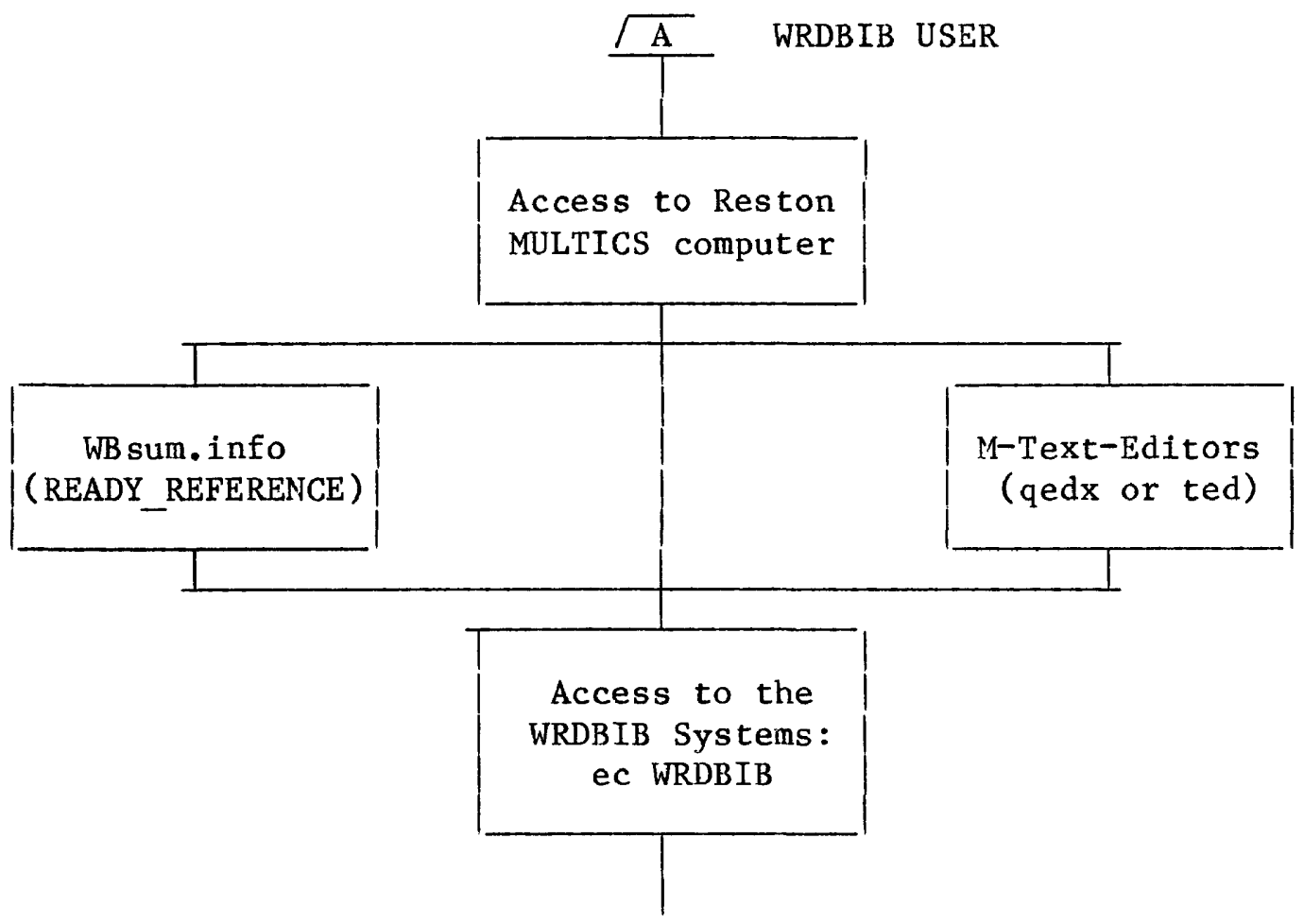

I B PROGRAM EXECUTION 
C.2. PROGRAM EXECUTION CHECKLIST:

EXECUTE A WRDBIB PROGRAM BY USING OR CREATING THE RIGHT RESPONSE FILE:

(Choose procedure in PATH I or II or a combination thereof.)

PATH I

2.1. SELECT A WRDBIB PROGRAM

2.2. SELECT A WRDBIB RESPONSE FILE
PATH II

2.1. CREATE YOUR WRDBIB PROGRAI

2.2. CREATE YOUR OWN RESPONSE FILE (Provide your own responses)

-- To change the REPORT FORMAT--use the MULTICS editor [qx, ted]

-- Specify report OUTPUT MEDIUM: terminal or central site

-- Specify disposition of OUTPUT files: Save: yes/no

2.3. USE THE PROPER PROGRAM STATEMENT (command) TO START YOUR PROGRAM! ENTER [OPTIONAL] CONTROL ARGUMENTS BY CALLING A RESPONSE FILE WITH A SUITABLE REPORT FORMAT AND SPECIFYING INTERACTIVE CHANGES OF SELECTED PARAMETERS :

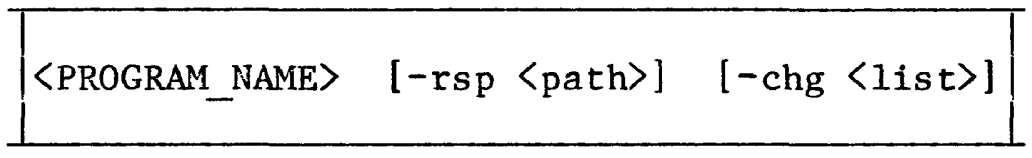

NOTE: You must specify the "-change" argument: "-change 〈list>" together with the "-response" argument. You may specify interactive change of one or all control parameters during PROGRAM EXECUTION:

$$
\begin{aligned}
& \text {-- change INPUT files .............. [-chg in] } \\
& \text {-- change MATCH (selection) criteria ....[-chg mc] } \\
& \text {-- change SORT criteria .............. [-chg sc] }
\end{aligned}
$$

Example:

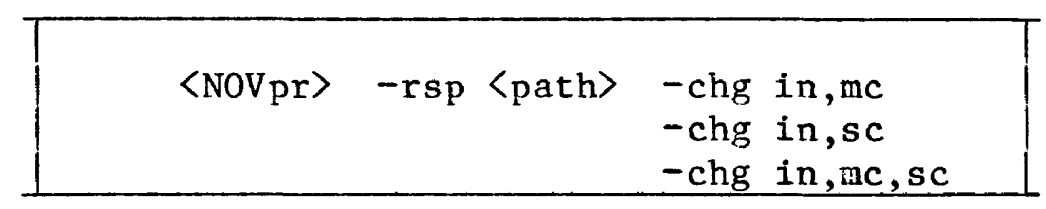

2.4. EXECUTE RETRIEVAL AND/OR REPORT GENERATION PROGRAM:

-- Respond to all queries

-- Enter statements to the system according to specified format!

See: Section C.3. ENTRY CONVENTIONS. 
C.3. ENTRY CONVENTIONS:

ALL STATEMENTS TO THE SYSTEM END IN A BLANK AND A PERIOD OR A PERIOD ON A NEW LINE!

RETRIEVAL STATEMENTS MUST BE ENTERED ACCORDING TO SPECIFIED FORMAT:

$$
\mid\langle\text { DICTIONARY VARIABLE }\rangle=\langle\text { OPERATOR }\rangle\langle\text { VALUE }\rangle \mid
$$

-- SELECT APPROPRIATE OPERATOR TO FACILITATE ALPHAMERIC OR NUMERIC COMPARISONS: pub=eq1981 . (DIRECT MATCH USES "equal, eq" OPERATOR.)

-- USE "pn" (partial name) TO MATCH A SUBSTRING IN AN EXTENDED FIELD. FOR EXAMPLE--SEARCHING THE "title" FIELD: tit=pn"FLORIDA" • (Substring must be enclosed in quotation marks!)

-- ALL INDEX TERMS (VALUES) ARE ENTERED IN CAPS.

-- NO BLANKS ARE ALLOWED IN VALUE TERM.-- CONNECT TWO ADJACENT INDEX WORDS USING THE UNDERSCORE: "NEW_YORK"

For a discussion of the RETRIEVAL STATEMENT format see Section II.6. See also MATCH CRITERIA in PROGRAM EXECUTION EXAMPLES in Section III! online read the RETRstmt.info unit! 
C.4. USE MULTICS EDITOR:

Use "qedx" or "ted" to read and edit your files. Always make sure you know the specifications of your RESPONSE file! (For application see APPENDIX_I.) A summary of basic "edit" commands is given below:

4.1 Edit mode is used to change data. edit-

$\begin{array}{ll}r \text { (read) } & \text { - reads data from a file into the buffer } \\ p \text { (print) } & \text { - writes to the terminal } \\ P \text { (print) } & \text { - "ted" only: line numbers precede each line } \\ d \text { (delete) } & \text { - deletes line(s) in buffer } \\ s \text { (substitute) } & \text { - replaces characters } \\ \text { w (write) } & \text { - writes from the buffer to a segment } \\ q \text { (quit) } & \text { - terminates the editor }\end{array}$

4.2 Input mode is used to enter data from your keyboard into the buffer. (You are using buffer 0, b0, unless you changed buffers.*) Enter by typing-
a (append) - add after current line
$i$ (insert) - insert before current line
c (change) - replace current line

There are no request in the "input" mode. You just enter data. Exception is the " $\mathrm{f}$ " which ends the "input" mode and returns you you to the "edit" mode. (Be sure you know which mode you are in!)

4.3 Using "qedx":

"qedx" uses an imaginary line pointer. present location is give by $\quad .=$ or $=$ last line in text is given by $\$=$ locate by absolute line number 1 or 10 or 15 locate by relative line number $\quad-1$ or +2 locate by content of line /xyz/

where $|x y z|=$ "regular expression"

"qedx" requests are addressable. The line number or range of lines should precede the "qedx" request. $1, \$ p$ (print complete file from first to last line)

., 15 p (print from current line through line 15)

$10 \mathrm{p} \quad$ (print line 10)

$\mathrm{p} \quad$ (print current line)

"ted" supplies line-numbering feature:

$1, \$ P \quad$ (prints file with line number preceding each line)

Requests may follow one another in a string except the following must be at the end of the line or on a new line:
$r$ (read)
e (execute)
w (write)
q (quit)

This is because all except $q$ may be followed by an argument.

* For use of buffers see Introductory Multics Handbook. 


\section{C.5. ESSENTIALS OF FILE MANAGEMENT}

5.1. Multics Commands:

Familiarize yourself with basics of FILE MANAGIENT (set access, list access, link, copy, etc.)

(For applications see APPENDIX_I.)

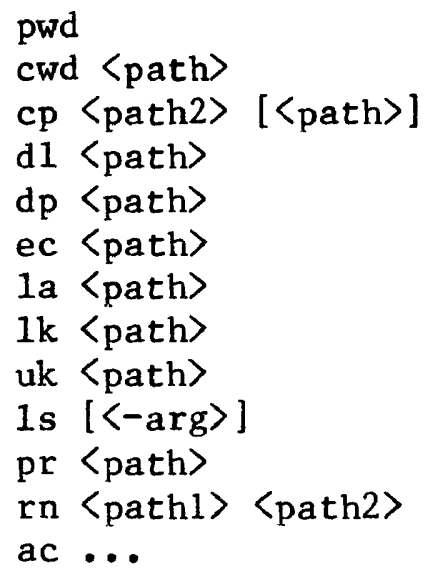

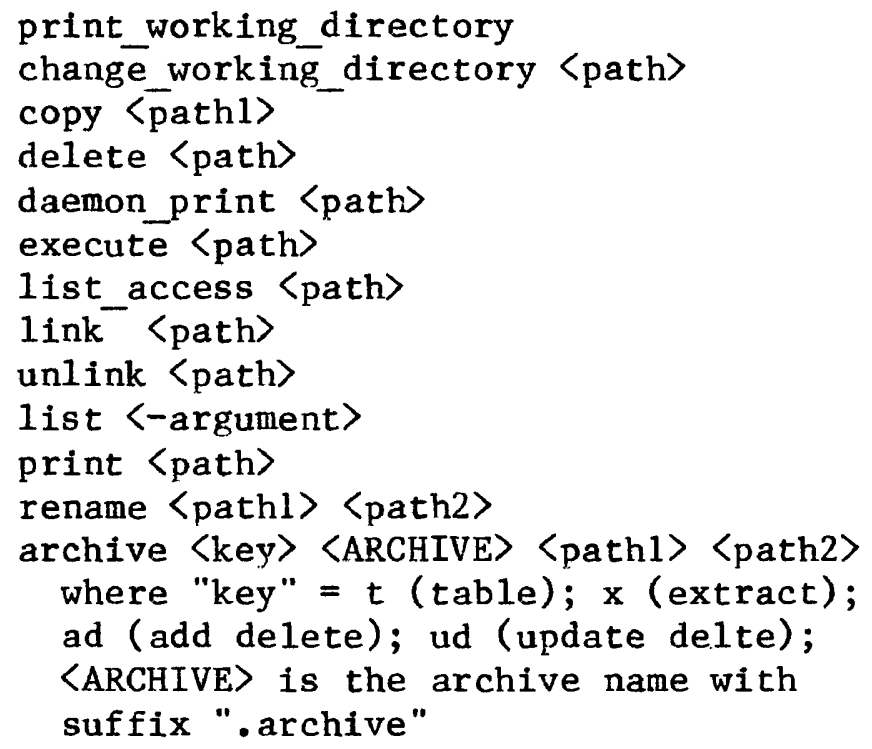

5.2. Keep Track of Your Working Directory:

-- Monitor size and most recent entries

( 1 s $-t t ; 1$ s $-\mathrm{ft} \mathrm{N}$ where $\mathrm{N}=1,2,3 ;$ )

-- Monitor contents and access information

( $1 \mathrm{a}\langle\mathrm{seg}\rangle, 1 \mathrm{~s}, 1 \mathrm{~s}-1 \mathrm{k}$, Is $-\mathrm{a} ;$ )

(1s*.〈suffix〉: 1s *.response ; 1s *.data ; 1s *.report;)

(1s 〈prefix〉* : 1s auth* ; ls prefix***;

1s ret_*.* or 1 s ret*.data)

-- Monitor cost ( $\mathrm{ru}, \mathrm{ru}-$ long)

(See Section III.D. and APPENDIX_III: WRDBIB RETRIEVAL SESSION step 10.) 
D. LISTING OF MULTICS READY_REFERENCE SECTIONS:

03/24/83 Ready References

D.1. Introduction:

Ready References are compact segments of documentation, with two purposes:

(1) To give users an opportunity to use the main features of Multics commands or functions that they are not familiar with, without having to read the complete documentation.

(2) To serve as quick references for all users--new or experienced--to the more commonly-used features of various commands and functions.

Each ready reference segment consists of specific instructions and examples. It is not intended that these references will replace existing documentation; it will often be necessary to refer to the full documentation. In particular, Commands and Active Functions, order number AG92, gives more detail about the use of Multics commands presented here. MPM Reference Guide, AG91, gives information about the general usage of Multics.

TABLE OF CONTENTS:

\begin{tabular}{|c|c|c|c|}
\hline Name & No. & Revised & Subject \\
\hline - & -- & $08-13-80$ & Croating abroviationa \\
\hline $\begin{array}{l}\text { abbrev_rr } \\
\text { abs } \mathrm{rr}^{-}\end{array}$ & $\begin{array}{l}13 \\
14\end{array}$ & $08-29-80$ & $\begin{array}{l}\text { Creating abbreviations } \\
\text { Submitting absentee jobs }\end{array}$ \\
\hline archive $\mathrm{rr}$ & 07 & $08-13-80$ & Archiving segments \\
\hline buffer $\overline{\mathbf{r}} \mathbf{r}$ & 13 & $08-29-80$ & Use of buffers with qedx and ted \\
\hline carry $\overline{r r}$ & 10 & $08-29-80$ & Moving files from one site to another \\
\hline compose rr & 20 & $03-10-81$ & Formatting manuscript text with compose \\
\hline $\operatorname{con} \mathrm{rr}^{-}$ & 05 & $03-24-83$ & Computer managed meetings (continuum) \\
\hline help rr & 19 & $03-11-83$ & Using the help command \\
\hline labeis rr & 11 & $07-02-81$ & Making address files and labels \\
\hline 1 ts $\mathrm{rr}^{-}$ & 04 & $08-13-80$ & Logging interactive terminal sessions \\
\hline $\operatorname{mai} \overline{1} \mathrm{rr}$ & 03 & $04-22-81$ & Sending mail and messages to other users \\
\hline new_user_rr & 01 & $03-11-83$ & Helpful information for new users \\
\hline probe rre & 06 & $03-12-81$ & Probe, debugging aid for compiled programs \\
\hline $\mathrm{qx} \mathrm{rr}^{-}$ & 02 & $08-14-80$ & The qedx editor, and how to edit segments \\
\hline read_mail_rr & 17 & $08-29-80$ & Reading mail and messages from others \\
\hline $\begin{array}{l}\text { ready_ret } \\
\text { runoff rr }\end{array}$ & 08 & $08-14-80$ & $\begin{array}{l}\text { 1ntroduction and table of contents for rrs } \\
\text { Creating manuscript text with runoff }\end{array}$ \\
\hline segs $\overline{r r}$ & 12 & $08-14-80$ & Common commands used with segments \\
\hline send mail rr & 16 & $08-29-80$ & Sending mail to other users \\
\hline tab it $\mathrm{rr}^{-}$ & 09 & $08-29-80$ & Creating data formatted in columns \\
\hline ted rr $^{-}$ & 18 & $05-26-82$ & Creating and editing text using ted \\
\hline
\end{tabular}


D.2. Getting Copies:

There are three ways to get a copy of any of the ready reference segments. To get a copy of the segment about computer managed meetings, for example, do one of the following:

1. Type: help con rr -all

2. Dprint a copy by typing: $d p>d o c>i i s>c o n$ rr.info

3. Call any of the ISD offices listed below to get an $81 / 2$ by 11 inch printed page, or a bound set of all the Ready References.

$\begin{array}{lc} & \text { FTS } \\ \text { Denver, CO } & 234-5322 \\ \text { Flagstaff, AZ } & 261-1312 \\ \text { Menlo Park, CA } & 467-2663 \\ \text { Reston, VA } & 928-7123\end{array}$

COMMERCIAL (303) $-234-5322$

(602) $-779-3311$ Ext. 1312

(415) $-326-2663$

( 703) $-860-7123$

Using "help" Command:

To review parts of a ready reference, the help command may be used with the -title argument. help rdm rr -title

This prints a heading line, a list of section titles, the number of lines in each section, and then asks: More help?

You can then type the section request to read the one you want to see next: scn examples (The system will read section "examples".) 
SECTION II.

INTRODUCTION TO WRDBIB FEATURES

A. PROGRAM EXECUTION OVERVIEW

B. WRDBIB FILES AND STATEMENTS

C. OUTPUT FEATURES 
A. PROGRAM EXECUTION OVERVIEW.

A.1. WRDBIB PROGRAM FEATURES:

WRDBIB, a Multi_trieve application program, was created to provide an easy method of retrieving data and generating reports from WRDBIB bibliographic data files. To aid the user the Multi trieve program operates in a tutorial mode; however, for effective use a working knowledge of the MULTICS command language and the use of its editors [gedx or ted] is most desirable. The Multi_trieve program is available able at both MULTICS sites: Reston and Denver.

The RETRIEVAL process operates in two stages:

(1) Program Creation:

The user links to the Multi_trieve system using the exec_com:

ec multi_trieve |

NOTE: A link to >udd>Userast>LHarms>multitrieve must be provided in the working_directory. (See APPENDIX_I for description of >IO directory.)

The user provides the name of the INPUT segment to be searched and a DATA DICTIONARY describing the record variables. From this information the program creates a customized retrieval PROGRAM for the user. (See section B.2. below. Online read WBsum.info segment: Compdict.info.)

\section{(2) Program Execution:}

To execute a program the user must issue the program command (PROGRAM STATEMENT) that will link him/her to the Multi_trieve system and initiate processing according to custom features specified by the associated [optional] arguments. This involves the actual execution of a11 user responses as entered at the terminal, or specified in the form of a selected RESPONSE file supplied in argument form: "-rsp 〈path〉". An optional "-change list" argument, entered together with the "-response" argument allows the user to interactively change custom parameters :

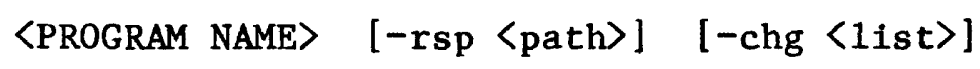

where "1ist" may include: "in" (INPUT file), "mc" (MATCH criteria), and "sc" (SORT criteria) in any combination.

See: Section_III for a detailed discussion of WRDBIB program execution procedures. 
A.2. PROGRAM STATEMENT (Command):

To execute a program the user must issue the program command that will link him to the Multi trieve system and initiate processing according to custom features which may be entered at the terminal or specified by the associated [optional] arguments. The following PROGRAM STATEMENTS apply to WRDBIB program execution: (Brackets denote optional arguments!)

$$
\langle\text { PROGRAM NAME }>[- \text { rsp }\langle\text { path }\rangle][\text {-chg }\langle 1 \text { ist }\rangle]
$$

EXPLORATORY RETRIEVAL/CREATING RESPONSE FILE:(Use PROGRAM NAME: "NOVpr".)

NOVpr

-- execute to list its associated DATA DICTIONARY. Use "BREAK" key to interrupt further execution!

-- execute exploratory retrieval programs, "dumplisting" sample records at the terminal and saving the retrieved data segments.

-- execute a full retrieval and report generation program in order to create your own RESPONSE file.

REPORT GENERATION:

NOVpr -rsp FORM NOVpr -rsp AUT

\footnotetext{
-- the "rsp 〈path>" argument supplies a set of responses, created during a previous program execution, and saved as RESPONSE file: "〈path> response". (Be sure you know the specified INPUT file!)

-- FORM.response together with the statement: "MATCH criteria:=al1 .", that is "ALL RECORDS WILL BE SELECTED", will reformat a previously retrieved data segment (named by either the RESPONSE file or the PROGRAM. (Executing with control arguments-see below!)

-- AUT.response under the same conditions will create an AUTHOR INDEX for a given INPUT file: Again, "ALL RECORDS WILL BE SELECTED." (See also below!)
}

RETRIEVAL AND/OR REPORT GENERATION:

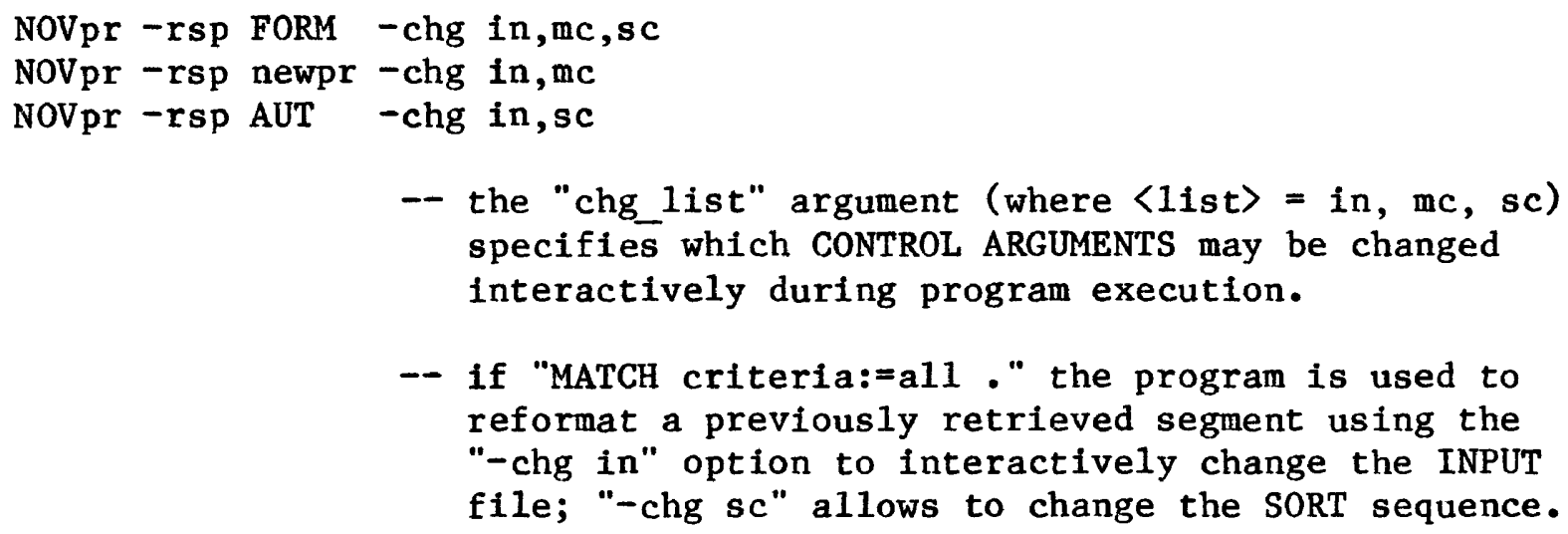


A.3 SYSTEMS FEATURES: Briefly the features of the WRDBIB program are as follows: (See section II.B for a description of these applied Multi trieve features.)

FILE INPUT: An arbitrary number of INPUT files can be used for any given run. All of the INPUT files must be compatible with the DATA DICTIONARY used during the creation of the WRDBIB custom program. File input may be changed interactively by specifying a PROGRAM STATEMENT (command) with control arguments and entering the "change in" argument as follows: NOVpr -rsp FORM - chg in

RECORD SELECTION: The basic RETRIEVAL STATEMENT consists of a name from the DATA DICTIONARY designating the variable field (a constant), an operator relating how this constant is to be compared to the corresponding value (a variable) in the INPUT record (the search term).

Operators defining relational conditions for numeric variables are: "equal to, eq"; "greater than, gt"; less than, 1t"; "range, rg" between two values; numeric "or".

To compare alphameric strings we use the "partial name, pn" operator followed by the value term--enclosed in quotes-- which identifies a unique string within an extended variable field. For example, when searching the title field (tit), citation field (cit), or the descriptor field (des):

$$
\begin{aligned}
& \text { tit=pn"FLORIDA" } \\
& \text { des=pn"AQUIFER" }
\end{aligned}
$$

NOTE: ALL VALUE TERMS MUST BE ENTERED IN CAPITAL LETTERS. THE LAST RETRIEVAL STATEMENT MUST END IN A BLANK AND A PERIOD OR A PERIOD ON A NEW LINE.

The "equal, eq" operator may be used for direct match of short alphameric fields, such as the WRSIC (accession) number. (For example: 80-00562 where the dash "-" is a nonnumeric character!) Complete selection criteria may consist of any number of basic RETRIEVAL STATEMENTS. (Each variable field may be referenced once only during a given RETRIEVAL run!) These MATCH criteria can be changed interactively provided, a "change mc" argument has been included in the PROGRAM STATEMENT: NOVpr -rsp FORM - chg mc.

OUTPUT: After the desired records have been selected various REPORTS can be printed. The user can elect to simply "dump" some of the records at the terminal or at the central site, use the "Standard MT" (Multi trieve) report format, or create his own format by using $\bar{a}$ suitable customized RESPONSE file. (See section II.B.7. RESPONSE FILE.) The user has the option to SORT his "standard_MT" or custom REPORT.

OUTPUT segments can be saved for later use. The segments are identified by the system as follows: ("XXXX" are numeric identifiers!) retXXXX. report ret_XXXXXX.data ret_XXXXXX. response contains the user's report. contains the retrieved data segment. contains the saved user RESPONSE file if it was created during the session! 
A.4. SYSTEMS RESPONSES: When the user executes a WRDBIB program, it will perform the following program functions: (For example see fig. II-1.)

-- If response argument entered, read the RESPONSE segment and state the 〈resp_path〉.

-- State the path of your INPUT file. In response to the "change_in" statement query the user for the name of a different INPUT file, or of additional INPUT file(s).

-- Query the user for statement of MATCHING criteria ("mc"). Read them back to you and ask for your verification or correction.

-- Retrieve the desired records; state the number of records read and the number of records selected for each file.

-- Provide the following output options: (a) "dump-listing, (b) generate a report using MT-"standard" format, or (c) generate report "custom"-formatted by the user. (d) No report. In every event the system will save data segment for future use.

-- Generate a custom-formatted report according to specifications of your RESPONSE file. You will be asked to provide interactively: (a) Your REPORT title; (b) designate if you wish "descriptors" to be printed in your custom REPORT.

-- Provide for SORTING of the retrieved records. If you entered a "change sc" argument, you will be asked to designate an alternate SORT sequence.

-- Print or display a formatted report at a specified site (terminal or central/remote site.)

* -- Query the user if he wishes to prepare "another report".

* -- Query the user if he wishes to make (execute) "another run".

** -- Allow the user to save the PROGRAM and his OUTPUT files including the newly created RESPONSE file for later use.

Compare the responses (instructions) contained in a given RESPONSE File against the above list of possible program functions. (See Section B.7.3. RESPONSE File--EXAMPLE: Fig. II-7.)

*

Only during initial RETRIEVAL program requiring user-supplied responses. (The user creates his own RESPONSE file.) Yes/no responses solicited.

** Only during "Creation Program" when the user compiles his custom PROGRAM and creates a customized RESPONSE file--yes/no response! The system will also save REPORT and DATA segments--if the user or his RESPONSE file so indicate. (The user may edit his RESPONSE file accordingly: Yes/no responses are required.) 
A.5. PROGRAM EXECUTION EXAMPLE USING WRDBIB LIBRARY FILES.

The PROGRAM STATEMENT specifies a change of MATCH criteria given in the RESPONSE file: "Form.response". (See: Section III. PROGRAM EXECUTION.) NOTE: User statements and responses follow the initial colon ":"!

: NOVpr -rsp FORM - chg m

MULTI TRIEVE RESPONSES READ FROM FILE

>user_dir_dir>Wrdbib>NTamberg>FORM.response <--

INPUT FILE $S$ : >user_dir_dir>Wrdbib>NTamberg>auth81 «-

ALL RECORDS WILL BE SELECTED. <

DO YOU WISH TO CHANGE, AND OR DELETE ANY OF THESE VALUES?

: yes

TO DELETE A VARIABLE ENTER A $d$ AS THE VALUE, SUCH AS $x x=d$

TO ADD OR CHAIJGE A VARIABLE ENTER AS NORMAL INPUT

SUCH AS $\mathrm{xx}=\mathrm{eq} \ldots$...

ENTER MATCHING CRITERIA FOR RECORD SELECTION.

: aut=pn"POST"

ENTER YOUR ADDITIONAL CRITERIA.

RETRIEVAL

: des=pn"GLACIER" .

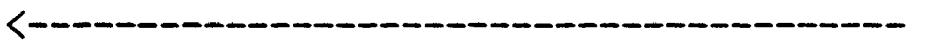

STATEMENTS

NAME CONDITION VALUE
aut
des
$\mathrm{pn}$
\begin{tabular}{ll|l} 
POST & - \\
GLACIER & "AND"-Logic
\end{tabular}

DO YOU WISH TO CHANGE OR DELETE ANY OF THESE VALUES?

: no

TOTAL NUMBER OF RECORDS READ $=640$

TOTAL NUMBER OF RECORDS SELECTED $=5$

* "Enter title line"

$\begin{array}{ll}\text { "Enter title line" } & \text { REPORT- } \\ \text { A. POST's GLACIER REPORTS for 1980/81: } & \text { GENERATION }\end{array}$

REPORT-

:

**

THE NAME OF SAVED REPORT PRINT FILE IS ret3522. report

THE NAME OF THE SAVED DATA SEGMENT IS ret_183478.data <--

FILE OUTPUT

END OF JOB (Leve1 2)

r 16:35 4.547 612 level 2 ("Ready" message)

* Interactive prompt for custom report title.

** The SORT criteria (sc) of the FORM.response file specify SORT by WRSIC number: "wno a ."

Figure II-1.--PROGRAM EXECUTION USING CONTROL ARGUMENTS: RESPONSE File responses are altered online by argument: "-change mc". 
A.6. CUSTOM REPORT FORMAT:

POST's GLACIER REPORTS

1 POST, A.;

1980

PRELIMINARY BATHYMETRY OF MC CARTY FIORD AND NEOGLACIAL

CHANGES OF MC CARTY GLACIER, ALASKA, GEOLOGICAL SURVEY OPEN-FILE REPORT 80-424, 1980. 4 SHEETS.

2 POST, A.; 81-00056

DATE : $01 / 31 / 83$

PAGE : 1

PRELIMINARY BATHYMETRY OF AIALAK BAY AND NEOGLACIAL CHANGES OF AIALIK AND PEDERSON GLACIERS, ALASKA, GEOLOGICAL SURVEY OPEN-FILE REPORT 80-423, 1980. 1 SHEET.

3 POST, A. ; 81-00057

PRELIMINARY BATHYMETRY OF BLACKSTONE BAY AND NEOGLACIAL CHANGES OF BLACKSTONE GLACIERS, ALASKA, GEOLOGICAL SURVEY OPEN-FILE REPORT 80-418, 1980. 2 SHEETS.

$81-00138$

Figure II-2a.--A TYPICAL CUSTOM REPORT: POST'S GLACIER REPORTS. The bibliographic citation format is specified by RESPONSE file FORM.response. Records were sorted numrically on the WRSIC_no.

POST's GLACIER REPORTS (1980+)

1 POST, A.;

DATE : $01 / 31 / 83$

PAGE : 1

PRELIMINARY BATHYMETRY OF MC CARTY FIORD AND NEOGLACIAL CHANGES OF MC CARTY GLACIER, ALASKA, GEOLOGICAL SURVEY OPEN-FILE REPORT 80-424, 1980. 4 SHEETS.

*BATHYMETRY, *GLACIERS, *ALASKA, *GLACIAL DRIFT, *ICEBERGS, GLACIAL SEDIMENTS, FJORDS, SCOUR, DATING, GLACIOLOGY, HYDROGRAPHY, MAPS, PROFILES, *MCCARTY GLACIER(AK), *MCCARTY FIORD(AK).

2 POST, A.; $81-00056$

PRELIMINARY BATHYMETRY OF AIALAK BAY AND NEOGLACIAL CHANGES OF AIALIK AND PEDERSON GLACIERS, ALASKA, GEOLOGICAL SURVEY OPEN-FILE REPORT 80-423, 1980. 1 SHEET.

*BATHYMETRY, *GLACIERS, *ALASKA, *GLACIAL DRIFT, *ICEBERGS, GLACIAL SEDIMENTS, FJORDS, SCOUR, DATING, GLACIOLOGY, HYDROGRAPHY, MAPS, PROFILES, *AIALIK BAY(AK), AIALIK GLACIER(AK), PEDERSON GLACIER(AK).

$81-00057$

Figure II-2b.--CUSTOM REPORT WITH DESCRIPTORS: POST'S GLACIER REPORTS. Report format is specified by RESPONSE file: "newpr.response". 
II.B. WRDBIB FILES AND STATEMENTS 
B. WRDBIB FILES AND STATEMENTS.

B.1. DATA FILES AND STATEMENT FORMATS REQUIRED FOR PROGRAM EXECUTION:

To execute a RETRIEVAL and REPORT-GENERATION PROGRAM using the multi_trieve software, the user must have access to the following four types of filles:

(1) 〈DATA DICTIONARY> -- lists the retrievable (addressable) variables by their label. (optional print label), starting position within the input record, and size. The DATA DICTIONARY is used to compile a custom MULTI TRIEVE PROGRAM against WRDBIB INPUT files. (See DICT.ec.info!) The user must know his variables in order to formulate his MATCH criteria in terms of RETRIEVAL STATEMENTS.

(2) 〈PROGRAM〉

(3) 〈INPUT FILES>

-- The PROGRAM provides a framework for systems' queries and user responses. The PROGRAM name acts as a COMMAND starting program execution according to user responses.

-- are DATA files or segments which the user may search according to specified selection/MATCH criteria. INPUT files must be compatible with the format specified in the DATA DICTIONARY used for PROGRAM compilation. (See INPUT.info.)

(4) 〈RESPONSE FILES〉* -- constitute the sum-total of all responses provided by the user during the execution of a given retrieval and/or report-generation PROGRAM. RESPONSE files may be stored and recalled in argument form (-response 〈path〉) for retrievals which make use of the same REPORT format specifications. To change some of the RESPONSE file parameters online a "-change list" argument may be added to the PROGRAM STATEMENT. (See RESPONSE.info!)

PROGRAM STATEMENT: PROGRAM entry syntax to start program execution is given below: (See Section III for PROGRAM EXECUTION procedures.

1 〈PROGRAM name $>$ rsp 〈path $>$ chg 〈change list $\rangle$ |

For example:

$$
\begin{array}{lll}
\text { NOVpr } & \text { rsp FORM } & \text {-chg in mc } \\
\text { NOVpr } & \text { rsp AUi } & -c h g \text { in, sc }
\end{array}
$$

This will prompt the following changes online:

$$
\begin{aligned}
& \text {-- "-chg in" will allow change of INPUT file(s) } \\
& \text {-- "-chg mc" will allow change of MATCH criteria } \\
& \text {-- chg sc" will allow change of SORT criteria }
\end{aligned}
$$

* The use of a custom RESPONSE file is optional; the user may choose to supply his/her own responses! 


\section{B.2. DATA DICTIONARY:}

The DATA DICTIONARY contains all data elements describing the WRDBIB data files and all input segments derived from it to be used in retrievals.

There is no limit to the number of variable names the DICTIONARY can contain or to the length of the names. The variable names cannot contain any special characters except the underscore, " ". The DICTIONARY must contain the re- trieval name, starting position (no.), and size of each variable field (number of characters); the elements must be separated by blanks. Print names may be included optionally following the corresponding retrieval name, separated by blanks. If the print name is to include blanks, it must be enclosed in quotes. (Print names are used as headers in standard reports.) The DATA DICTIONARY does not have to define every character in the input record, only those the user is interested in. The variables can be in any order, overlap one another, or skip characters.

The user can provide the DATA DICTIONARY describing WRDBIB input segments in one of two ways:

-- The DATA DICTIONARY may be created by using the Multics text editor.

-- The system can query the user to enter his DATA DICTIONARY descriptions directly into the PROGRAM.

$\begin{array}{llcc}\text { RETRIEVAL NAME } & \text { PRINT NAME } & \text { START POS } & \text { FIELD LENGTH } \\ \text { wno } & \text { wrsic.no } & 1 & 8 \\ \text { acyr } & \text { acc.yr } & 1 & 2 \\ \text { acno } & \text { acc.no } & 4 & 5 \\ \text { aut } & \text { author } & 9 & 90 \\ \text { s so } & \text { source } & 99 & 120 \\ \text { tit } & \text { title } & 219 & 200 \\ \text { cit } & \text { citation } & 419 & 230 \\ \text { des } & \text { descriptor } & 649 & 380 \\ \text { pub } & \text { pub.yr } & 1029 & 4 \\ \text { idn } & \text { ident } & 1033 & 2\end{array}$

Figure II-3.--DATA DICTIONARY DESCRIPTION: "extdict" 


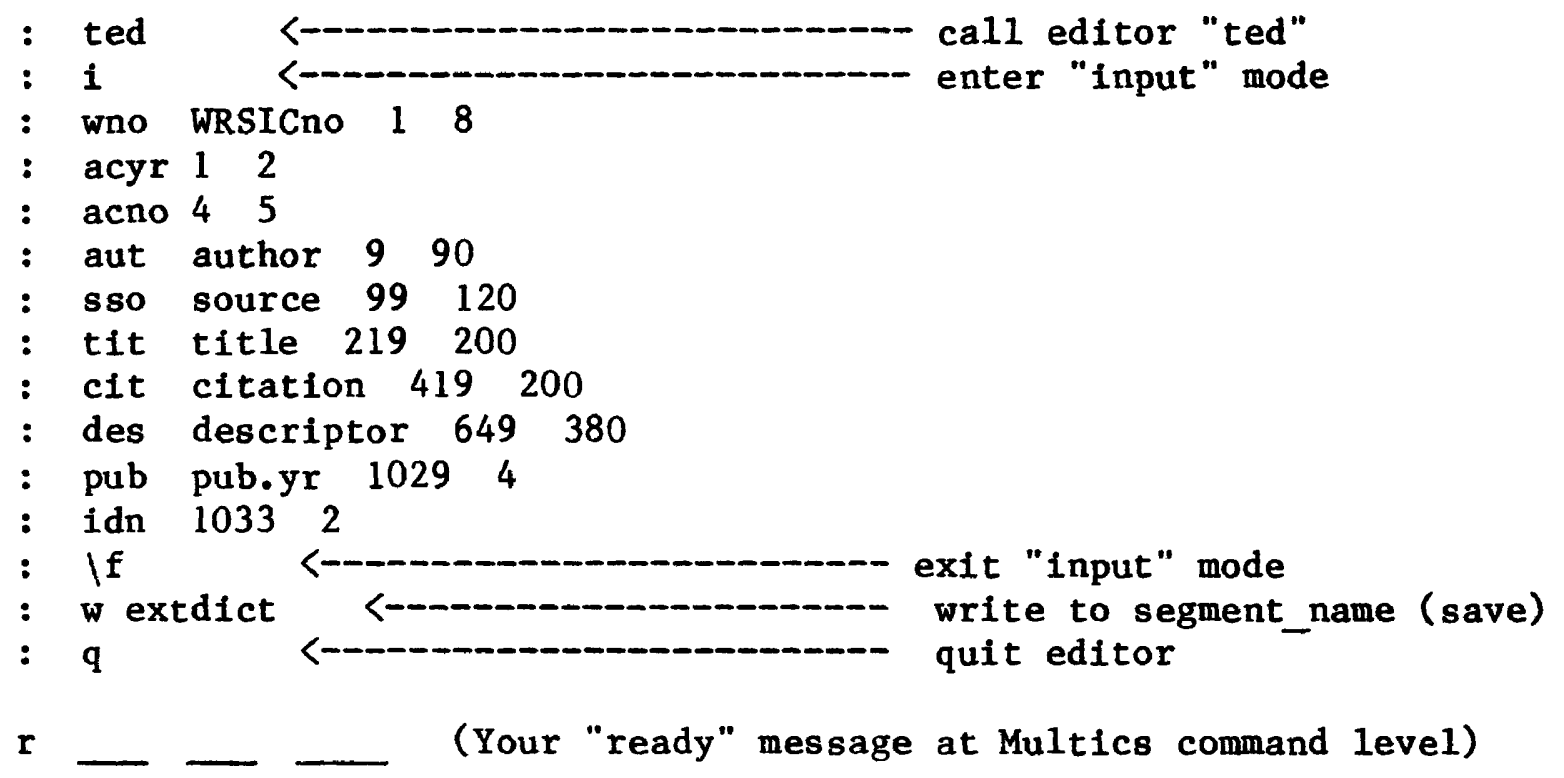

The segment "extdict" now contains a DICTIONARY describing a data segment (INPUT record) to be used in retrievals.

APPLICATION: The DATA DICTIONARY is used to create a custom PROGRAM by linking to MULTI_TRIEVE software and compiling against a WRDBIB INPUT (DATA) file. The syntax is as follows:

or

1: ec multi_trieve extdict

where the optional [-norun] argument prevents immediate execution of the newly created program!

NOTE: See also online "help" segments: DICT.ec.info 
B.2.2 DICTIONARY CREATED DURING CREATION PROGRAM:

The user enters the MULTI_TRIEVE "exec_com": (See: Multics Handbook!)

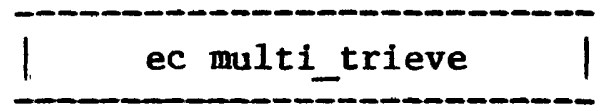

and the system will solicit the DATA DICTIONARY from him. (Fig. II-4 .)

The user enters the retrieval name, print name (optional), starting position, and size of each variable of his DATA DICTIONARY separated by blanks. When completed the user transmits a blank and a period. (Note: The colon ":" is followed by user entries!)

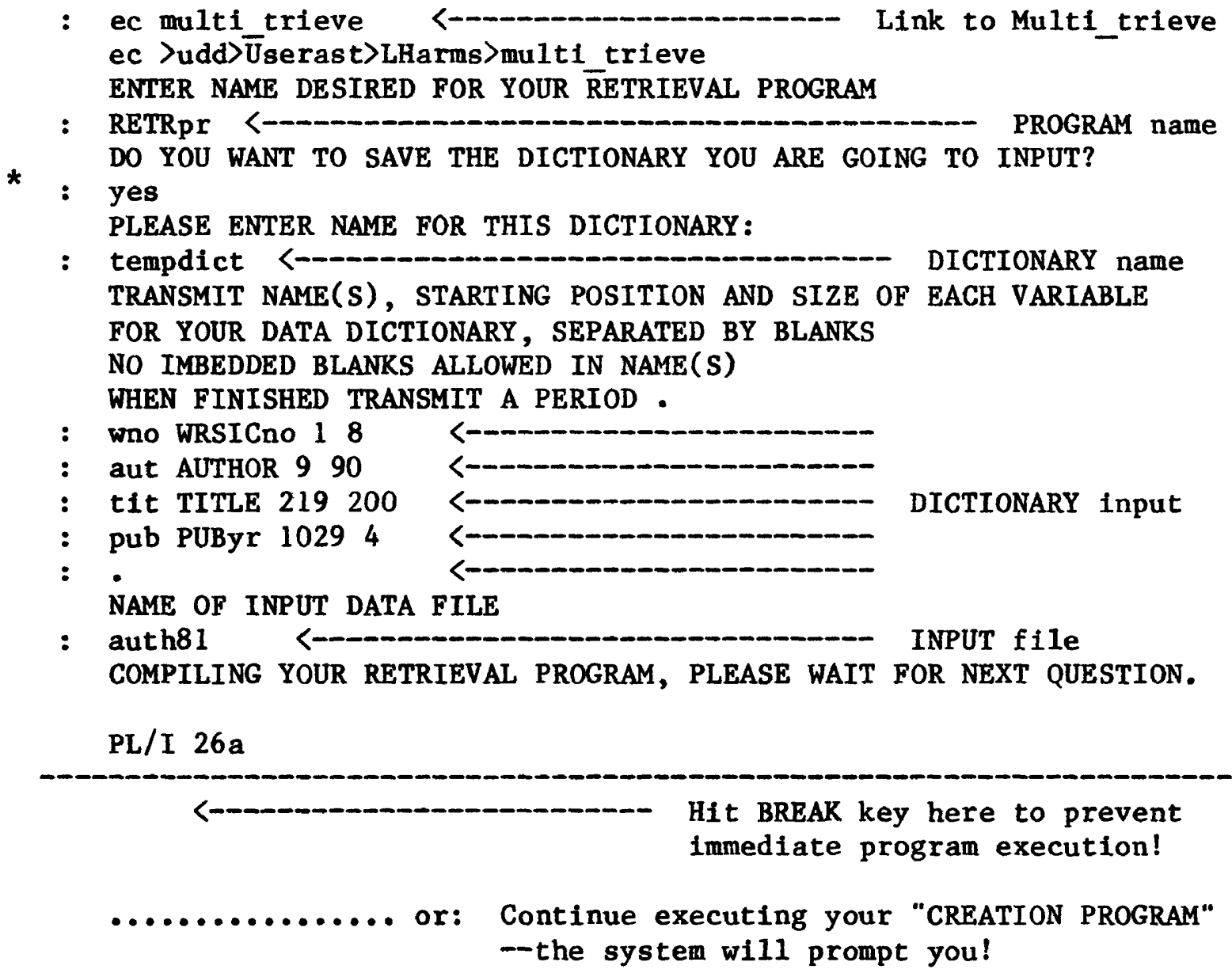

Figure II-4.--DATA DICTIONARY CREATED DURING PROGRAM EXECUTION.

* NOTE: The user has the option of saving the DATA DICTIONARY that was just entered. This DATA DICTIONARY could then be used later for PROGRAM compilation using method B.2.1. (See comPdict.info.) 
B.3. CREATING A WRDBIB PROGRAM: (COMPILING)

When the user activates the Multi trieve process in order to create a custom WRDBIB PROGRAM he/she can specify the name of a segment which contains the DATA DICTIONARY.

PROCEDURE: To initiate program compilation use the "exec_com": multi_trieve.ec and optional arguments as given below.

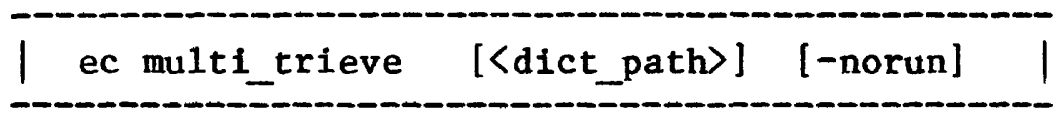

-- the system will ask the user to supply a PROGRAM NAME,

-- the system will ask the user to supply the name of the INPUT file,

-- the system will ask the user to supply the a DATA DICTIONARY in order to define the variables in the INPUT file--provided, a DICTIONARY has not been referenced in argument form in the exec_com command!

-- the optional [] "-norun" argument prevents immediate execution of the newly created PROGRAM.

A "PROGRAM CREATION" example using a WRDBIB DATA DICTIONARY is given in fig. II-5 - (For direct input of a DATA DICTIONARY into the PROGRAM see fig. II-4.)

: ec multi trieve extdict - norun ec >udd $>\bar{U}$ serast $>$ LHarms >multi trieve extdict - norun ENTER NAME DESIRED FOR THE RETRIEVAL PROGRAM:

: NOVpr NAME OF INPUT FILE

: auth81 COMPILING YOUR RETRIEVAL PROGRAM, PLEASE WAIT FOR NEXT QUESTION.

PL/I 26a

DO YOU WANT TO SAVE YOUR RETRIEVAL PROGRAM FOR LATER USE?

: yes

THE NEXT TIME YOU WANT TO EXECUTE YOUR PROGRAM ENTER THE COMMAND NOVpr

GOOD BYE
$\mathbf{r}$ (Your "ready" message!)

Figure II-5.--CREATING A CUSTOM PROGRAM USING A WRDBIB DICTIONARY. The program is saved for future application.

See also: Online ready reference -- Compdict.info. 


\section{B.4. INPUT FILES :}

B.4.1. WRDBIB INPUT FILES:

The user has the option to search the following primary INPUT files:

(1) The "Master" file: "auth6880" - containing 7407 records, and

(2) the "Current" (update) files.

$\begin{array}{ll}\text { (1) The "Master" file: } & \begin{array}{l}\text { "auth6870" } \\ \text { "partitioned into } \\ \text { four sections) }\end{array} \\ \begin{array}{l}\text { "auth7174" } \\ \text { "auth7980" }\end{array}\end{array}$

(2) The "Current" files :

Update files 1979/80: "auth356" ( 356 records)

Acc.yr. 1981 to $5 / 82$ : "auth81") ( 827 records)

*

tape-archived INPUT files may be recalled on demand. (See APPENDIX_I)

for procedure.)

The user may substitute the names of other files to be searched. These files may be subsets of the Master file or the Current files which have been retrieved on a major retrieval key: ret_XXXXXX.data. (See APPENDIX_III, steps $7,8,9$. )

A11 files specified will be searched to find records that meet the MATCH criteria. When the program finishes searching a file, it will print the name of the file, the number of records read, and the number of records retrieved. The program retains the names of all INPUT files until the user is finished with his session. The next time the program is executed, the user will once again have the opportunity of searching other files. 
B.4.2 ALTERING INPUT FILES DURING PROGRAM EXECUTION:

When the user enters the "-change in" argument in addition to the

"-response 〈path〉" argument in his PROGRAM STATEMENT:

$$
\text { NOVpr -rsp FORM - chg in । }
$$

the system will print the following prompts:

YOUR CURRENT INPUT FILE IS >udd>Wrdbib>NTamberg>auth7980 DO YOU WISH TO USE A DIFFERENT INPUT FILE?

: (yes/no) (- USER response THE NEW INPUT FILE MUST BE COMPATIBLE WITH THE DICTIONARY DESCRIBING THE OLD INPUT FILE. PLEASE ENTER THE NAMES OF INPUT FILES. THE NAMES MUST BE SEPARATED BY BLANKS. THE LAST NAME MUST BE FOLLOWED BY A BLANK AND A PERIOD.

The user may search several files simultaneously. Additional files may be entered as response to the second prompt:

DO YOU WANT TO SEARCH ADDITIONAL FILES WHICH CONFORM TO THE DICTIONARY?

: yes

PLEASE ENTER THE NAMES OF INPUT FILES. THE NAMES MUST BE SEPARATED BY BLANKS. THE LAST NAME MUST BE FOLLOWED BY A BLANR AND A PERIOD. GW.dt Org.dt . ANY MORE FILES TO SEARCH?

: no

INPUT FILES: >udd>Wrdbib>NTamberg $>$ I0>auth8 1 $>$ udd $>$ Wrdbib $>$ NTamberg $>$ IO $>$ GW. dt $>$ udd $>$ Wrdbib $>$ NTamberg $>$ IO $>$ Org.dt

NOTE: All the files selected must conform to the DATA DICTIONARY describing the original file. (See section B.2.)

NOTE: If the name of a file entered does not exist, the PROGRAM will notify the user of the problem. The user may reenter any incorrect file names.

For examples of INPUT procedures see SECTION_III: Fig.s III-6, III-7, III-9. Online see: INPUT.Info, PROG.ex.info, and PRROG.ec.info. 


\section{B.5. DEFINING PROGRAM VARIABLES:}

\section{B.5.1 CHECKING INTERNAL PROGRAM DICTIONARY:}

Before beginning his retrieval session using a WRDBIB PROGRAM, the user should make sure he knows its DICTIONARY specifications. A brief check may be run by entering the PROGRAM name and executing as shown below. (Fig. II-6.)

NOTE: The colon ":" denotes user response.

: NOVpr

YOUR CURRENT INPUT FILE IS >udd>Wrdbib>NTamberg>IO>auth8 1

DO YOU WISH TO USE A DIFFERENT INPUT FILE?

: no

DO YOU WANT TO SEARCH ADDITIONAL FILES WHICH CONFORM

TO THE DICTIONARY?

: no

DO YOU WANT TO SEE THE DICTIONARY?

: yes

$\begin{array}{llcc}\text { DICTIONARY DESCRIPTION } & \\ \text { RETRIEVAL NAME } & \begin{array}{c}\text { PRINT NAME } \\ \text { wrsic.no }\end{array} & \text { START POS } & \text { FIELD LENGTH } \\ \text { wno } & \text { acc.yr } & 1 & 8 \\ \text { acyr } & \text { acc.no } & 1 & 2 \\ \text { acno } & \text { author } & 4 & 5 \\ \text { aut } & \text { source } & 9 & 90 \\ \text { sso } & \text { title } & 99 & 120 \\ \text { tit } & \text { citation } & 219 & 200 \\ \text { cit } & \text { descriptor } & 649 & 230 \\ \text { des } & \text { pub.yr } & 1029 & 380 \\ \text { pub } & \text { ident } & 1033 & 4 \\ \text { idn } & & & 2\end{array}$

DO YOU HAVE ANY STRICTLY NUMERIC FIELDS IN YOUR DATA ...

To interrupt program execution hit BREAK key here

Figure II-6.--CHECKING PROGRAM DICTIONARY. 


\section{B.5.2 DECLARING NUMERIC VARIABLES:}

Notice that we are dealing with string variables up to 380 characters long. We have defined both, alphabetic and numeric variables; the latter must be declared as numeric when numeric comparisons are desired. (See RETRIEVAL STATEMENT.) They may be treated as alphameric strings, if so desired. To define numeric variables proceed as follows:

DO YOU HAVE ANY STRICTLY NUMERIC FIELDS IN YOUR DATA THAT YOU WANT TREATED AS NUMERIC VARIABLES FOR COMPARISON PURPOSES?

: yes

PLEASE ENTER THE VARIABLES TO BE TREATED AS NUMERICS

THE NAMES MUST BE SEPARATED BY BLANKS

THE LAST NAME MUST BE FOLLOWED BY A BLANK AND A PERIOD.

: pub acyr acno .*

Notice the format: One or more variables from the DICTIONARY are entered separated by blanks; the statement ends with a blank and a period.

The user defined the publication year ( $p u b$ ), the accession year (acyr), and the accession number (acno) as numeric variables. Therefore, numeric comarisons may be specified in subsequent RETRIEVAL STATEMENTS using operators "equal, eq", "greater than, gt", "less than, 1t", the numeric "or", the "range" between to numerics. (See examples in section B.6.) 
B.6. RETRIEVAL STATEMENT.

B.6.1 HOW TO FORMULATE YOUR RETRIEVAL STATEMENT: The user must know how to formulate his RETRIEVL STATEMENT(s). The following syntax applies:

$$
\mid\langle\text { variable name }\rangle=\langle\text { relational operator }\rangle\langle\text { VALUE }\rangle
$$

where 〈variable name> is one of the variable fields listed in the DICTIONARY. 〈relational operator〉 designates the condition to be checked (eq, pn, lt, gt, rg, or), and

〈VALUE> refers to a particular INDEX TERM to be matched in the INPUT file(s). (The 〈VALUE> string must be entered in CAPITAL LETTERS!)

NOTE: When searching WRDBIB input files described by the WRDBIB DICTIONARY the best search results are achieved with three or less RETRIEVAL STATEMENTS--which comprise the MATCH criteria (mc).

A GIVEN ENTRY OF MATCH CRITERIA MUST END IN A BLANK AND A PERIOD OR A PERIOD ON A NEW LINE FOLLOWING THE LAST RETRIEVAL STATEMENT.

B.6.2 RETRIEVAL RELATIONAL OPERATORS: The following relational operators can be used in a general retrieval request:

DESCRIPTIVE NAME

partial name match

(partial notation)

equal

less than

greater than

range

numeric or
RETRIEVAL NAME

APPLICATION

pn -- - for alphameric strings

eq $\quad--$ for alphameric comparisons

$1 t$

gt

$\mathrm{rg}$

or
-- for numeric comparisons *

The user may wish to create a report using ALL the records in the data file. The special retrieval command to inform the program that all records are to be retrieved is the condition: "all ."

* WRDBIB variables which may be treated as numerics are: Publication year, pub; (WRSIC) accession year, acyr; and accession number, acno. (See fig. II-6 DICTIONARY DESCRIPTION. See also Examples in section B.6.3.) 


\section{B.6.3 EXAMPLES :}

Enter RETRIEVAL STATEMENTS according to format shown below. The system will prompt you as follows:

(1) When providing your own responses to a RETRIEVAL program: ENTER MATCHING CRITERIA FOR RECORD SELECTION

: (- - - Enter RETRIEVAL STATEMENT

(2) When using "-response" and "-change mc" arguments:

ALL RECORDS WILL BE SELECTED. DO YOU WISH TO CHANGE, AND OR DELETE ANY OF THESE VALUES?

: (yes/no) (If yes, the system will specify the entry format)

TO DELETE VARIABLES ENTER A $d$ AS THE VALUE, SUCH AS $\mathbf{x x}=\mathbf{d}$ TO ADD OR CHANGE A VARIABLE ENTER AS NORMAL INPUT SUCH AS $x x=e q . .$. (or $x x=p n " \ldots .$. . See below!) ENTER MATCHING CRITERIA FOR RECORD SELECTION. :

For string searches use the "partial name, pn" operator:

NOTE: The term that is to be matched within a variables field follows the pn operator and must be enclosed in quotes.

: des=pn"ACID_RAIN" - (No blanks are allowed between words-For numeric comparisons:

NOTE: The relational operators "range, rg", and "or" use the slash "/" to separate one value from another. If any value used with these operators contains a slash, each slash must be preceded by the escape character " " to notify the program that the next slash is part of the value and not the delimiter! (See Multi trieve Manual.)

pub=1t1980 . (to retrieve reports published before 1980) acyr=eq82 . (to retrieve reports accessed in 1982 acno=or00066/00075/00123 . having specified accession numbers) pub=rg1980/1982 . (to retrieve reports published during $1980,1981,1982$.

For direct (alphameric) comparisons use operator: "equal, eq" wno=eq81-00756 . (to retrieve by direct accession number match. where "-" is a non-numeric character.)

pub=eq1981 . (to retieve al1 reports published in 1981.)

(See also EXAMPLES in Section_III: Figs. III-3 and III-5.) 
B.6.4 COMPOUND (LOGIC) OPERATORS: "AND"/"OR".

To formulate a desired search the user may compound his retrieval statements by introducing logic operators:

"OR" $\operatorname{logic} \ldots \ldots \ldots \ldots$ within one variable field

"AND" logic ......... combining two or more variable fields

"OR" logic allows to specify alternate forms of a descriptor or all applicable descriptors denoting one search concept.

"AND" logic allows to combine two or more search concepts, such as the "author" statement and a "title" term; a "citation" term and a "descriptor" value. (See EXAMPLES below.)

APPLICATION OF "AND/OR" (LOGIC) OPERATORS: Boolean logic is used implicetly in Multi_trieve retrieval statements.

EXAMPLE of "AND" Logic--when searching the Current file: "auth81":

RETRIEVE ALL MAP REPORTS AUTHORED OR COAUTHORED BY POST SINCE 1980

Upon system prompt type compound RETRIEVAL STATEMENTS as shown below:

ENTER MATCHING CRITERIA FOR RECORD SELECTION

: aut=pn"POST"

: cit=pn"MAP" . $\quad$ (Compare fig. II-1.)

EXAMPLE of "OR" Logic:

Use "OR" operator to retrieve all aspects expressing one search concept.

Use "OR" operator to express variant spelling forms of desired index term.

: des=pn"GROUNDWAT"GROUND-WAT"GROUND_WAT"AQUIFER"WELL" •

NOTE: The user may use combinations of "AND/OR" logic as long as the every variable field is only referenced once during a given RETRIEVAL run.

NOTE: Two successive RETRIEVAL runs will result in "AND" 1 ogic, when the second program uses the data retrieved in the first run as INPUT in the second. This approach is used for large volume output. See RETRIEVAL PROBLEM illustrated by the "Retrieval Session" in APPENDIX_III.

(See also APPENDIX_III: WRDBIB RETRIEVAL SESSION. Step 2.) 


\section{B.7. RESPONSE FILE:}

\section{B.7.1 RESPONSE FILE FUNCTION:*}

The RESPONSE file incorporates all system's queries and the responses provided by the user during an entire MULTI TRIEVE session. Such a session may include several retrievals and severäl reports. The purpose of a customized RESPONSE file is to allow the user to run similar retrieval and report generation programs without having to reenter all the detailed specifications. The label for the RESPONSE file is of the form retXXXXXX.response where "XXXXXX" is a numeric. (The user is advised to rename his customized RESPONSE files; the suffix ".response" must be retained.)

To use the RESPONSE file, the user enters it as an argument when the MULTI_TRIEVE program is executed. The program statement is of the form:

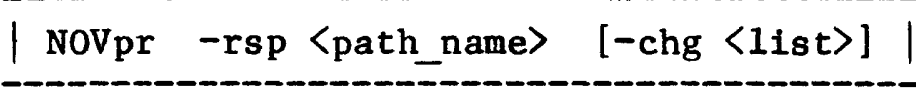

\section{B.7.2 ALTERING RESPONSE FILE DURING PROGRAM EXECUTION:}

To alter some of the information contained in a RESPONSE FILE, the "-change" argument can be used when the Multi trieve program is executed. The 〈list> may contain one or more input parameters specifying online change of either the INPUT file(s), (in), or different MATCH (selection) criteria (mc). Shown below is a PROGRAM STATEMENT with control arguments "-response newpr" specifying RESPONSE file "newpr. response" and "-change 〈list>" arguments: "-chg in, mc"--that is, different INPUT files and MATCH criteria. The user enters:

| NoVpr -rsp newpr - chg in,me |

RESPONSE file specifications may contain keywords " $\langle \% \mathrm{D}\rangle$ " or " $\langle \% \mathrm{~S}\rangle$ " which will cause the program to interactively ask the user for additional input. (See section C.4 Creating a Custom Report.)

Fig. II-7. shows an edited RESPONSE FILE. The data before the ":=" on each line are descriptors the program attaches to describe the responses. The data after the ":=" are the user's response to the program's questions. * For more detail see WBsum.info segments: RESPONSE.info and REPgen.info
online. 
B.7.3 EXAMPLE OF RRESPONSE FILE:

Figure II-7 below lists a typical RESPONSE file with customized REPORT specifications.

different input files:=no any more files: no

R dictionary: $=$ no (-) INPUT Files: $\mathrm{E}$ - chg in $T$ any numeric fields:=no matching criteria:=a1l . change criteria:=no

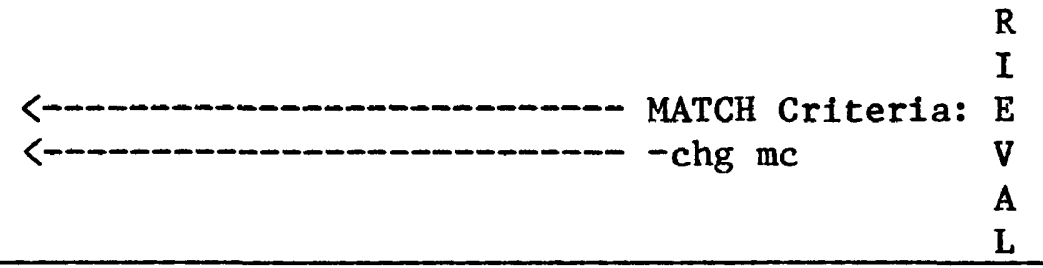

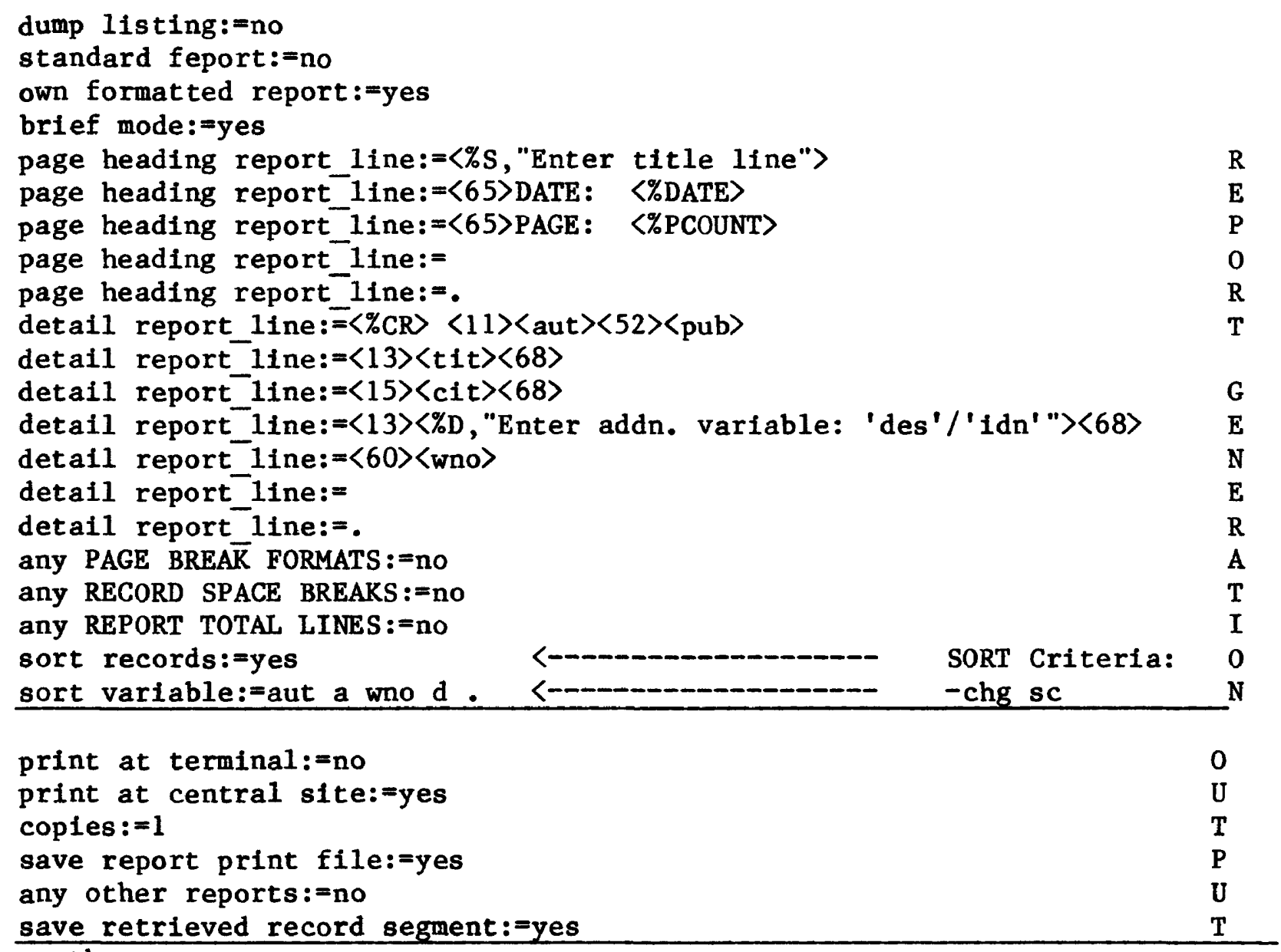
another run: $=$ no

Figure II-7.--TYPICAL RESPONSE FILE SPECIFIES A CUSTOM REPORT FORMAT (Edited version of "newpr.response".) 


\section{OUTPUT FEATURES.}

C. 1. SORTING

The records that have been selected by the retrieval process can be sorted prior to printing a report. The user should abstain from sorting on long variable fields. Limit your sorting to short variables, such as the WRSIC number ("wno") and the publication year ("pub"). You may also sort the author field ("aut") and the organizational source ("sso").

SORT STATEMENT:

The variable fields selected for sorting must be followed by a qualifier: " $a$ " (ascending sort sequence) and " $d$ " (descending). The first name entered becomes the major sort key, the next the secondary key. The names and the - lrt sequence character must be separated by blanks. The sort input is terminated by a blank and a period. An example of this input is given below:

EXAMPLE :

The records are to be sorted on two fields. "pub", the publication year will be the major sort key followed by author field "aut". "pub" will be sorted in descending " $\mathrm{d}$ " order (reverse chronological) and "aut" w11l be sorted in ascending " $a$ " sequence (from $A$ to $Z$ ).

Program:

DO YOU WANT TO SORT THE RETRIEVED

RECORDS PRIOR TO PRINTING THE REPORT?

User response

: yes

Program:

PLEASE ENTER THE VARIABLES NAMES TO SORT ON EACH

FOLLOWED BY EITHER AN "a" FOR ASCENDING SEQUENCE OR

A "d" FOR DESCENDING. THE ORDER THEY ARE ENTERED WILL

BE THE SORT ORDER. ALL ITEMS MUST BE SEPARATED BY

BLANKS AND THE LAST ENTRY TERMINATED BY A BLANK AND

A PERIOD.

User response

: pub d aut a . 
C.2. "DUMP-LISTING" OUTPUT

C.2.1 "DUMP-1isting" PROCEDURE :

If you specified that a sample of your output (1-5 records) be "dumplisted" at the terminal, the system will oblige when you respond to the query: (See RETRIEVAL PROGRAM example in fig. II-8)

DO YOU WANT A SIMPLE DUMP LISTING OF SOME OF YOUR RECORDS?

: yes

HOW MANY RECORDS DO YOU WANT TO SEE?

: 1

DO YOU WANT THE DUMP PRINTED AT YOUR TERMINAL?

: yes

- The system will "dump-1ist" one record at the terminal!

A11 elements will be listed in the sequence they have been entered into the system (using the 132 character paper width--see fig. II-9.)

If you specified OUTPUT at the central site you will get a statement showing which segments or files have been saved and their respective (defau1t) labels:

$$
\begin{array}{ll}
\text { retXXXX.report } & \text { (where } X=\text { numeric) } \\
\text { ret_XXXXXX.data } & \text { (for saved data segment) }
\end{array}
$$

(See also: Section C.3: Standard_MT Report Generation-OUTPUT SEQUENCE.) 


\section{C.2.2 RETRIEVAL PROGRAM: Using "Dump-listing" Option.}

: NOVpr <-

YOUR CURRENT INPUT FILE IS >udd>Wrdbib>NTamberg>TEMP>auth 1 DO YOU WISH TO USE A DIFFERENT INPUT FILE?

: no

DO YOU WANT TO SEARCH ADDITIONAL INPUT FILES WHICH CONFORM TO THE DICTIONARY?

: no

DO YOU WANT TO SEE THE DATA DICTIONARY?

: no

DO YOU HAVE ANY STRICTLY NUMERIC FIELDS IN YOUR DATA THAT YOU WANT TREATED AS NUMERIC VARIABLES FOR COMPARISON PURPOSE?

: no ENTER MATCHING CRITERIA FOR RECORD SELECTION.

: tit=pn"COLORADO" .

NAME CONDITION VALUE

tit pn COLORADO

DO YOU WISH TO CHANGE, ADD OR DELETE ANY OF THESE VALUES?

: no

TOTAL NUMBER OF RECORDS READ $=640$

TOTAL NUMBER OF RECORDS SELECTED $=31$

DO YOU WANT A SIMPLE DUMP LISTING OF SOME OF YOUR RECORDS?

: yes

HOW MANY RECORDS DO YOU WANT TO SEE?

: 1

DO YOU WANT THE DUMP PRINTED AT YOUR TERMINAL

: yes

one record is "dump_listed" at your terminal

(See format in fig. II-9.)

DO YOU WANT THE DUMP PRINTED AT THE CENTRAL SITE?

: no

Hit BREAK key if you wish to interrupt further program execution!

If you wish to save the retrieved data continue below!

DO YOU WISH TO CREATE A STANDARD REPORT USING THE SELECTED RECORDS?

: no

DO YOU WISH TO CREATE YOUR OWN FORMATTED REPORT?

: no

DO YOU WANT TO SAVE THE SEGMENT CONTAINING THE RECORDS JUST RETRIEVED?

: yes

(-- save data!

THE NAME OF THE SEGMENT SAVED IS ret_100410.data

DO YOU WISH TO MAKE ANOTHER RUN?

: no

DO YOU WANT TO SAVE YOUR RESPONSES SO YOU CAN RUN THIS SESSION AGAIN?

: no

END OF JOB (Leve1 2)

Figure II-8.--RETRIEVAL PROGRAM DUMP-LISTING OUTPUT. The format of a "dump-listed" record is shown in fig. II-9. 


\section{C.2.3 EXAMPLE: "DUMP-LISTING" OUTPUT:}

The first record retrieved by the preceding retrieval program is dump-listed in the same sequence its data elements were entered into the data base. (See section B.2. DATA DICTIONARY.)

NOTE: Headings are labels from the DATA DICTIONARY associated with the "NOVpr" program! Each data field begins on a new line.)

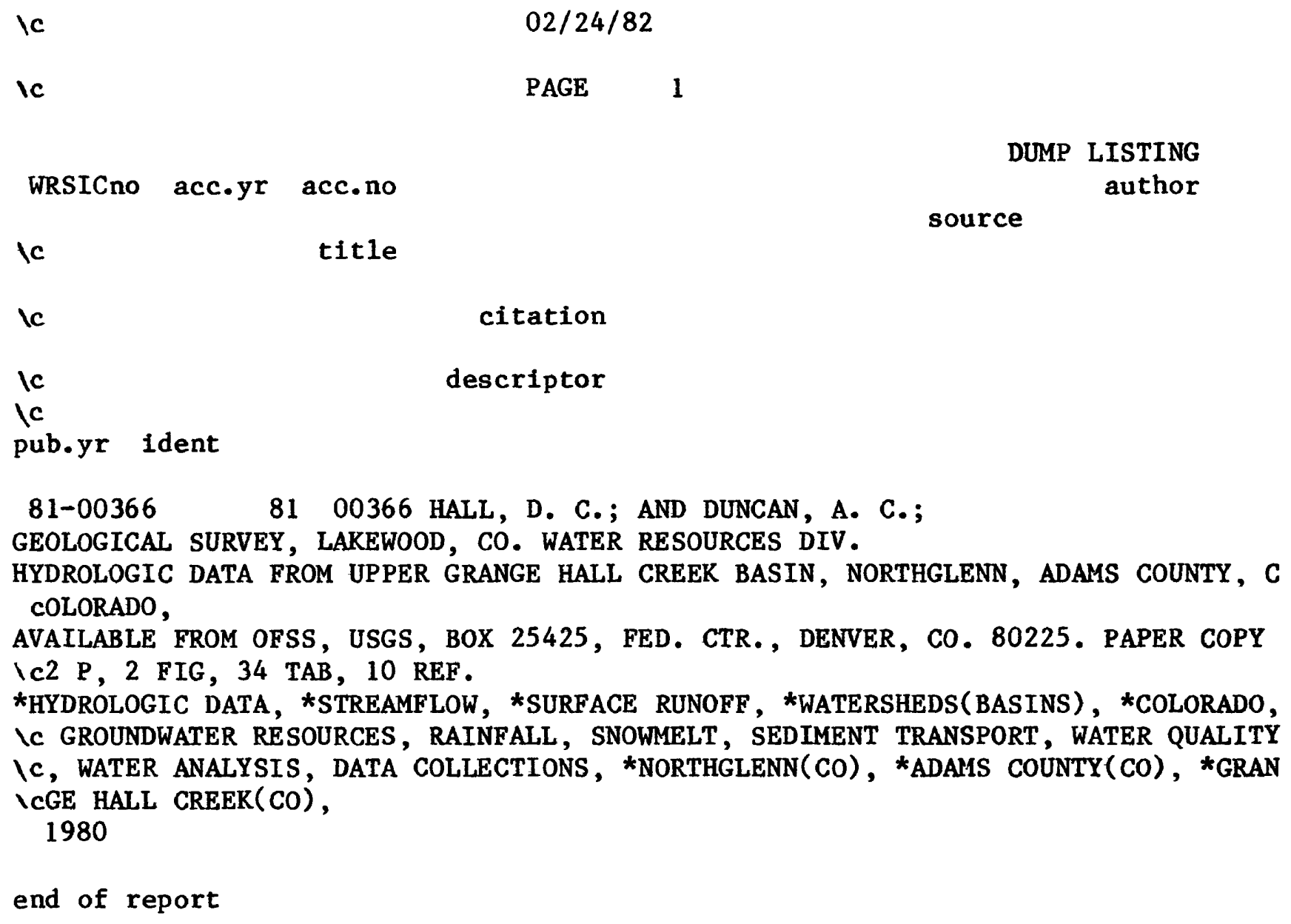

Figure II-9. "DUMP-LISTING" OUTPUT: One sample record is listed at the terminal. (Note the sutomatic wraparound feature (c) adjusting for CRT screen width.) 


\section{C.3. CREATING A STANDARD REPORT:}

\section{C.3.1 CREATING A "Standard MT" REPORT:*}

After inspecting one dump-listed record at the terminal (see section C.2.3. SAMPLE RETRIEVAL PROGRAM), the user may want to generate a "standard MT" report. This allows him to generate a somewhat structured report: The user may specify the sequence of desired print variables, he may use breaks to list subtotals (of numeric variables), and he may sort on any designated variable. The user may provide a page heading (title). (The default line length of the report will be 134 characters!)

STANDARD REPORT: The retrieval program queries the user's response to the various report options. The report options are as follows:

-- User specified page heading.

-- Printing of any or all items from the data dictionary.

-- Page breaks when the value of any variable(s) change.

-- Double space breaks when the value of any variable(s) change.

-- Accumulating report totals and averages for any numeric variables.

-- Accumulating subtotals and averages for any numeric variables. These are printed on page breaks and/or double space breaks.

-- Performing arithmetic calculations.

-- Obtaining record counts for any break condition.

-- Suppressing the printing of detail lines.

-- Sorting the retrieved records prior to printing the report.

-- Printing the report at the user's terminal or at the central site or both.

-- Printing as many different reports as desired from the retrieved records.

-- Saving report segment for possible printing by the user at a later time.

-- Using any character as a report highlighter.

* "Standard_MT" stands for STANDARD_MULTI_TRIEVE (REPORT). 
C.3.2 STANDARD REPORT GENERATION PROPCEDURE. REPORT specifications are as follows: (User responses follow the colon ":".)

DO YOU WISH TO CREATE A STANDARD REPORT USING THE SELECTED RECORDS? C : yes

DO YOU WANT THE BRIEF MODE OF QUESTIONS FOR REPORTS?

: yes

YOU MAY ENTER A MAXIMUM OF 5 LINES FOR THE PAGE HEADING. T PLEASE ENTER LINE 1

: COLORADO RECORDS

PLEASE ENTER LINE 2

[This signifies end of page heading!] $T$

: $\quad$

PLEASE ENTER THE VARIABLE NAMES (as listed in the dictionary) N

TO BE PRINTED.

: aut pub tit wno .

[names are separated by blanks and A end in a blank and a period!] $\quad R$

DO YOU WANT PAGE BREAKS WHEN ANY VARIABLES CHANGE?

: no

DO YOU WANT DOUBLE SPACES WHEN ANY VARIABLES CHANGE?

$\mathbf{R}$

: no

DO YOU WANT ANY REPORT TOTALS?

: no

DO YOU WANT ANY RECORD CALCULATIONS?

: no

DO YOU WANT ANY REPORT CALCULATIONS?

: no

DO YOU WISH TO SUPPRESS THE PRINTING OF THE DETAIL LINES?

: no

DO YOU WANT TO SORT THE RETRIEVED RECORDS PRIOR TO PRINTING THE REPORT?

: yes

PLEASE ENTER THE VARIABLE NAMES TO SORT ON

: aut a .

DO YOU WANT THE REPORT PRINTED AT YOUR TERMINAL? $\quad$ R

: no

DO YOU WANT THE REPORT PRINTED AT THE CENTRAL SITE?

: yes

HOW MANY COPIES DO YOU WANT PRINTED AT THE CENTRAL SITE?

$: 1$

DO YOU WANT TO SAVE THE REPORT PRINT FILE?

: yes

THE NAME OF THE SAVED REPORT PRINT FILE IS ret1806.report U

DO YOU WANT ANY OTHER STANDARD REPORTS FROM THIS RETRIEVAL?

: no

** DO YOU WISH TO CREATE YOUR OWN FORMATTED REPORT <-: no

(OUTPUT continued)

Use WRDBIB RESPONSE files to create custom formatted REPORTS!

(See section C.4. below: CREATING A CUSTOM REPORT.) 


\section{C.3.2 OUTPUT PROCEDURE continued:}

DO YOU WANT TO SAVE THE SEGMENT CONTAINING THE RECORDS JUST RETRIEVED?

: yes

THE NAME OF THE SEGMENT SAVED IS RET_101253.data

DO YOU WISH TO MAKE ANOTHER RUN?

: no

DO YOU WANT TO SAVE YOUR RESPONSES SO YOU CAN RUN THIS SESSION AGAIN?

: yes

THE NAME OF THE SEGMENT SAVED IS ret101253.response

END OF JOB (Level 2)

DO YOU WANT TO SAVE YOUR RETRIEVAL PROGRAM FOR LATER USE? no GOOD BYE

r $10: 198.9172459$

Online see WBsum.info section: REPgen.info.

C.3.3 SAMPLE RESPONSE FILE: Shows "Standard_MT" REPORT specifications:

different input file:=no

any more files:=no

dictionary:=yes

any numeric fields:=no

matching criteria:=tit=pn"COLORADO" .

change criteria:=no

dump 1isting:=no

records to dump: $=0$

print at terminal:=no

print at central site:=no

standard report:=yes

brief mode:=yes

page heading:=COLORADO RECORDS

page heading:=.

VARIABLES PRINTED:=aut pub tit wno -

any PAGE BREAKS:=no

any DOUBLE SPACE BREAKS:=no

any REPORT TOTALS:=no

any RECORD CALCULATIONS : $=$ no

any REPORT CALCULATIONS:=no

suppress detail lines:=no

sort records:=yes

sort variable:=aut $a$.

print at terminal:=no

print at central site:=yes

copies : $=1$

save report print file:=yes

any more standard reports:=no

own formatted report:=no

save retrieved record segment:=yes

another run: $=$ no

Figure II-10.--STANDARD REPORT RESPONSE FILE: "STD.response"

NOTE: The "Standard MT" format is useful for numeric applications. (See the Mult $\bar{I}$ trieve Manual for detailed information.) 
C.4. CREATING A CUSTOM REPORT:

C.4.1 Report Format Specifications: When the user chooses to create his own formatted report, the format of each line of the report is specified. There are six categories of lines:
(1) Page heading......................... for WRDBIB custom reports
(2) Detail record lines................... for WRDBIB custom reports
(3) Before record break................ptional
(4) After record break..............ptional Used in:
(5) Page break.......................... Reports.
(6) Report total...............................
(See section C.3.)

C.4.2 Header Lines and Detail Record Lines: A report line can be constructed from two items:
(1) User text
(2) Keywords enclosed by angle brackets, "〈>"

A report line can contain either one or both of these items. User text is anything entered by the user not enclosed by angle brackets. A typical report line might look like this: (See section 10. KEY-WORDS.

$$
\begin{aligned}
& \text { page heading report_1ine: }=\langle 64\rangle \text { DATE: }\langle \% \text { DATE }\rangle \\
& \text { page heading report_1ine: }=\langle 64\rangle \text { PAGE: }\langle \% \text { PCOUNT }\rangle \\
& \text { detail report_line: }=\langle \% C R\rangle\langle 10\rangle\langle\text { author }\rangle\langle 60\rangle\langle 62\rangle\langle\text { pubyr }\rangle\langle 66\rangle
\end{aligned}
$$

C.4.3 Printing Wraparound: If the user specifies an item ("des"= descriptor field) for which the allowed print length is smaller than the actual length specified in the data dictionary, the program will automatically print the item on a many lines as necessary, aligning the starting print position with the originally specified column for that item. The lines entered by the user are considered logical lines. Due to wraparound, a logical line could generate several physical lines to be printed in the report. (See fig. II-11.) 
WOLANSKY, R. M.; MILLS, L. R.; WOODHAM, W. M.;

$1979<----$ Publn. year

AND LAUGHLIN, C. P.;

POTENTIOMETRIC SURFACE OF FLORIDAN AQUIFER, SOUTHWEST

FLORIDA WATER MANAGEMENT DISTRICT AND ADJACENT AREAS, MAY 1979,

GEOLOGICAL SURVEY OPEN-FILE REPORT 79-1255, 1979.

1 SHEET.

*MAPS, *AQUIFERS, *WATER LEVELS, *POTENTIOMETRIC LEVEL, <---- Descriptors *FLORIDA, WATER WELLS, WATER UTILIZATION, IRRIGATION, WATER LEVEL FLUCTUATIONS, *FLORIDAN AQUIFER, SOUTHWEST

FLORIDA, WATER MANAGEMENT.

$$
\text { 81-00141 }
$$

Figure II-11.--CUSTOM-FORMATTED REPORT: An Example of Wraparound Printing.

\section{C.4.4 Using Key-words:}

The items enclosed by " \langle\rangle $"$ are considered keywords by the program. These include line position numbers preceding and following data variables. When the program encounters a pair of angle brackets, it attempts to replace that string with the appropriate action. Key-words proper are tagged with the "\%" sign. (See section 5. Selected Key-word List.)

Example:

$$
\begin{aligned}
& \langle \% \text { DATE }\rangle \quad \ldots \ldots \ldots \ldots \text { will print the current date } \\
& \langle \% \text { COUNT }\rangle \text {......... will print the current page number } \\
& \langle \% \mathrm{CR}\rangle \quad \ldots \ldots \ldots \ldots \text { will print the record count } \\
& \langle 11\rangle\langle\text { aut }\rangle \ldots \ldots \ldots \ldots \text { indicates starting position of } \\
& \text { "author" field on given line. }
\end{aligned}
$$

If no key-word matches the string the program allows the user to reenter the line or use the line as it exists. It sends an "Error Message". (See section: ERROR MESSAGES.) Anything not enclosed by angle brackets is considered user text and will be printed as it appears.

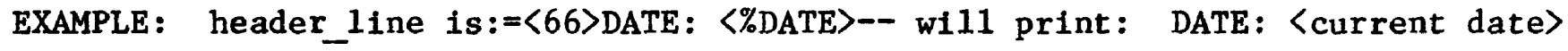

\section{C.4.5 Key-Words Prompting User Interaction:}

$\langle \% s, "$ title string" $\rangle$............... for inactive report title entry, $\langle \% \mathrm{D}$, add print variable string" $\rangle \quad \ldots .$. specifies an addtional "print" variable from DATA DICTIONARY.

WRDBIB APPLICATION: See Section_III. PROGRAM EXECUTION using the "newpr.response" file as "-response" argument. (Fig. III-9.) 
C.5. SELECTED KEY-WORD LIST:

Key-Words: There are many key-words that can be used to format a report. Some key-words have predetermined sizes and formats. Following is the Key-Word list:

\section{$\langle\mathbf{n}\rangle$ \\ $\langle ?\rangle$ \\ $\langle "\rangle$ \\ $\langle>$}

$\langle!\rangle$

$\langle>$

$\langle \%$ PAGE $>$

$\langle \% \mathrm{C}\rangle$

$\langle \% \mathrm{CR}\rangle$ where " $n$ " is an integer between 1 and 136 . This indicates ther starting column for the item following the " $\langle\mathbf{n}\rangle$ ".

indicates the line is to be printed only if the data from the record is nonblank.

causes the line to be centered.

controls the underline feature for a given line. The underline keyword operates in pairs. The first" $<>$ " encountered in a report line turns on the underline feature. All text and data following it will be underlined until a second" $\langle>$ " is encountered or the end of the report line is reached. There can be any number of pairs of underline keywords on a report line.

controls the boldface printing feature for a given line. The boldface printing keyword operates in pairs. The first " $\langle$ ! " encounterd in a report line turns on the boldface printing feature. All text and data following it will be goldface printed until a second " $\langle!\rangle "$ is encountered or the end of the report line is reached. There can be any number of pairs of boldface printing keywords on a report line.

controls the capitalized letter feature for a given line. The capitalized letter keyword operates in pairs. The first " $\langle>$ " encountered in a report line turns on the capitalized letter feature. All text and data following it will be capitalized until a second " \langle\rangle $"$ is encountered or the end of the report line is reached. There can be any number of pairs of capitalized letter keywords on a report line.

when the tilde, "w", is embedded in the user's data record it will force a line break for texttype information, if: wraparound is required.

causes a page eject.

causes the record count for the current break to be used in a calculation or printed. The size of the count is seven characters.

causes the count for the record to be printed. The size of the count is seven characters. 
$\langle \% \mathrm{CB}\rangle$

causes the count (KW) for the current record break to be printed. The size of the count is seven characters.

$\langle \% \mathrm{CP}\rangle$

causes the count for the current record for the current page break to be printed. The size of the count is seven characters.

$\langle \%$ DATE $\rangle$

causes the date to be printed. The size of the date is eight characters and is of the form $\mathrm{mm} / \mathrm{dd} / \mathrm{yy}$.

$\langle \%$ PCOUNT $\rangle$

causes the page count to be printed. The size of the new page count is six characters.

$\langle \% \mathrm{D}[$, "prompt_string"]) $\rangle$

causes the program to prompt the user, interactively, for a variable name from the dictionary even when the user program is executing using the "response" argument. The name is then substituted for the "\%D" in the report line and evaluated as the dictionary name keywords listed earlier. The user can provide his own prompt message, "prompt string", or a default message of "PLEASE ENTER DICTIONARY VRIABLE NAME:" is printed.

$\langle \% \mathrm{~S}[$, "prompt_string"] $)\rangle$

causes the program to prompt the user, interactively, to enter a character sting to be substituted for the "\%S" even when the user program is executing using the "response" argument. This string can contain any text or keywords the user chooses to enter. The user can provide his own prompt message, "prompt_string", or a default message of "PLEASE ENTER REPLACEMENT STRING:" is printed. 


\section{SECTION III. \\ WRDBIB PROGRAM EXECUTION \\ PROCEDURES}

A. RETRIEVAL: EXECUTING W/USER-SUPPLIED RESPONSES

B. RETRIEVAL AND REPORT GENERATION USING CONTROL ARGUMENTS

C. REPORT GENERATION: USING CONTROL ARGUMENTS

D. DIRECTORY CHECK 
A. RETRIEVAL: EXECUTING W/USER-SUPPLIED RESPONSES

A.1. OVERVIEW: PROGRAM STATEMENT (Command)--

HOW TO ENTER AND EXECUTE A RETRIEVAL PROGRAM:

The user has two options:

(1) Enter and execute an exploratory RETRIEVAL PROGRAM: Enter the name of your compiled PROGRAM and the system will prompt you for responses. You will be creating your own RESPONSE file. (See example below!) Save the retrieved data segment for subsequent REPORT GENERATION.

: $\quad\langle$ PROGRAM NAME $>*$

(2) Enter and execute a custom RETRIEVAL AND REPORT GENERATION PROGRAM. Enter your PROGRAM STATEMENT and [optional] CONTROL ARGUMENTS:

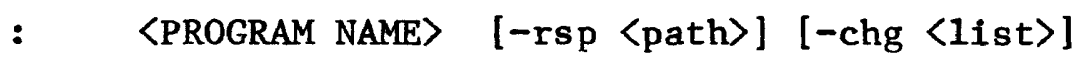

where -rsp 〈path> calls a previously created RESPONSE file: 〈path〉.response, which provides all responses for succesful program execution including format specifications for a custom formatted REPORT. (See: Section II. RESPONSE FILE.)

-chg 〈list> the "list" specifies the CONTROL ARGUMENTS which are to be altered interactively by the user: "in"= INPUT file(s), "mc"= MATCH (selection) criteria, "sc"= SORT criteria

NOTE: The "-chg_list" argument must be entered together with the "-rsp 〈path>" argument which it modifies. (Examples follow below.)

* When you elect to use WRDBIB PROGRAMS, RESPONSE and INPUT files: you need only compile a PROGRAM if you wish to change the DATA DICTIONARY describing your INPUT (DATA) files. (See COMPdict.info!) 
EXAMPLES OF PROGRAM STATEMENTS: (User entry follows the initial colon ":")

: NOVpr

: NOVpr -rsp RETR - chg in,mc

: NOVpr -rsp newpr - chg in, mc

: NOVpr -rsp FORM -chg in

: NOVpr -rsp AUT -chg in,sc (retrieves and saves data--creates RESPONSE file. (see fig. III-1.)

(retrieves data--see fig. III-3; and creates REPORT--see fig. III-5.)

(creates REPORT froin previously retrieved data--figs.III-7,III-9.)

(creates AUTHOR INDEX using previously retrieved data--fig. III-12.)

NOTE: The outcome of a PROGRAM is determined by user responses. When using a custom RESPONSE file (in argument form) the user must be familiar with all specifications therein in order to use available "change" argument options to full advantage.

Use Multics editor, qedx, to read and edit your RESPONSE file. (See fig. III-4.) 
A.2. OVERVIEW: RETRIEVAL REQUEST STRUCTURE:

The user must know how to formulate a WRDBIB RETRIEVAL STATEMENT using the Multi trieve format, and how to apply "AND/OR" logic in order to compound search statements. The user may enter several search requests using separate lines for each statement and terminating with a blank and a period following the last statement or with a period on a separate line. One or more RETRIEVAL STATEMENTS comprise the MATCH CRITERIA (mc).

The Syntax of the RETRIEVAL STATEMENT is as follows:

$$
\langle\text { Dict_Variable }\rangle=\langle\text { operator }\rangle\langle\text { VALUE }\rangle \text {. }
$$

\section{(1) VARIABLE:}

(2) OPERATIONAL CONDITIONS: (Operator)

For alphameric strings:

APPLICATION :

For numeric variables:

APPLICATION :

(3) VALUE:

(4) "OR"-LOGIC: The user may enter several values to be matched against a given variable field. Examples are entry of near-synonyms and alternate spelling modes:

$$
\text { des=pn"GROUNDWATER"GROUND_WATER"GROUND-WATER"AQUIFER"WELL" • }
$$

(5) "AND"-LOGIC: Two or more RETRIEVAL STATEMENTS represent "AND" logic. For example, retrieve on search statement: FLORIDA AND 〈GW-concept〉

$$
\text { tit=pn "FLORIDA" }
$$

des=pn"GROUNDWATER"GROUND_WATER"GROUND_WATER"AQUIFER"WELL" •

For more detail see RETRIEVAL SESSION: Steps 1 and 2 in APPENDIX_III. 
A.3 RETRIEVAL PROGRAM EXECUTION

A.3.1 PROCEDURE_A: HOW TO EXECUTE A RETRIEVAL PROGRAM--IN FOUR EASY STEPS.

(1) PROGRAM STATEMENT (Command): Enter the NAME of a custom program and proceed to execute. Supply all responses to program prompts.

You are creating a RESPONSE file. (User responses follow the ":")

: NOVpr (See fig. III-1. RETRIEVAL PROGRAM.)

(2) FILE INPUT: Respond to the following prompts!

-- DO YOU WISH TO SEARCH A DIFFERENT INPUT FILE? (yes/no)

-- DO YOU WANT TO SEARCH ADDITIONAL INPUT FILES WHICH CONFORM

TO THE DICTIONARY? (yes/no)

If a DIFFERENT INPUT file is desired respond to the following prompt:

-- PLEASE ENTER THE NAMES OF INPUT FILES.

THE NAMES MUST BE SEPARATED BY BLANKS.

THE LAST NAME MUST BE FOLLOWED BY A BLANK AND A PERIOD.

: auth82 . (For example see fig. III-5.)

(3) RECORD SELECTION: Respond to the following prompts!

-- DO YOU WANT TO SEE THE DATA DICTIONARY? (yes/no)

(This will print the labels of all variables you may want

to search, starting position in record, and field length!)

-- DO YOU HAVE ANY STRICTLY NUMERIC FIELDS IN YOUR DATA... (yes/no)

(You must define numeric variables for comparison purposes!)

-- ENTER MATCHING CRITERIA FOR RECORD SELECTION

: des=pn"POTOMAC" - (See section RETRIEVAL STATEMENT above!)

NOTE: ALL INDEX TERMS (VALUES) ARE ENTERED IN CAPS!

USE UNDERSCORE TO CONNECT INDEX WORDS SEPARATED BY A BLANK!

ALL STATEMENTS TO THE SYSTEM END IN A BLANK AND A PERIOD

OR A PERIOD ON A NEW LINE FOLLOWING THE STATEMENT!

(4) OUTPUT:

-- Dump-1ist (yes) one (1) record at the terminal, if so desired!

-- Save retrieved data segment for INPUT in a REPORT GENERATION program.

-- Save your newly created RESPONSE file if you wish to use it again for a similar retrieval run. (See section III.A.4.; fig. III-2. RETR.response.)

EXAMPLE :

RETRIEVE "POTOMAC" REPORTS FROM UPDATE FILE "auth81".

See: Fig. III-1 below for PROGRAM EXECUTION. 


\section{A.4 RETRIEVAL OUTPUT}

A.4.1 RETRIEVAL RESPONSE FILE: RETR.response

Listed below are responses used to execute your RETRIEVAL PROGRAM and stored (optionally) in your new RESPONSE file, RETR.response: (See fig. III-1 for program execution example.)

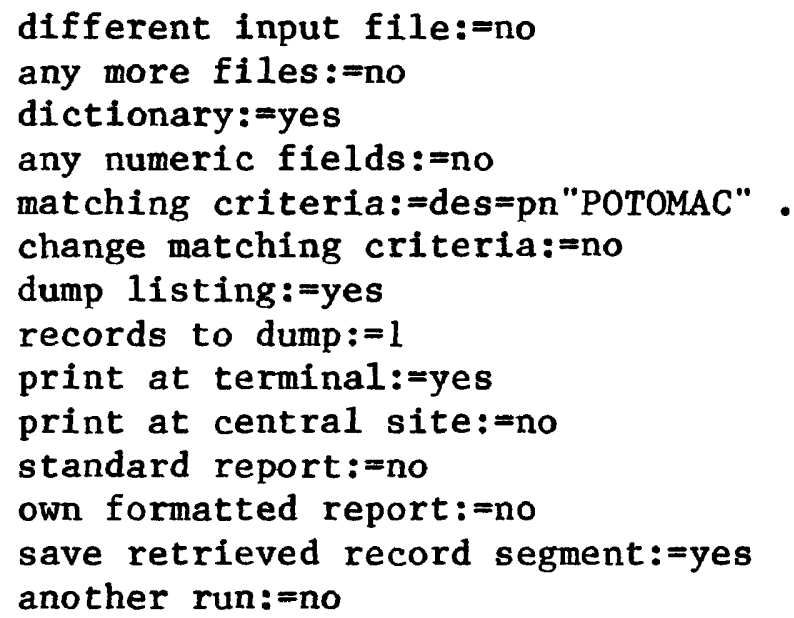

Figure III-2.--RETRIEVAL RESPONSE FILE: "RETR.response".

APPLICATION OF RETR.response: Use as step 1 to retrieve data! The user may use RETR. response for future RETRIEVAL runs when no custom REPORT is desired. (EXPLORATORY RUNS!) The RESPONSE file is used as "-response" argument together with one or more "-change_list" arguments. See examples of PROGRAM STATEMENTS (commands) below:

(1) to enter a different or additional INPUT files

: NOVpr -rsp RETR - chg in

(2) to change the MATCH (selection) criteria

: NOVpr -rsp RETR -chg mc

(See fig. III-3.)

(3) to change INPUT and MATCH criteria

: NOVpr -rsp RETR - chg in,mc

See: Section_B. RETRIEVAL AND REPORT GENERATION USING CONTROL ARGUMENTS.

A.4.2 DATA SEGMENT: ret XXXXXX.data (where XXXXXX is numeric) The saved data segment may $\bar{b}$ e used (1) as INPUT for further RETRIEVAL or (2) in a REPORT_GENERATION program. (See: Section_C.)

To reformat a previously retrieved data segment enter a PROGRAM STATEMENT using a "response" argument (including suitable report format specifications) and a "change in" argument to enter file ret XXXXXX.data.

: NOVpr -rsp FORM -chg in (See fig. III-7.)

NOTE: Choose "FORM.response" to generate a list of bibliographic citations. (Fig. III-8.) The "change in" argument will provide the prompts allowing you to change your INPUT file. Your MATCHING criteria should read: Matching criteria=all .-- ALL RECORDS WILL BE SELECTED. 
B. RETRIEVAL AND REPORT GENERATION USING CONTROL ARGUMENTS

Execute a custom RETRIEVAL AND REPORT GENERATION PROGRAM using contro1 arguments: Your "-response, -rsp" argument will supply a RESPONSE file which will provide all the necessary responses for program execution. The user must provide interactive responses to "-change, -chg 〈1ist $\rangle$ " prompts, and respond to queries resulting from key-words 〈\%S used in report format specifications. (See: Section II.C.4.)

To execute an exploratory RETRIEVAL PROGRAM proceed according to steps (1)-(4). To execute a one-step RETRIEVAL \& REPORT GENERATION PROGRAM do steps (1)-(8). (See Section_C for REPORT_GENERATION PROGRAMS: Reformatting retrieved data.)

B.1 PROCEDURE_B : Using -rsp〈path〉 -chg 〈list〉

(1) Select your RESPONSE file. (Read and/or edit responses!)

-- For exploratory RETRIEVAL use RETR.response and appropriate "-change 〈list〉" arguments. (See fig. III-3.)

-- For one-step RETRIEVAL \& REPORT GENERATION programs use newpr.response or FORM. response as your response argument, and "-change <1ist>" arguments. (See figs. III-4 and III-6.)

(2) Select INPUT file(s).

(3) Enter PROGRAM STATEMENT. Use the following syntax:

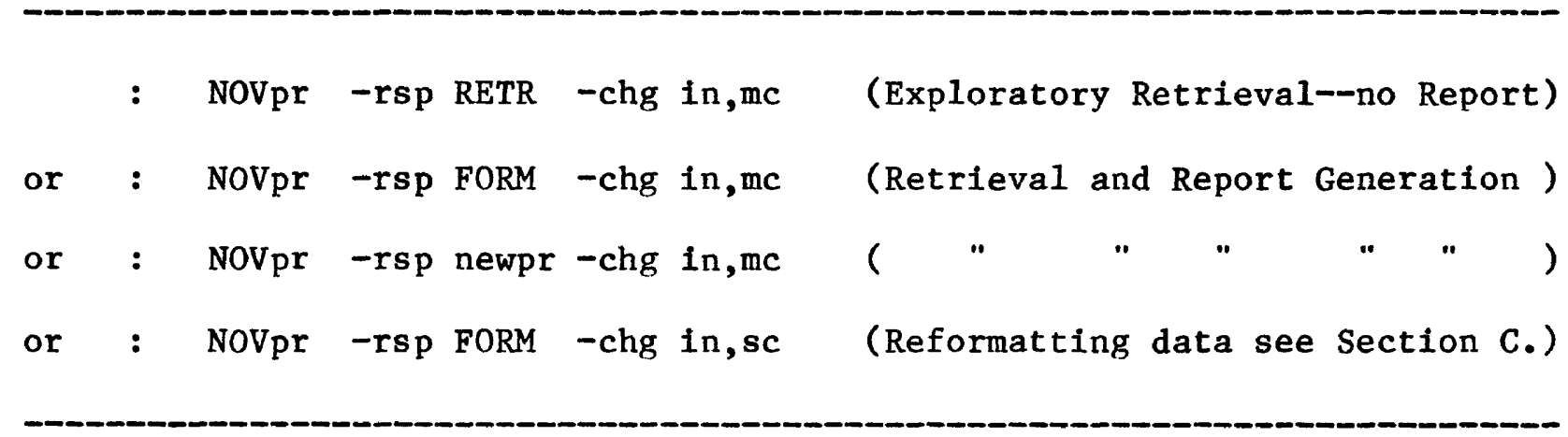

(4) Execute by responding to prompts of your RESPONSE file:

-- Enter your desired INPUT file(s).

-- Enter your RETRIEVAL STATEMENTS according to specified format. (See: HOW TO FORMULATE YOUR RETRIEVAL STATEMENT, section A.2)

-- Respond with yes/no responses where indicated.

-- Save retrieved data segment. (See fig. III-3.)

For REPORT GENERATION see steps (5) to (8). 
PROCEDURE_B Continued:

(5) Generate custom-formatted REPORTS using WRDBIB RESPONSE files: The REPORT GENERATION sequence may be executed as a separate PROGRAM. (See Section_C.)

(6) Use the "-chg sc" argument in your PROGRAM STATEMENT for an alternate SORT sequence. (See: Section_C.5 NUMERIC INDEX.)

-- Enter yes/no responses as prompted.

- Enter SORT statement according to format.

(7) Respond to special interactive features prompted by key-words:

-- Enter your REPORT title when prompted: "Enter title line!"

- When entering the "newpr.response" file as "response argument" use the $\langle \% \mathrm{D}$, "Add print variable 'des '/idn'" feature to interactively add the "descriptor" variable to custom REPORT.

(8) Dprint REPORT, specify no. of copies. Rename file, when saved!

NOTE: A typical RETRIEVAL AND REPORT GENERATION PROGRAM (one-step procedure) is shown in fig. III-5.

See also APPENDIX_III: PROGRAM EXECUTION EXAMPLES in steps 5, 6, 8, 8A. 
B.2 RETRIEVAL PROGRAM: Using -rsp RETR -chg mc

EXAMPLE: EXPLORATORY RETRIEVAL. (NO REPORT GENERATED.)

PROBLEM: RETRIEVE WATER SUPPLY PAPERS FROM UPDATE FILE "auth81".

: NOVpr -rsp RETR -chg mc <-

MULTI TRIEVE RESPONSES READ FROM FILE

>user_dir dir>Wrdbib>NTamberg>RETR. response <- "RESPONSE" path

INPUT FILES: >user_dir_dir>Wrdbib>NTamberg>auth81 - $-\ldots$ INPUT file

ALL RECORDS WILL BE SELECTED. DO YOU WISH TO CHANGE, AND OR DELETE ANY OF THESE VALUES?

: yes

TO DELETE A VARIABLE ENTER A d AS THE VALUE, SUCH AS $\mathrm{xx}=\mathrm{d}$

TO ADD OR CHANGE A VARIABLE ENTER AS NORMAL INPUT

SUCH AS $\mathrm{xx}=\mathrm{eq} . \ldots$.

ENTER MATCHING CRITERIA FOR RECORD SELECTION.

: cIt=pn"SUPPLY PAP"

(- new MATCH critria

ENTER YOUR ADDDITIONAL CRITERIA.

:

NAME

cit

DO YOU WISH TO CHANGE OR DELETE ANY OF THESE VALUES?

: no

RETRIEVAL

TOTAL NUMBER OF RECORDS READ $=640$

TOTAL NUMBER OF RECORDS SELECTED $=14$

THE NAME OF THE SAVED DATA SEGMENT IS ret_183478.data <--- OUTPUT END OF JOB (Leve1 2)

r 16:35 4.547 612 level 2 ("Ready" message)

: rn ret_183478.data WSP81.dt (rename data segment!)

":" precedes user responses

Figure III-3.--RETRIEVAL PROGRAM EXECUTION USING CONTROL ARGUMENTS:

RESPONSE file responses are altered online by argument: "-chg mc".

NOTE: The retrieved data segment may be reformatted according to PROCEDURE_C (fig. III-7.) The following custom REPORTS may be generated: $A$ BIBLIOGRAPHY (fig. III-8.) and an AUTHOR INDEX (fig. III-13.) 


\section{B.3 RETRIEVAL AND REPORT GENERATION PROGRAM}

\section{B.3.1 RESPONSE FILE: "newpr.response":}

Use RESPONSE file "newpr.response" with REPORT format specifications for RETRIEVAL and custom REPORT GENERATION with optional descriptors. SELECT AND READ YOUR RESPONSE FILE: (Use Multics text editor!)

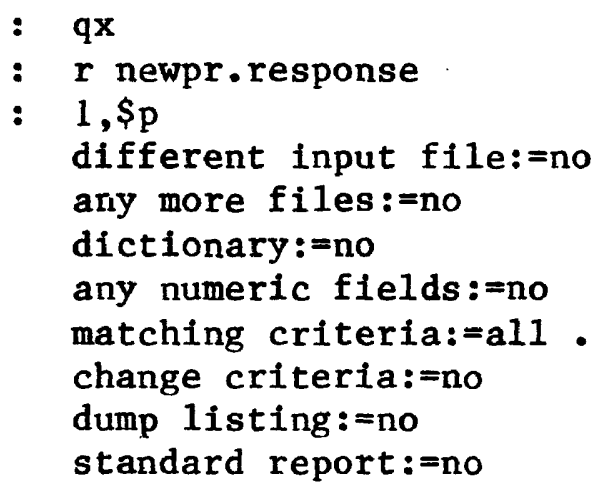

Figure III-4.-- RESPONSE FILE: "newpr.response" provides detailed specifications for a custom-formatted REPORT. Prompts for interactive entry of a REPORT title and an additional print variable are included in form of key-words. (See: Section II.C.4. KEY-WORDS.)

See fig. III-5 for PROGRAM EXECUTION procedure using "newpr.response" and "-change in,mc" arguments. The custom REPORT is given in fig. III-10. 
B.3.2 PROGRAM EXECUTION: Using -rsp newpr -chg in,mc

EXAMPLE: RETRIEVAL AND REPORT GENERATION (One-step Procedure). PROBLEM: RETRIEVE "POTOMAC" REPORTS FROM UPDATE FILE "auth81".

: $\quad$ NOVpr -rsp newpr -chg in,me MULTI TRIEVE RESPONSES READ FROM FILE $>$ udd $>\bar{W}$ rdbib $>$ NTamberg $>$ TEMP $>$ newpr. response $\quad<---\quad$ RESPONSE_path YOUR CURRENT INPUT FILE IS >udd>Wrdbib>NTamberg>TEMP>auth82 <-- INPUT DO YOU WISH TO USE A DIFFERENT INPUT FILE?

: yes

THE NEW INPUT FILE MUST BE COMPATIBLE WITH THE DICTIONARY DESCRIBING THE OLD INPUT FILE. PLEASE ENTER THE NAMES OF INPUT FILES. THE NAMES MUST BE SEPARATED BY BLANKS. THE LAST NAME MUST BE FOLLLOWED BY A BLANK AND A PERIOD.

: auth81. ANY MORE FILES TO SEARCH?

: no

INPUT FILES: >user_dir_dir $>$ Wrdbib>NTamberg $>$ TEMP $>$ auth 81

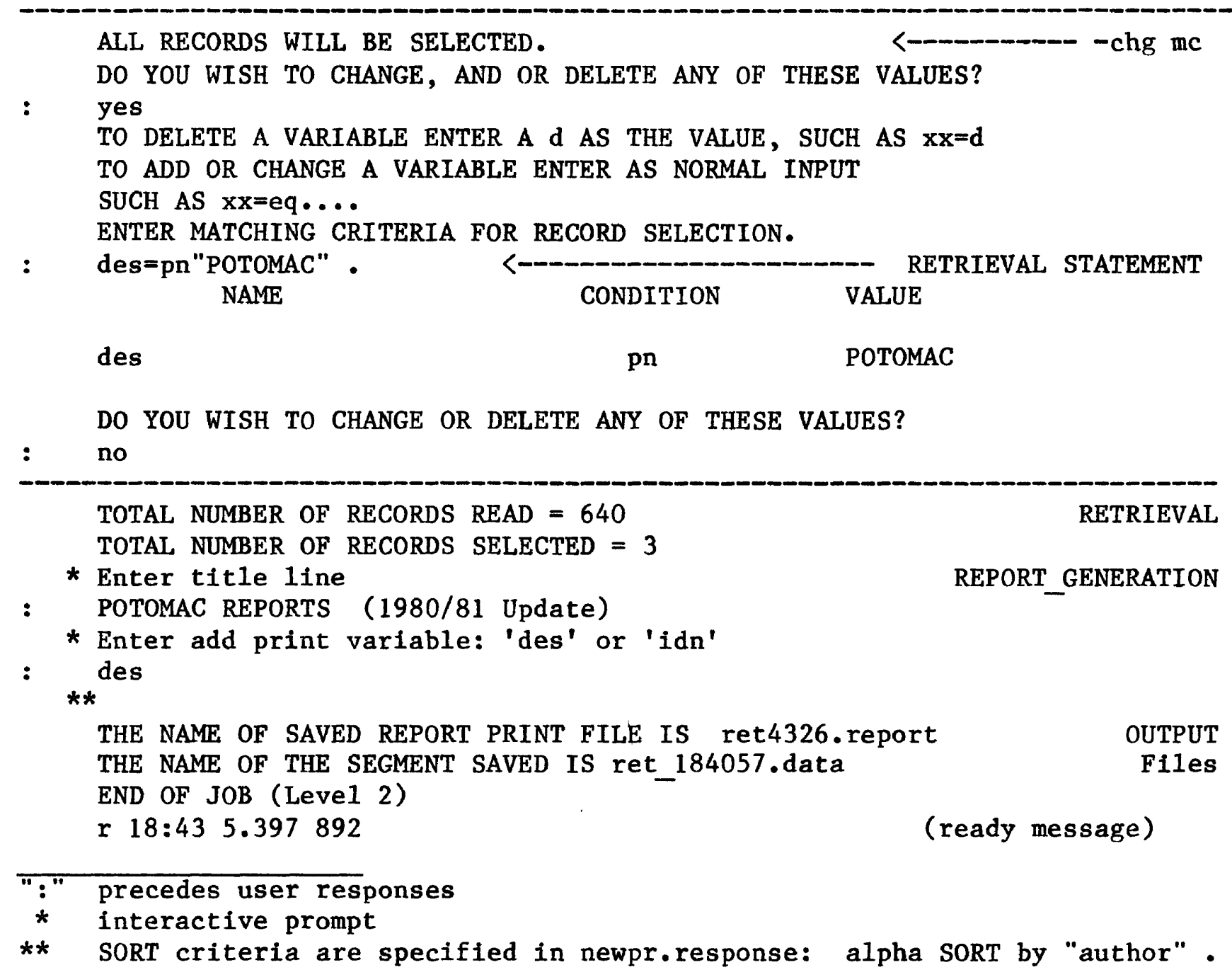

Figure III-5.- A TYPICAL ONE-STEP RETRIEVAL AND REPORT GENERATION PROGRAM: Using "newpr.response" file as "response" argument and "change in,mc" arguments. (See: OUTPUT--REPORT with descriptors in fig. III-10.) 
C. REPORT GENERATION USING CONTROL ARGUMENTS

C.1 REFORMATTING PREVIOUSLY RETRIEVED DATA (Step_2)

C.1.1 PROCEDURE_C: Using -rsp 〈path> -chg 〈list〉

Should you wish to reformat a previously retrieved data segment: ret XXXXXX.data (See EXAMPLE in fig. III-2.), execute a REPORTGENERATION PROGRAM using selected control arguments as step_2 to your RETRIEVAL PROGRAM (See section B.2.) Proceed as follows:

(1) Select a RESPONSE file with appropriate report format specifications to serve as your "response" argument. -- Your RETRIEVAL STATEMENT should read: "matching criteria:=all ." -- Use Multics editor to read and edit as needed! (See fig. III-4.)

(2) To reformat a previously retrieved data segment enter the "-change in" argument in your PROGRAM STATEMENT:

-- You wish to use a DIFFERENT INPUT FILE: ret_101253.data .

(3) Enter the following PROGRAM STATEMENT (command) to start your program: Select either entry!

: NOVpr -rsp FORM -chg in (For bibliographic REPORT)

: NOVpr - rsp newpr - chg in (For bibliographic REPORT w/descriptors)

NOTE: You do not need to change the "change mc" argument if your RESPONSE file contains the statement: "matching criteria:=a11 ." (See fig. III-4.) However, if you do not read your RESPONSE file beforehand, by all means enter:

: NOVpr -rsp newpr -chg in,mc

or : NOVpr -rsp FORM - chg in,mc

The system will print the specified MATCHING criteria and state:

ALL RECORDS WILL BE SELECTED.

DO YOU WISH TO CHANGE, AND OR DELETE ANY OF THESE VALUES?

: no $\quad-\infty-\infty$ Your response!

(4) The system will select ALL RECORDS and reformat them according to RESPONSE file specifications.

(5) Since your "retrieved" data segment is identical to your INPUT data segment, delete the data segment!

(6) Dprint REPORT; enter no. of copies. To save, rename report file!

See: Fig. III-7 for a sample execution of a REPORT GENERATION program. using RESPONSE file, FORM.response. Fig. III-9 illustrates program execution using RESPONSE file: "newpr.response". The resulting custom REPORT is identical with the one generated by the one-step procedure in Section_B.3.2. (See fig. III-10.) 
C.1.2 RESPONSE FILE: "FORM.response"

The customized RESPONSE file "FORM.response" includes REPORT format specifications for bibliographic citations. Type "print, pr" command to read the file:

: pr FORM.response

different input file:=no

any more files:=no

dictionary: $=$ no

any numeric fields:=no

matching criteria:=all .

change criteria: $=$ no

dump listing:=no

standard report: $=$ no

own formatted report:=yes

brief mode:=yes

page heading report line: $=\langle \% \mathrm{~S}$, 'enter title line' $\rangle$

page heading report_line: $=\langle 68\rangle$ DATE: 〈\%DATE $\rangle$

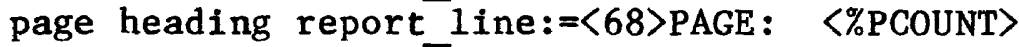

page heading report line:=

page heading report line:=.

detail report line: $=\langle \% \mathrm{CR}\rangle\langle 11\rangle\langle$ aut $\rangle\langle 48\rangle\langle 50\rangle\langle$ pub $\rangle$

detail report 1 ine: $:\langle 9\rangle\langle t i t\rangle\langle 69\rangle$

detail report 1 ine: $:\langle 11\rangle\langle$ cit $\rangle\langle 70\rangle$

detail report 1 ine $:=\langle 60\rangle\langle$ wno $\rangle$

detail report line:=.

any PAGE BREA $\bar{K}$ FORMATS: $=$ no

any RECORD SPACE BREAKS:=no

any REPORT TOTAL LINES:=no

sort records:=yes

sort variable:=wno $a$.

SORT statement

print at terminal:=no

print at central site:=yes

copies : $=1$

save report print file:=yes

any other reports:=no

save retrieved record segment:=yes

another run:=no

r - (Ready message!)

Figure III-6.--RESPONSE FILE: "FORM.response" when used with "-change in,mc" arguments, provides all specifications for RTRIEVAL and custom REPORT GENERATION. Includes numeric SORT on WRSIC (accession) number.

NOTE: For application as "response" argument see Section_C. fig. III-7. Reformatting previously retrieved data. 
C.2 CUSTOM REPORT GENERATION: Using -rsp FORM -chg in

\section{C.2.1 REFORMATTING PROGRAM EXAMPLE:}

: NOVpr -rsp FORM -chg in (-D- PROGRAM STATEMENT MULTI TRIEVE RESPONSES READ FROM FILE $>$ udd $>\bar{W}$ rdbib $>$ NTamberg $>$ TEMP $>$ FORM. response YOUR CURRENT INPUT FILE IS >udd>Wrdbib>NTamberg>TEMP>auth81 <--

/*The user wants to change his INPUT file--prompts follow!*/

DO YOU WISH TO USE A DIFFERENT INPUT FILE?

: yes

THE NEW INPUT FILE MUST BE COMPATIBLE WITH THE DICTIONARY DESCRIBING THE OLD INPUT FILE. PLEASE ENTER THE NAMES OF INPUT FILES. THE NAMES MUST BE SEPARATED BY BLANKS. THE LAST NAME MUST BE FOLLLOWED BY A BLANK AND A PERIOD.

: WSP81.dt . <-chg in

/*This is a previously retrieved data segment */ ANY MORE FILES TO SEARCH?

: no INPUT FILES: >user_dir_dir $>$ Wrdbib $>$ NTamberg $>$ TEMP $>$ WSP $81 . d t$

TOTAL NUMBER OF RECORDS READ $=14$

RETRIEVAL TOTAL NUMBER OF RECORDS SELECTED $=14$

* Enter title line

: WATER SUPPLY PAPERS (1980/81 Update)

REPORT_GENERATION

THE NAME OF SAVED REPORT PRINT FILE IS ret4326.report

THE NAME OF THE SEGMENT SAVED IS ret_184057.data

OUTPUT END OF JOB (Leve1 2)

r $18: 435.397892$

("Ready" message)

\footnotetext{
":" precedes user responses

* interactive prompt requesting REPORT title

** SORT criteria are specified in FORM.response: "wno a."
}

Figure III-7.-- REFORMATTING PREVIOUSLY RETRIEVED DATA ACCORDING TO "FORM.response": REPORT cites bibliographic citation only.

NOTE: The custom REPORT for updated citations of WATER SUPPLY PAPERS is shown in fig. III-8.

See also: AUTHOR INDEX to the REPORT which has been generated using the "AUT.response" file (fig. III-12). The AUTHOR INDEX is shown in fig. III-13; a NUMERIC INDEX is given in fig. III-14. 
1 HERB, W. J.;

1980

DATE : $02 / 07 / 83$

PAGE : 1

SEDIMENT-TRAP EFFICIENCY OF A MULTIPLE-PURPOSE IMPOUNDMENT, NORTH BRANCH ROCK CREEK BASIN, MONTGOMERY COUNTY, MARYLAND, 1968-76,

AVAILABLE FROM SUPT. OF DOCUMENTS, GPO, WASHINGTON, DC 20402, PRICE, $\$ 2.50$. GEOLOGICAL SURVEY WATER-SUPPLY PAPER 2071, 1980. 41 P, 19 FIG, 11 TAB, 19 REF.

2 REED, L. A.;

1980

SUSPENDED-SEDIMENT DISCHARGE, IN FIVE STREAMS NEAR

HARRISBURG, PENNSYLVANIA, BEFORE, DURING, AND AFTER HIGHWAY CONSTRUCTION,

AVAILABLE FROM SUPT. OF DOCUMENTS, GPO, WASHINGTON, DC 20402, PRICE, \$2.25. GEOLOGICAL SURVEY WATER-SUPPLY PAPER 2072, 1980. 37 P, 17 FIG, 8 TAB, 10 REF.

3 FAYE, R. E.; AND CHERRY, R. N.; 1980

$81-00361$

CHANNEL AND DYNAMIC FLOW CHARACTERISTICS OF THE

CHATTAHOOCHEE RIVER, BUFORD DAM TO GEORGIA HIGHWAY 141, AVAILABLE FROM SUPT. OF DOCUMENTS, GPO, WASHINGTON, DC 20402, PRICE, \$3.25. GEOLOGICAL SURVEY WATER-SUPPLY PAPER 2063, 1980. 66 P, 22 FIG, 13 TAB, 11 REF.

4 WHITE, A. F.; CLAASSEN, H. C.; AND 1980

$81-00362$ BENSON, L. V.;

THE EFFECT OF DISSOLUTION OF VOLCANIC GLASS ON THE WATER CHEMISTRY IN A TUFFACEOUS AQUIFER, RAINIER MESA, NEVADA, AVAILABLE FROM SUPT. OF DOCUMENTS, GPO, WASHINGTON, DC 20402, PRICE, \$2.25. GEOLOGICAL SURVEY WATER-SUPPLY PAPER 1535-Q, 1980. 34 P, 11 FIG, 5 TAB, 36 REF.

5 BROGDEN, R. E.; HUTCHINSON, E. C.; 1979

$81-00831$

AND HILLIER, D. E.;

AVAILABILITY AND QUALITY OF GROUNDWATER, SOUTHERN UTE INDIAN RESERVATION, SOUTHWESTERN COLORADO,

AVAILABLE FROM SUPT. OF DOCUMENTS, GPO, WASHINGTON, DC 20402 , PRICE, \$1.75. GEOLOGICAL SURVEY WATER-SUPPLY PAPER 1576-J, 1979. 28 P, 4 FIG, 1 PLATE, 5 TAB, 11 REF.

6 ZACK, A. L.;

1980

81-01197

GEOCHEMISTRY OF FLUORIDE IN THE BLACK CREEK AQUIFER SYSTEM OF HORRY AND GEORGETOWN COUNTIES, SOUTH CAROLINA--AND ITS PHYSIOLOGICAL IMPLICATIONS, AVAILABLE FROM SUPT. OF DOCUMENTS, GPO, WASHINGTON, DC 20402, PRICE, \$2.50. GEOLOGICAL SURVEY WATER-SUPPLY PAPER 2067, 1980. 40 P, 11 FIG, 1 PLATE, 2 TAB, 24 REF.

$81-02677$

Figure III-8.--CUSTOM REPORT: BIBLIOGRAPHIC CITATIONS ONLY. Generated by FORM.response. 
C.3 REPORT GENERATION W/DESCRIPTORS: Using -rsp newpr -chg in,mc

\section{C.3.1 REFORMATTING PROGRAM EXAMPLE:}

: NOVpr -rsp newpr -chg in,mc

MULTI TRIEVE RESPONSES READ FROM FILE

>user_dir_dir>Wrdbib>NTamberg>TEMP>newpr.response <-- - - RESPONSE_path

YOUR CURRENT INPUT FILE IS >user_dir_dir $>$ Wrdbib>NTamberg>TEMP>auth8 $\overline{1}$

INPUT

DO YOU WISH TO USE A DIFFERENT INPUT FILE?

: yes

THE NEW INPUT FILE MUST BE COMPATIBLE WITH THE DICTIONARY DESCRIBING

THE OLD INPUT FILE.

PLEASE ENTER THE NAMES OF INPUT FILES.

THE NAMES MUST BE SEPARATED BY BLANKS.

THE LAST NAME MUST BE FOLLLOWED BY A BLANK AND A PERIOD.

: ret_101253.data . -chg in

ANY MORE FILES TO SEARCH?

: no

INPUT FILES: >user_dir_dir $>$ Wrdbib $>$ NTamberg $>$ TEMP $>$ ret_101253.data

ALL RECORDS WILL BE SELECTED.
DO YOU WISH TO CHANGE, AND OR DELETE ANY OF THESE VALUES?
no

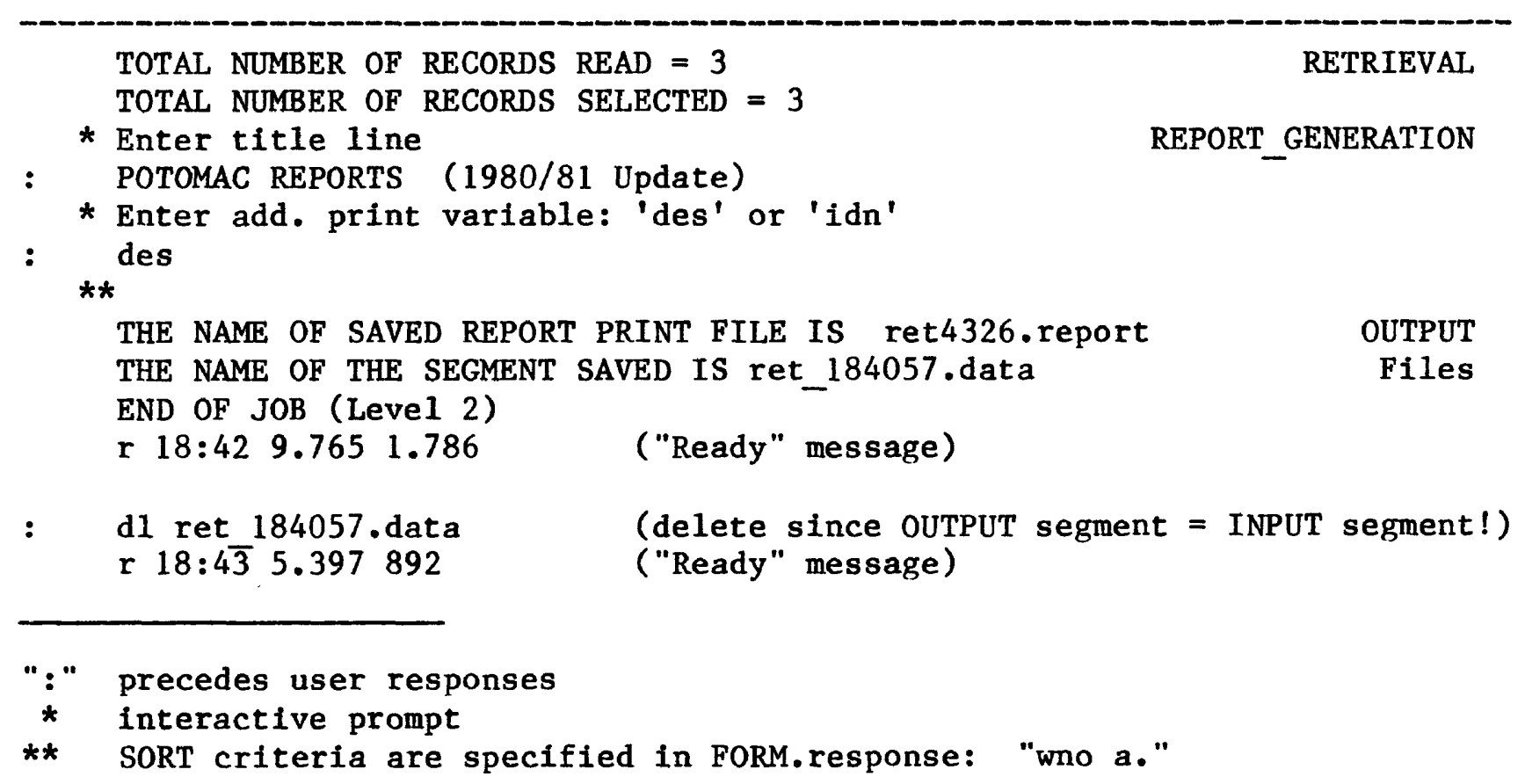

Figure III-9.--CUSTOM REPORT GENERATION: REFORMATTING PREVIOUSLY RETRIEVED DATA SEGMENT ACCORDING TO RESPONSE FILE: "newpr.response". REPORT may include optional "descriptors" (des).

NOTE: The custom REPORT is shown in fig. III-10. The same REPORT has been obtained by executing a one-step RETRIEVAL and REPORT GENERATION program according to PROCEDURE_B. (See fig. III-5.) 
1 LANG, D. J.; AND GRASON, D.;

WATER-QUALITY MONITORING OF THREE MAJOR TRIBUTARIES TO THE CHESAPEAKE BAY--INTERIM DATA REPORT, AVAILABLE FROM THE NATIONAL TECHNICAL INFORMATION SERVICE, SPRINGFIELD, VA 22161 AS PB81-113888, IN PAPER COPY, IN MICROFICHE. GEOLOGICAL SURVEY WATER-RESOURCES INVESTIGATIONS 80-78, SEPTEMBER, 1980. 66 P, 1 FIG, 5 TAB, 9 REF.

*WATER QUALITY, *BASIC DATA COLLECTIONS, *WATER ANALYSIS, *RIVERS, *CHESAPEAKE BAY, BAYS, SAMPLING SITES, SEDIMENT TRANSPORT, SEDIMENTS, BOTTOM SEDIMENTS, NUTRIENTS, TRACE ELEMENTS, PESTICIDES, HERBICIDES, INSECTICIDES, POTOMAC RIVER, JAMES RIVER(VA), SUSQUEHANNA RIVER(MD).

$81-01184$

2 LUZIER, J. E.; 1980 DIGITAL-SIMULATION AND PROJECTION OF HEAD CHANGES IN THE POTOMAC-RARITAN-MAGOTHY AQUIFER SYSTEM, COASTAL PLAIN, NEW JERSEY,

AVAILABLE FROM THE NATIONAL TECHNICAL INFORMATION SERVICE, SPRINGFIELD, VA 22161 AS PB81-115768, IN PAPER COPY, IN MICROFICHE. GEOLOGICAL SURVEY WATER-RESOURCES INVESTIGATIONS 80-11, MAY, 1980. 72 P, 32 FIG, 6 TAB, 33 REF.

*GROUNDWATER RESOURCES, *MODEL STUDIES, *HYDROGEOLOGY, *AQUIFER CHARACTERISTICS, *NEW JERSEY, COMPUTER MODELS, WATER SUPPLY, PUMPING, DRAWDOWN, ENCROACHMENT, SALINE WATER, WATER YIELD, POTENTIOMETRIC LEVEL, GROUNDWATER RECHARGE, HYDROLOGIC PROPERTIES, LEAKAGE, TRANSMISSIVITY, GROUNDWATER MOVEMENT, SIMULATION ANALYSIS, EVALUATION, HEAD LOSS, *COASTAL PLAIN(NJ), *POTOMAC-RARITAN-

3 RUNNER, G. S.; 1980 $81-01185$

WEST VIRGINIA DEPARTMENT OF HIGHWAYS RESEARCH PROJECT 16 , 'RUNOFF STUDIES ON SMALL DRAINAGE AREAS' (TECHNIQUE FOR ESTIMATING MAGNITUDE AND FREQUENCY OF FLOODS IN WEST VIRGINIA), AVAILABLE FROM THE OFSS, USGS BOX 25425, FED. CTR., DENVER, CO 80225, PRICE: \$6.00 IN PAPER COPY, \$3.50 IN MICROFICHE. GEOLOGICAL SURVEY OPEN-FILE REPORT 80-1218, OCTOBER, 1980. 44 P, 24 FIG, 9 REF. *FLOODS, *NATURAL STREAMS, *RUNOFF, *DRAINAGE AREA, ESTIMATING, FLOOD PEAK, FLOOD FREQUENCY, REGIONAL ANALYSIS, REGRESSION ANALYSIS, FREQUENCY ANALYSIS, FLOOD DATA, DATA COLLECTIONS, STREAM GAGES, *WEST VIRGINIA, OHIO RIVER BASIN, POTOMAC RIVER BASIN.

end of report $81-02985$

Figure III-10.--CUSTOM REPORT WITH DESCRIPTORS GENERATED BY "newpr.response"• 


\section{C.4 INDEX REPORT GENERATION: Using -rsp AUT -chg in}

C.4.1 RESPONSE FILE: "AUT.response" contains the INDEX format specifications. Use the "AUT.response" file in argument form (-rsp AUT) to create an AUTHOR INDEX for your subject bibliography:

: NOVpr -rsp AUT - chg in

First, enter the "print, pr" command to read AUT.response:

: pr AUT.response

different input file:=yes

input file:=auth82 .

any more files:=no

dictionary: $=$ no

any numeric fields:=no

matching criteria:=all .

change criteria:=no

dump listing:=no

standard report: $=$ no

own formatted report:=yes

brief mode:=yes

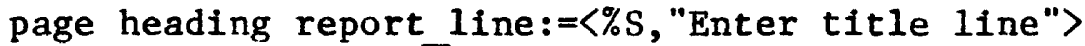

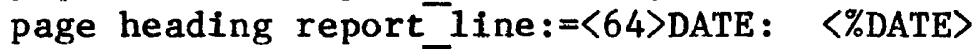

page heading report 1 ine: $=\langle 64\rangle$ PAGE: $\langle \%$ PCOUNT $\rangle$

page heading report line: $=\langle 2\rangle$ WRSICNo $\langle 9\rangle\langle 15\rangle$ AUTHOR $\langle 72\rangle$ PUByr

page heading report line:=

page heading report line:=.

detail report line: $=\langle$ wno $\rangle\langle 11\rangle\langle$ aut $\rangle\langle 70\rangle\langle 72\rangle\langle$ pub $\rangle$

detail report line:=

detail report line:=.

any PAGE BREAT FORMATS:=no

any RECORD SPACE BREAKS:=no

any REPORT TOTAL LINES:=no

sort records:=yes

sort variable:=aut a .

print at terminal:=no

print at central site:=yes

copies $:=1$

save report print file:=yes

any other reports: $=$ no

save retrieved record segment:=no

another run:=no

r - - (Ready message!)

Figure III-11.--RESPONSE FILE "AUT.response": CREATES INDEX REPORT SORTS ALPHABETICALLY ON AUTHORS' NAMES.

See: Fig. III-12 for the AUTHOR INDEX format. 
C.4.2 GENERATE AUTHOR INDEX: EXAMPLE

EXECUTE AN AUTHOR INDEX PROGRAM USING RESPONSE FILE "AUT.response" as "-response" argument and the "change in" argument to enter the retrieved data segment. (See fig. III-7.)

: NOVpr -rsp AUT -chg in

MULTI TRIEVE RESPONSES READ FROM FILE

$>\mathrm{udd}>\overline{\mathrm{W}}$ rdbib $>$ NTamberg $>$ TEMP $>$ AUT.response YOUR CURRENT INPUT FILE IS >udd>Wrdbib>NTamberg>TEMP>auth81

/*The user wants to change his INPUT file--prompts follow!*/

INPUT

DO YOU WISH TO USE A DIFFERENT INPUT FILE?

: yes

THE NEW INPUT FILE MUST BE COMPATIBLE WITH THE DICTIONARY DESCRIBING

THE OLD INPUT FILE.

PLEASE ENTER THE NAMES OF INPUT FILES.

THE NAMES MUST BE SEPARATED BY BLANKS.

THE LAST NAME MUST BE FOLLLOWED BY A BLANK AND A PERIOD.

: WSP81.dt .

(-

/*This is a previously retrieved data segment */

ANY MORE FILES TO SEARCH?

: no

INPUT FILES : >user_dir_dir $>$ Wrdbib $>$ NTamberg $>$ TEMP $>$ WSP81 .dt

\footnotetext{
TOTAL NUMBER OF RECORDS READ $=14$

TOTAL NUMBER OF RECORDS SELECTED $=14$

* Enter title line

RETRIEVAL

REPORT_GENERATION

: WATER SUPPLY PAPERS: AUTHOR INDEX (Update 1980/81)

THE NAME OF SAVED REPORT PRINT FILE IS ret4326. report

END OF JOB (Level 2)

r $18: 435.397892$

("Ready" message)

$\begin{array}{ll}\text { ":" } & \text { precedes user responses } \\ * & \text { interactive prompt } \\ \text { ** } & \text { SORT criteria are specified in AUT.response: "aut a ." } \\ & \text { (alphabetically by "author" in ascending sequence.) }\end{array}$
}

Figure III-12.--REPORT GENERATION: CREATING AUTHOR INDEX REPORT.

NOTE: The AUTHOR INDEX REPORT is shown in fig. III-13. 
C.4.3 AUTHOR INDEX REPORT:

TOTAL NUMBER OF RECORDS READ = 14

TOTAL NUMBER OF RECORDS SELECTED $=\quad 14$

INPUT FILES : >udd>Wrdbib>NTamberg $>$ TEMP $>$ WSP81 . dt

WATER SUPPLY PAPERS: AUTHOR INDEX (Update 1980/81)

DATE: $12 / 07 / 82$

PAGE : 1

\begin{tabular}{|c|c|c|}
\hline WRSICNo & AUTHOR & PUByr \\
\hline $81-02912$ & BATTEN, W. G.; AND HINDALL, S. M.; & 1980 \\
\hline $81-01197$ & BROGDEN, R. E•; HUTCHINSON, E. C.; AND HILLIER, D. E•; & 1979 \\
\hline $81-00362$ & FAYE, R. E.; AND CHERRY, R. N.; & 1980 \\
\hline $81-04333$ & FETH, J. H.; & 1981 \\
\hline $81-00060$ & HERB, W. J.; & 1980 \\
\hline $81-02708$ & JORGENSEN, D. G.; & 1980 \\
\hline $81-06100$ & KIMBALL, B. A.; & 1981 \\
\hline $81-06101$ & MCDONALD, M. G.; & 1981 \\
\hline $81-03271$ & MUIR, K. S.; AND COPLEN, T. B.; & 1981 \\
\hline $81-00361$ & REED, L. A.; & 1980 \\
\hline $81-06087$ & SCHAEFER, F. L.; AND WALKER, R. L.; & 1981 \\
\hline $81-00831$ & WHITE, A. F.; CLAASSEN, H. C.; AND BENSON, L. V•; & 1980 \\
\hline $81-06099$ & WYRICK, G. G•; AND BORCHERS, J. W.; & 1981 \\
\hline $81-02677$ & ZACK, A. L.; & 1980 \\
\hline
\end{tabular}

Figure III-13.--INDEX REPORT TO RETRIEVAL OF WATER SUPPLY PAPERS ACCORDING TO RESPONSE FILE: "AUT.response".

(Sorted alphabetically by "author" in ascending sequence.) 
C.5 NUMERIC INDEX REPORT GENERATION: Using -rsp AUT -chg in, sc

C.5.1 GENERATING NUMERIC SORT:

To change the SORT parameter in the RESPONSE file, AUT.response, the user must supply the "-change sc" argument in his/her PROGRAM STATEMENT:

$$
\text { NOVpr - rsp AUT - chg in, sc }
$$

The user will then respond to the following prompts at the REPORT GENERATION stage: (See REPORT format in fig. III-11.)

DO YOU WANT TO SORT AS BEFORE?

: no

DO YOU WANT TO SORT THE RETRIEVED RECORDS PRIOR TO PRINTING THE REPORT? : yes PLEASE ENTER THE VARIABLES NAMES TO SORT ON

: wno a . (SORT "wno" field in ascending sequence!)

For more detail see Section II.C.1. SORTING. 
C.5.2 NUMERIC INDEX REPORT:

INPUT FILES : >user_dir_dir $>$ Wrdbib $>$ NTamberg $>$ TEMP $>$ WSP81 .dt

INDEX TO WSP REPORT (SORTED ON WRSIC NO.)

DATE : $02 / 08 / 83$

PAGE : 1

\begin{tabular}{|c|c|c|}
\hline WRSICNo & AUTHOR & PUByr \\
\hline $81-00060$ & HERB, W. J.; & 1980 \\
\hline $81-00361$ & REED, L. A. ; & 1980 \\
\hline $81-00362$ & FAYE, R. E.; AND CHERRY, R. N.; & 1980 \\
\hline $81-00831$ & WHITE, A. F.; CLAASSEN, H. C.; AND BENSON, L. V•; & 1980 \\
\hline $81-01197$ & BROGDEN, R. E•; HUTCHINSON, E. C.; AND HILLIER, D. E•; & 1979 \\
\hline $81-02677$ & ZACK, A. L.; & 1980 \\
\hline $81-02708$ & JORGENSEN, D. G.; & 1980 \\
\hline $81-02912$ & BATTEN, W. G.; AND HINDALL, S. M•; & 1980 \\
\hline $81-03271$ & MUIR, K. S.; AND COPLEN, T. B.; & 1981 \\
\hline $81-04333$ & FETH, J. H•; & 1981 \\
\hline $81-06087$ & SCHAEFER, F. L•; AND WALKER, R. L•; & 1981 \\
\hline $81-06099$ & WYRICK, G. G.; AND BORCHERS, J. W.; & 1981 \\
\hline $81-06100$ & KIMBALL, B. A.; & 1981 \\
\hline $81-06101$ & MCDONALD, M. G.; & 1981 \\
\hline
\end{tabular}

end of report

Figure III-14.--NUMERIC INDEX REPORT TO RETRIEVED WATER SUPPLY PAPERS: Sorted on WRSIC (Accession) number. 
D. DIRECTORY CHECK:

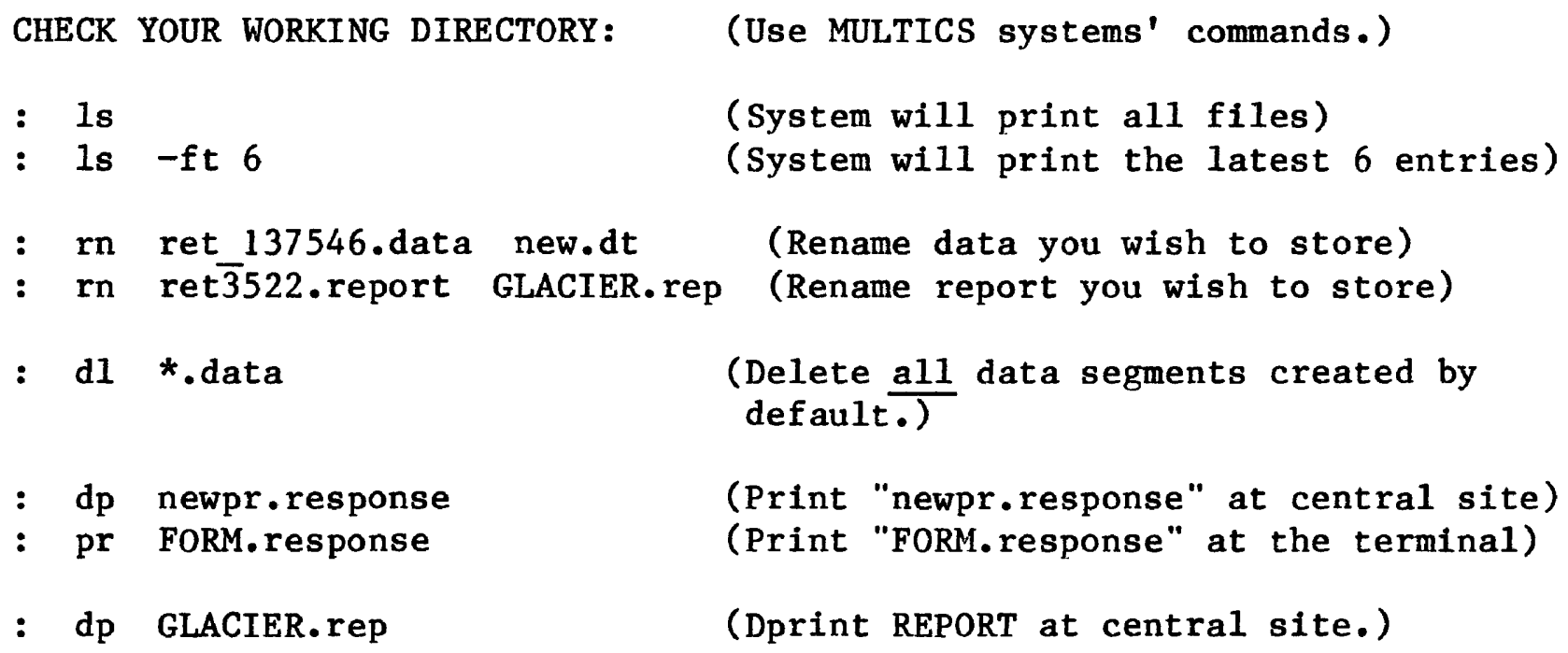

For more detail on Listing Procedures see APPENDIX_I.B.

See also APPENDIX III. WRDBIB RETRIEVAL AND REPORT GENERATION SESSION. Step_10. 


\section{APPENDIX I.}

A. WRDBIB DATA BASE ACCESS

B. WORKING DIRECTORY AND WRDBIB FILES: LISTING PROCEDURES 
A.1. CHECKLIST: ACCESS PROCEDURES--HOW TO ESTABLISH ACCESS TO RESTON MULTICS AND WRDBIB PROGRAMS.

If you wish to execute a MULTI TRIEVE application program to either retrieve records from the WRDBIB data base according to specified search criteria, and/or to prepare a custom formatted report, you must be familiar with the following procedures:

-- Establish your person_id, project_id (user_id), and your password

-- Master access procedure to RESTON MULTICS using port-sharing device (psd). (For "login procedure" see section A.2.)

-- Secure access to MULTI TRIEVE software and WRDBIB files in the Working Directory by linking to and executing the following command ("exec_com"): (See section A.3)

$1 k>$ ud $d>$ Wrdbib $>$ NTamberg $>$ IO $>$ WRDBIB .ec ec WRDBIB

-- Check out the WRDBIB library of programs, dictionaries, input files, reports, and response files (providing various input/ output options): Selectively list, print or dprint files. (See section $B_{.}$)

-- If you have questions pertaining to program execution and/or application of programs to your own files see WBsum.info segments. Enter the following command:

ec WRDBIB (This will place you in the IO working dir and explain how to use the "help" command.)

-- Enter suggested "info" segments using the "help" command. help 〈path〉 〈-argument>

For example:

help WBsum -title help -pn WBsum -title (you may omit the .info suffix) (if you use your own directory and have established search_paths)

For more information see section I.B.

NOTE: For RETRIEVAL AND/OR REPORT GENERATION PROCEDURES see Section III WRDBIB PROGRAM EXECUTION and the RETRIEVAL SESSION in APPENDIX III. 


\section{A.2.1 DIAL UP PROCEDURE:}

-- Dial the telephone number of the computer. Check, if you need to access the outside line! If yes, dial $9+$ your number. If you are working with a 300/1200 baud terminal, dial:

in Reston: $\quad 860-3150$ or $476-5051$ or your DATAphone number in Denver: $232-0058$

You will hear the telephone ring, and when the computer answers, a steady high-pitched tone will be heard.

-- Insert the telephone handset into the coupler (with the cord as indicated) or push DATA button on your phone--as the case may be! The light marked ready or carrier should go on.

(If not, repeat the dial up procedure!) Proceed as shown below.

-- When the "ready" light comes on, the system will print:

$\begin{array}{ll}\text { enter class } & \text { [system asks for desired baud rate] } \\ \text { enter class } 41 & \text { [type: } 41 \text { (from } 300 \text { baud port code)] } \\ \text { CR } & \text { [ } 42 \text { (for } 1200 \text { baud port code)] } \\ & \text { [hit carriage retrurn and wait for } \\ \text { computer access.] }\end{array}$

CONNECTING TO THE RESTON MULTICS [system's response]

class 41 start [communication to Multics established]

\section{A.2.2 LOGIN PROCEDURE:}

-- The computer will respond with a 2 or 3 line "banner". If the computer is not operating, it will either not answer or it will have a tone but will not respond. The "banner" will look something like this:

Multics MR7.0a: USGS; Reston, Va.

Load $=60.0$ out of 125.0 units: users $=60,12 / 08 / 821435.4$ est Wed

-- Your regular "login" procedure will look like the following: Proceed (user entry follows the colon ":")

: 1 JDoe wrdcrut

[where 1=login]

Password:

: $\quad$ XXXXXXXXXX

[systems response]

[enter your password]

You are protected from preemption until 1435. [systems response]

-- The system will proceed to execute your "start_up" commands and print any messages sent to you.

When all the house-keeping is done, you will receive the "ready" message and may proceed with your intended terminal session:

ready

[your "ready" message]

USER ASSISTANCE: For additional he1p call a USER ASSISTANT:

Denver 303-234-4810 234-4810

Reston 703-860-7179 928-7179 
A.3.1 THE Wrdbib WORKING DIRECTORY ">IO":

In setting access to directories the star convention is allowed when used to extend access to all projects for a given person_id.

Your "working directory" is:

$>$ udd $>$ Wrdbib $>$ NTamberg $>$ IO

List access to working directory:

la $>$ udd $>$ Wrdbib $>$ NTamberg $>$ IO

The system will print:

$\begin{array}{ll}\text { sma NTamberg.Wrdbib.* } & \text { Nma } \\ \text { JFisher.Help.* } \\ \text { sma } & \text { CSaboe.*.* } \\ \text { sma } & \text { *.SysDaemon.* }_{\text {sa }} \text { *.*.* }^{\circ}\end{array}$

NOTE: Access to directory >IO has been set for al1 users!

The user should note the access attributes that are available to him, where "s" (status) and "a" (append). (See: Appendix_II.)

A.3.2 WRDBIB.ec Command:

To learn about the WRDBIB library resident in the "IO" directory--execute the exec com, WRDBIB.ec, as shown below. This will transfer you into the "IO"directory and provide access to the WBsum.info segment describing WRDBIB RETRIEVAL and REPORT_GENERATION procedures.

Procedure: (Note: "read, $\mathbf{r}$ " and "execute, e" attributes have been set for general usage.--See: Appendix_II--access attributes!)

-- List access to segment WRDBIB.ec: 1a >udd>Wrdbib>NTamberg $>$ IO $>$ WRDBIB.ec

rew NTamberg.Wrdbib.*

rw *.SysDaemon.*

re $\quad *_{0} * *$

(General access has been set!)

-- Link to WRDBIB.ec:

lk $>$ udd $>$ Wrdbib $>$ NTamberg $>$ IO $>$ WRDBIB . ec

-- Execute WRDBIB :

ec WRDBIB

(This will provide all the necessary links and search_paths! See fig. A.I-1.)

NOTE: The user should be familiar with the following Multics commands:

-- Change working directory to "IO": $\quad$ cwd >udd $>$ Wrdbib $>$ NTamberg $>$ IO

-- Change working dir to your home directory: cwd

(There is no systems response after the _cwd command!)

-- Print working directory after "interrupts": pwd

(The system will print the path of your current working directory.) >user_dir_dir $>$ Wrdbib $>$ NTamberg $>$ IO ready

(systems ready message!) 
A.3.2 WRDBIB.ec Command continued:

PROCEDURE: To execute the exec_com WRDBIB.ec enter

: ec WRDBIB (The system will respond as follows!)

INTRODUCTION TO WBsum.info:

by N.Tamberg (revised September 1982)

To learn how to execute a WRDBIB RETRIEVAL \& REPORT GENERATION program using multi trieve software, the user should read the online WBsum.info segments.

The current procedure will do the following:

--place you into the >IO working directory,

- -list WBsum.info and its add names to give you an idea of the contents,

--start the introductory "help" segment by printing its header.

The user should selectively read the info.segment section by section. After each section the system will solicit user response: More help? Respond: "yes, y" "skip, s" "scn 〈string>" "no, n" "quit, q" .

To limit your CRT screen to 21 lines respond (yes) to the following query: Are you using a CRT (yes/no) ?

: yes - the system will print 21 lines, the "EOP" and stop. (Hit CR (carriage return) to continue reading.)

Segments $=1$, Lengths $=15$.

rew 15 WBsum.info

WBintro.info

INPUT.info

RETRs tmt.info

RETRpr.ec.info

RESPONSE.info

REPgen.info

PROG.ex.info

PROG.ec.info

GWpr.ec.info

REFORM.ec.info

INDEX.ec.info

DICT.ec.info

CoMPdict.info

C+E/STDrep.ec.info

Figure A-1.--CONTENTS OF "WRDBIB.ec: INTRODUCTION. 
LISTING CONTENTS OF WORKING DIRECTORY ">IO": $\begin{array}{ll}\text { You may list all files of "IO" directory by entering: } & \text { ls } \\ \text { You may list the first " } \mathrm{n} \text { " entries in IO ( }=1,2,3, \text { etc): } & \text { ls -ft } 3 \\ \text { You may list "links" to the Wrdbib directory and 1ts files: } 1 \mathrm{~s}-1 \mathrm{k} \\ \text { You may list the complete Io directory: } & 1 \mathrm{~s}-\mathrm{all} \\ \text { (See below!) } & \end{array}$

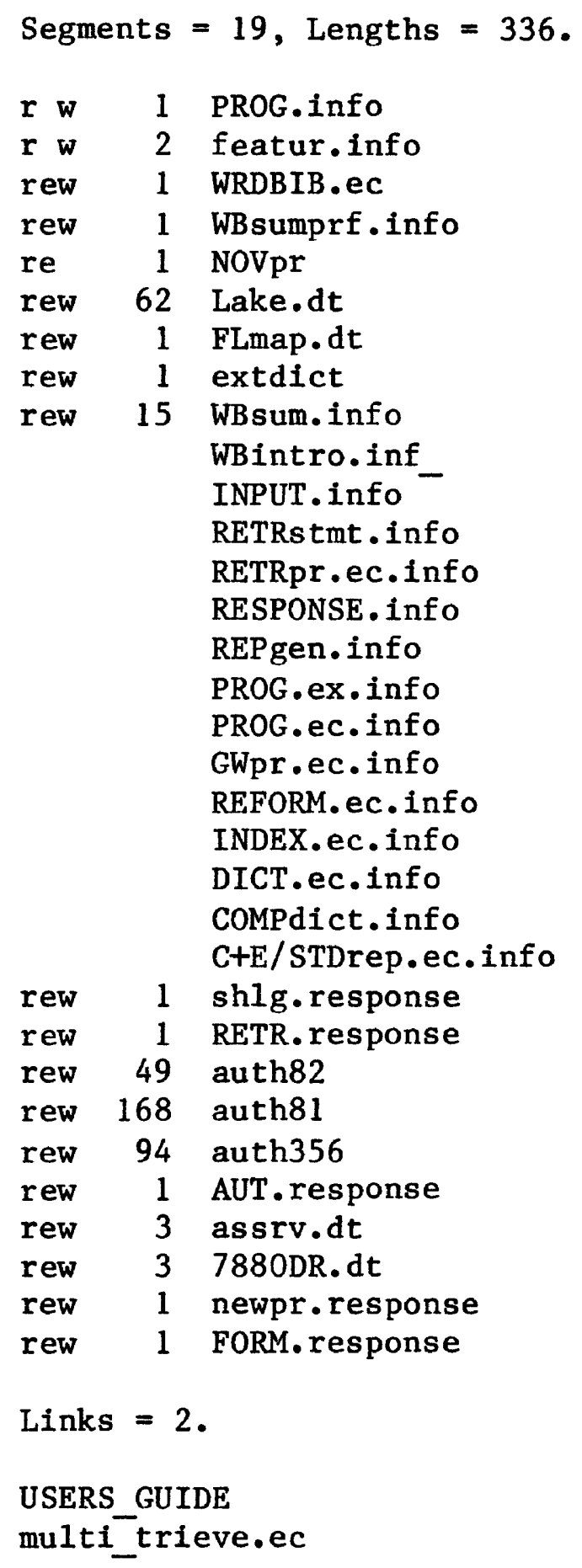

$>$ udd $>$ Wrdbib $>$ NTamberg $>$ TEMP $>$ USERS_GUIDE >udd>Userast>LHarms>multi_trieve.ec

Figure A-2.--LISTING WORKING DIRECTORY: >IO. 
B.2.1 SELECTIVE LISTING OF PROGRAMS AND DICTIONARIES: List the files at your disposal selectively as follows: Use star convention to Identify a class of files with a common suffix!

To list available PROGRAMS use command: 1s *pr To 1ist DATA DICTIONARIES use command: ls *dict To print an individual file (DICTIONARY): pr extdict (See below!)

$\begin{array}{llcc}\text { RETRIEVAL NAME } & \text { PRINT NAME } & \text { START POS } & \text { FIELD LENGTH } \\ \text { wno } & \text { wrsic.no } & 1 & 8 \\ \text { acyr } & \text { acc.yr } & 1 & 2 \\ \text { acno } & \text { acc.no } & 4 & 5 \\ \text { aut } & \text { author } & 9 & 90 \\ \text { sso } & \text { source } & 99 & 120 \\ \text { tit } & \text { title } & 219 & 200 \\ \text { cit } & \text { citation } & 419 & 230 \\ \text { des } & \text { descriptor } & 649 & 380 \\ \text { pub } & \text { pub.yr } & 1029 & 4 \\ \text { idn } & \text { ident } & 1033 & 2\end{array}$

Figure A-3.--DATA DICTIONRY: "extdict". "extdict" describes data elements of the "Current" Input record.

B.2.2 CHECKING DICTIONARY THAT WAS COMPILED WITH A PROGRAM:

PROGRAMS compiled against DICTIONARY used for searching

WRpr ................ wrsdict ......... "Master" file

NOVpr ................ extdict ......... "Current" files

PROCEDURE to check the DATA DICTIONARY associated with your PROGRAM:

- Enter the PROGRAM NAME and execute! : NOVpr (Press Carriage Return!)

-- Respond to queries: no -- until the query:

DO YOU WANT TO SEE THE DATA DICTIONARY?

-- Respond: yes The system will print the associated (internal) DICTIONARY!

- To exit program push BREAK button. The procedure is illustrated in Section II fig. II-6. 


\section{B.3. LISTING PROCEDURES: INPUT FILES}

INPUT FILES: The names are mnemonic and indicate the years covered:

To list enter: 1s auth* (for "Current" files)

1s msf (for multi_segment_files)

B.3.1 The user may search the following primary input files (INPUT data):

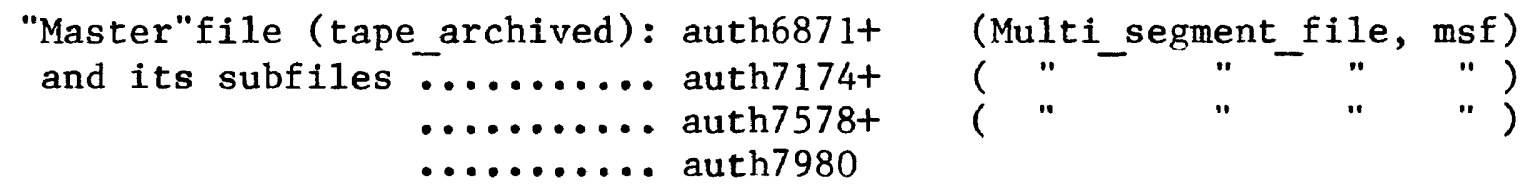

Updated "Current" files:..... auth365

(auth80)

..... auth81

..... auth82

B.3.2 The user may use any data segments derived from the above files. Their label is "ret XXXXXX.data". To list all segments with the suffix "data" using the star convention, enter: 1s *.data

For example the response may be:

$$
\begin{aligned}
& \text { Segments }=2 \text {, Lengths }=3 . \\
& \text { rew } 1 \text { ret_164217.data } \\
& \text { rew } 2 \text { ret_164007.data }
\end{aligned}
$$

-- Delete data segments you don't need: dl *.data

-- Rename data segments you wish to store: rn ret_164007.data FLmap.dt (Use common suffix ".dt" for renamed data segments!)

-- To list renamed data segments that end in the suffix ".dt", enter: $1 s * . \mathrm{dt}$

$$
\begin{aligned}
& \text { Segments }=6, \text { Lengths }=84 \text {. } \\
& \text { rew } 62 \text { lake.dt } \\
& \text { rew } 9 \text { lowflo.dt } \\
& \text { rew } 1 \text { FLmap.dt } \\
& \text { rew } 3 \text { assrv.dt } \\
& \text { rew } 3 \text { 7880DR.dt }
\end{aligned}
$$

+ tape-archived files may be recalled using procedure in section AI-B.4. 
The user must have "execute, $e$ " access to "master.ta"; 1ist access! The WRDBIB tape archive is labelled: "master.ta" .

The following procedure may be used to extract tape-archived files: (For more detail read up on the "tape archive, ta" command in your Multics Manual: Commands and Active Functions.)

\section{B.4.1 TO LIST CONTENTS OF "master.ta":}

-- Link to the listing label of the WRDBIB tape archive. (label ends in suffix ".ta": "master.ta")

: $\quad 1 \mathrm{k}>\mathrm{udd}>$ Wrdbib $>$ NTamberg $>$ TEMP $>$ master.ta

-- To inspect the contents of your tape archive prior to recalling the tape, type

: ta $t$ master (where the key " $t$ " stands for "table")

The system will print the table of contents of your tape archive!

B.4.2 TO EXTRACT TAPE-ARCHIVED SEGMENTS:

-- Send message to systems operator:

: sm sys oper Please find tape 112756

When tape is ready for mounting systems operator will notify you:

"tape is here!"

-- Enter command to extract desired sections of MASTER file!

Note: The WRDBIB tape-archive label is "master.ta"

: ta $\times$ master auth7578 auth7980

ready

(The system will aknowledge instruction)

: ta go master

(Issue "go" command to proceed!)

The systems operator will mount your tape 112756 and copy the specified segments into your working directory. (Since auth7578 and auth7980 are multi_segment files, msf, copy time from tape to disk may be longer.)

-- Upon "ready" message check your working directory.

: Is -ft 3 (System will list the new entries!)

-- Execute search of "Master" file sections: auth7578 auth7980.

See: Section III for PROGRAM EXECUTION PROCEDURES.

: d1 auth7578 auth7978

(delete files after your job is finished. you may extract them from tape_archive!) 


\section{B.5.1 RESPONSE FILES:}

-- To list available files use command: 1s *. response

- To print a selected file use command: pr FORM.response

A sample listing may include the following RESPONSE files:

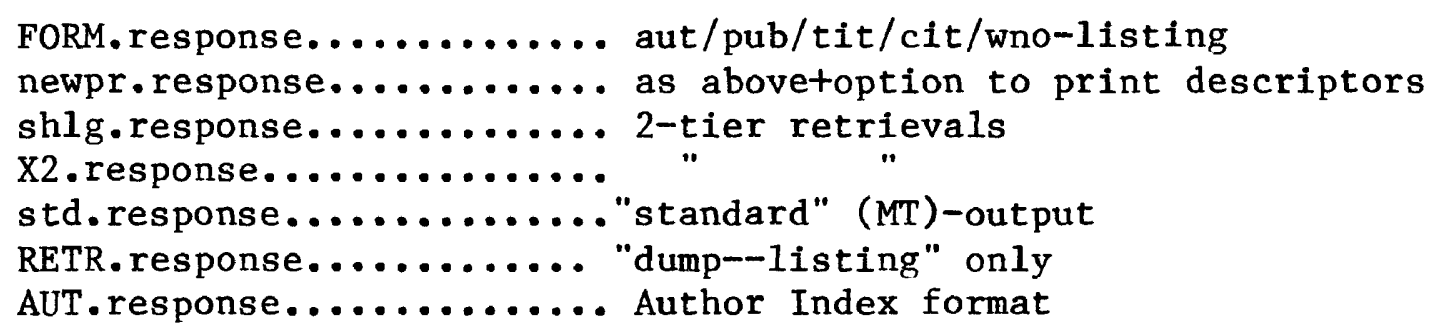

B.5.2 RESPONSE FILE ARCHIVE:

Response files are short segments which are best stored in a more compact form: They may be "archived" online, that is, the designated response segments are written consecutively to a file called 〈name>.archive. Use command "archive, ac", a function key (a=add, ad=add delete; u=update; $t=t a b l e ; x=e x t r a c t)$; the name of your "archive" (with suffix ".archive") and the names of RESPONSE files. The syntax is as follows:

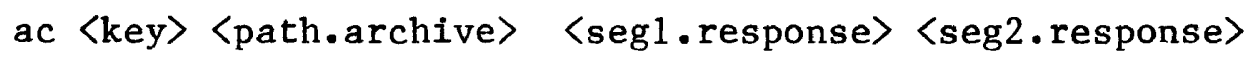

EXAMPLE: To add two response files to "RESP.archive" and have them deleted as individual segments, enter as follows:

ac ad RESP.archive X2.response std.response shlg.response

EXAMPLE: To extract RESPONSE files from RESP.archive:

First, check its contents: Enter key "table, $t$ "

Then: To extract use key " $x$ ".

Enter command: ac $t$ RESP

To extract files: ac $x$ RESP 〈name.response>

See: Multics Commands and Active Functions: Archive, ac. 
B.5.3 EDITING RESPONSE FILE: To edit a RESPONSE file use Multics texteditor "ted" with its line-numbering "Print, P" feature. Enter--

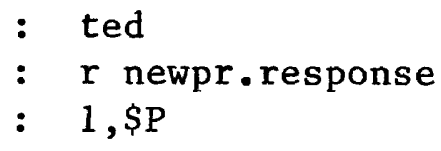

(read file into buffer)

(Capital P (Print) command will print each line --first to last--preceded with a line number!)

1 different input file:=no

2 any more files:=no

3 dictionary:=no

4 any numeric fields:=no

5 matching criteria:=all .

6 change criteria: $=$ no

7 dump listing: $=$ no

8 standard report: $=$ no

9 own formatted report:=yes

10 brief mode:=yes

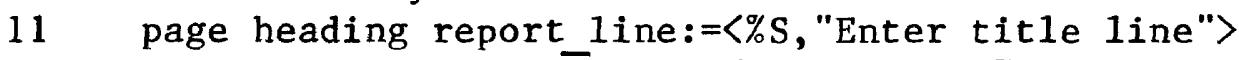

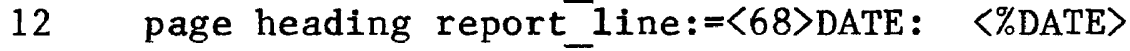

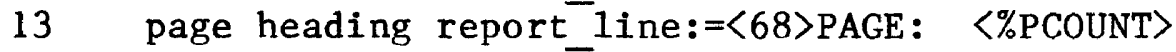

14 page heading report line:=

15 page heading report line:=.

16 detail report 1 ine: $=\langle \% \mathrm{CR}\rangle\langle 11\rangle\langle$ aut $\rangle\langle 48\rangle\langle 50\rangle\langle$ pub $\rangle$

17 detail report 1 ine: $=\langle 9\rangle\langle t i t\rangle\langle 69\rangle$

18 detail report 1 ine: $=\langle 11\rangle\langle$ cit $\rangle\langle 70\rangle$

19 detail report 1 ine $:=\langle 60\rangle\langle$ wno $\rangle$

20 detail report 1 ine:=.

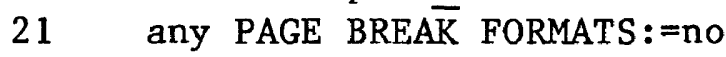

22 any RECORD SPACE BREAKS:=no

23 any REPORT TOTAL LINES:=no

24 sort records:=yes

26 print at terminal:=no

27 print at central site:=yes

28 copies $:=1$

29 save report print file:=yes

30 any other reports:=no

31 save retrieved record segment:=yes

32 another run:=no

To edit responses use the "substitute, $s "$ command and regular expressions:

: $31 \mathrm{~s} / \mathrm{yes} / \mathrm{no} / \mathrm{p}$

$\begin{array}{ll}: & w \\ : & q\end{array}$

ready
(The system will substitute "no" for "yes" in line 31 and print the resulting line!)

(write, w to segment name: Save the changed file) (quit the editor: Exit to Multics command level.)

(ready message) 
REPORT/DATA FILES: You may wish to check your saved REPORT or DATA files listed by their default label: "retXXXX.report" or "ret_XXXXXX.data".

Use of the star convention is recommended: The star stands for any string denoting one component of the segment name, if followed by a poeriod and a suffix. (Note that periods are used to separate component names!)

To list all segments with the suffix component "report" see below:

-- To 1ist enter: 1s*.report

$$
\text { 1s *.data }
$$

(See: Section B.3. INPUT FILES)

EXAMPLE :

1s *.report

Segments $=3$, Lengths $=3$.

rew 1 ret4242. report

rew 1 ret4147.report

rew 1 ret4058.report

If, renamed, but using a common suffix:

-- To 1ist enter: 1s *.〈suffix>

ls *. dt

1s *.rep

\section{EXAMPLE :}

1s *. rep

Segments $=2$, Lengths $=2$.

r w 1 POST.rep

r w 1 FLmap.rep 
APPENDIX II.

GLOSSARY OF SELECTED TERMS 
Access attributes-

Access attribut $t_{\lambda}^{e}$ identify the kinds of access which may be set for a segment or directory. The access attributes for segments are read $(r)$, write $(w)$, execute (e), and nul1 ( $n$ ). Those for directories are status ( $s$ ), modify (m), append (a), and null $(n)$. Access attributes are also known as access modes. (See also: Access identifier.)

Access contro1- The mechanism for determining who may reference or modify segments (files) and directories.

Access rights- An access control list (acl) describes the access attributes associated with a particular segment. The "ac1" is a list of user identifications and respective access attributes. It is kept in the directory that catalogs the segment or the parent directory. (See access attributes for access modes.)

Access identifier (access_id, access_name)-

A character string representing a user or class of users. It consists of three fields: Person id.Project id.tag -- where the tag is the process identifier: " $a$ " = interactive $m=a b-$ sentee; for example: NTamberg,Wrdbib.a (See printout!)

Access modes- See: Access attributes.

Add name/alternate name(s)-

A segment, directory, multisegment file, or link may have more than one name and may be referred to equally well by any one of its names. One of the names is the primary name. A segment often has more than one name because it is a program with alternate entry points. (See: Section I.B. WBsum.info.)

Alphameric- Refers to alphabetic and numeric characters.

Archive-

A method of storing segments online or on tape, so as to conserve space. Access to online archives is by the "archive, ac" command; access to tape archives is by a procedure using a set of "tape_archive, ta" commands. (See: Appendix_..)

Argument-

Author Index-

Citation-
See: Control argument.

Alphabetic crosslisting of authors' names of retrieved records against another variable (WRSIC/accession no., or publication year).

Cited source of publication: Series or journal; volume, number; year of publication; pages, figures, tables Citation (cit) is a variable field in the input record.

$$
\text { APP_II-1 }
$$


Command-

A program designed to be called by typing its name at a terminal. Most commands are system-maintained (Multics commands), but any user program (Multi trieve MT or WRDBIB) that takes only character-string input arguments--program name for example --can be used as a command. (See also: Program statement.)

Compiling (a program)-

See: Program creation.

Component (of an archive)-

One of the segments placed in an archive. (See the archive, "ac" command in Multics Commands and Active Functions Manual.)

Control argument-

An argument to a command specifies additional information required to execute a program. System control arguments begin with a hyphen, such as -a11, -long, -norun. The meaning of each control argument accepted by the command is given as part of the description of the command. (See Appendix A of the MPM Commands and Active Functions Manua1.) The Multi trieve program uses control arguments: -change $\langle 1$ ist $\rangle$ and -response 〈path〉 to prompt for information online. Positional arguments (without preceding hyphen) are used to define the control argument: -rsp 〈path> where 〈path> is the positional argument defining the desired response function in terms of a library response file. (Note: The program defines the position of these arguments.)

-change 〈1ist $\rangle$ argument-

When entered as part of the program statement (command) will solicit additional information from the user which allows online changes of values of certain parameters from those given in the -response argument. The positional argument 〈list> may include any or all parameters: INPUT file(s) (in), MATCH criteria (mc), SORT criteria ( $\mathrm{sc}$ ).

-response 〈path〉 argument-

When entered as part of the program statement (command) will recall the response file designated by (path>--in order to supply the required responses to the system. Certain parameters of the response argument may be changed online when the -change 〈list> argument is entered with it.

Current files- Input records used to update the Master file: 1980 todate.

Custom report- User-formatted report.

Custom program- User-created program using the exec com: ec multi trieve. The program includes a user-defined data dictionary and the user specified Input file.

Daemon-

One of several system service processes (sysdaemon) that perform such tasks as process creation, backup, and printing segments on the line printer (hence command: daemon_print, $d p$ ). 
Data dictionary-

Data elements-

Data segment-

Descriptor(s)-

Directory-

Directory (home)-

The home directory (or the initial working directory) is the one under which the user logs in. Usually this direcis named: >udd>projectid>personid . (See: Appendix_.)

Directory (parent)-

The immediately superior directory.

Directory (working)-

The working directory is the one under which the user is doing his work. Often the working directory is also the home directory. (This is always true at login time.) The user may redefine his working directory by use of the "change-wdir, cwd" command. Your working directory is: $>\overline{u d d}>$ Wrd $\overline{b i}$ bNTamberg $>$ IO . (The user may choose to copy this directory into his own home directory.)

Dump-1isting-

Editor-

Entry format-

Entryname-
Printing the unformatted record at the terminal or at the central site. The data elements are dumped in the same sequence as they appear in the dictionary: Each variable begins on a new (physical) line.

Text-editors "qedx, qx" or "ted" are Multics subsystems which may be called for data input or editing. Both editors operate in the input mode and the edit mode with their respective command sets; "qx" edit commands are upward compatible to "ted" . The editor must be exited using the "quit, $q$ " command before program execution at the Multics command level.

Format of statement to the system including syntax and punctuation.

The name by which a segment is cataloged in a directory. The entryname is not restricted to one component; it may contain two or more components, separated by periods. (For example: FORM.response; PROG.ec.info). 
Exec_com

File(s)-

Help command-

Index report-

Info segment-

Input (files)-

refer to user/computer interaction during program execution caused by the "-change" argument or by the $\langle \% \mathrm{~S}\rangle$ and the $\langle \% \mathrm{D}\rangle$ keywords used in the response file which serves as "-response" argument. (See: Section II.C.4. Key-words.)

Key-words-

Link-

A facility for executing a list of commands contained within a segment. The segment is created within a text editor; its cataloged name must end with the suffix ".ec". To execute use the "execute, ec" command followed by the segment name. (Drop the suffix!) (See: Multi_trieve.ec!)

Segment(s) in which related information is stored online.

A structured command which allows the user to read system's or user-created info segments providing ready reference on system's commands or a factual topic. The syntax is: help 〈segment path> [optional argument] The info segment suffix ".info" is not entered! For more information enter online: help help

See: Author Index. Numeric Index.

A ready reference information unit which is stored online and may be accessed with the help command. The information is structured in sections, and after each section the system solicits user response whether "More help?" is desired. The user must use a given set of responses. (See help command.) The info segment label must end with the suffix ".info" to identify it as such.

(1) Primary Input records which have been entered into the data base, and are described by the dictionary. They are the data files which serve as input into the WRDBIB program. (2) Secondary data files which have been retrieved on some search criterium and are, in turn, entered as input files into a program for further retrieval or report generation. Input files may be changed interactively, if included in the "list" of the "-change 〈list>"argument as "-change in" and entered with the program statement.

Interactive features-

Numbers, symbols or words entered in angle brackets denoting special action in specifying a report format during the report generation step. (See: Section II.C.5. Key-word List.)

An entry in a directory that points to a segment. A link enables a user to access a segment in directories other than his working directory, given proper access permission. The user may specify the segment by entryname (as though it were cataloged in the working directory) without having to make a copy of the segment. (This cuts down on storage cost.) 
Listing procedures-

Using the Multics "1ist, Is" command to list the contents of a given Directory at the terminal. Use of optional arguments ( $-t t,-a 11,-1 k,-f t N$, where $N=1,2,3 \ldots$. will control the extent of listing (See: Appendix_I.)

Logic (Boolean)- is implicit in the Multi trieve program. Two or more retrieval statements are compounded into an "ANDed" statement. A single retrieval statement may be expanded to include several descriptive terms (separated by quotes, or slashes if numeric)-- to express various aspects of a search concept. Here "OR" logic is implied.

Master file- Primary input file containing WRD records covering the WRSIC accession period 1968-1980.

Matching criteria-

Selection criteria entered in a structured format; serving to match the value of a data element, or the partial name (pn) of an extended data field (see Dictionary) according to specifications of relational operators (equal, eq; pn) with those contained in the input record (Input file). Matching criteria may be changed interactively when the "-change mc" argument is entered in the program statement.

Multics commands-

Systems commands at the command level are used in 2-letter and 3-letter abbreviations. (For example: cp, d1, 1s, pr, cwd, pwd - an overview is given in section I.C.5.)

Multisegment file, msf-

An indexed file that occupies more than one segment (the limit

is 256 "pages".). The "Master" file is a multisegment file. To manipulate a msf the user must proceed like with a directory: cwd 〈your msf name〉. (Check Multics Manual.)

Multi_trieve- File-management system designed for use on the Honeywe11 Multics system. It is designed to facilitate retrieval and report generation from fixed field records using simple English commands in the interactive mode.

Multi_trieve.ec-

A set of commands (an exec_com) which links the user directory to the Multi_trieve program.

Numeric fields- Defined as such to facilitate numeric comparisons during retrieval program execution. (See: Section II.B.5.2.)

Numeric index- Crosslisting of authors' names against the WRSIC (accesssion) number, sorted on the latter (semi-chronological order). Sorting on the publication year may be used for large output.

Online ready_reference-

See: Info segments. 
Operators-

Output file(s)-

Page (directory)-

Password-

Pathname-

Person_1d-

Profile (segment)-

The segment with the name (person id.profile> contained in a user's home directory. It contains the abbreviations for that user. It is created by the first call for the abbrev processor. (See: Introductory Multics Handbook.)

Program-

See: Custom program. WRDBIB Program.

Program creation-

Executing the Multi trieve.ec (exec_com) using the "-norun" argument. This will create and compile a custom program and save it under a given name for future use. This process is sometimes referred to as the "Creation program".

Program execution-

This involves entry of the program statement (command) which may include (optional) control arguments, responding to all systems queries using the format prompted by the system. When the "-response" argument is used, responses are provided by library response files. (See: Control arguments.)

Program statement-

First command entered to start program execution. The command line is in the form of a structured statement. The syntax is: 〈Program name> [control arguments] 
Project_id-

A project_id is an identification code under which a project is registered in the system. (Ex.: Wrdcr, Wrdbib)

Record selection-

See: Retrieval statement.

Reformatting- See: Report generation.

Relational Operators-

Used in a Retrieval statement to indicate how a given value (index word) should be matched within the input record.

Ready message- A message that is printed each time a user is at the command level and Multics is "ready" for another command.

Report generation-

Program execution in order to generate a custom report using a previously retrieved data segment as input. (See also: WRDBIB Programs.)

Response file- The sum total of all reponses provided by the user during a given program execution session and saved as an output file. The response file name must have the suffix ".response". (See also: Control arguments: "-response" argument.)

Retrieva1- Program execution, usually exploratory, to retrieve data. (No report generation.) (See also: WRDBIB Programs.)

Retrieval and Report Generation-

Executing an one-step retrieval and report generation program.

Retrieval statement-

A structured statement to the system involving the dictionary element, a relational operator, and the value to be matched in the input record. One or more statements comprise the Matching criteria.

Search path- References path_names of directories containing certain subroutines or data items that are referenced symbolically. If entered at the beginning of a session or included in start_up.ec will preferentially search the named directory for desired segment, such as info.segment "WBsum.info". Use "add search_path, asp" command. (See: Section I.B.)

Selection criteria-

See: Matching criteria.

Sort criteria- A structured statement to the system indicating if and how the retrieved records should be sorted. The syntax includes: The dictionary element and a qualifier separated by a space and ending in a blank and a period. Qualifiers are " $a$ " for "ascending" and " $d$ " for "descending" sequence. A nested sort sequence may be specified. The sort criteria may be changed interactively if included in the "list" of the "-change 〈list>" argument. 
Standard MT report-

Uses a standard Multi trieve format. The system will prompt the user, should he choose this option during his initial retrieval program. (See Section II.C.3.)

Star convention-

A method used by many commands to specify a group of segments and/or directories using a common component name (a star name). (Components are separated by a period ".": master.ta).

Start_up.ec-

An exec_com segment containing a set of rules that can be invoked automatically when th user logs in.

SysDaemon- See: Daemon.

User_dir_dir-

The user directory directory, which contains all project directories. Its pathname is >udd, and all user segments and directories are subordinate to it.

User_id- Refers to a Person_id.Project_id pair.

WB sum.info-

Info segment providing online ready reference for the WRDBIB system. (See also: Info.segment.) Include search path into your start_up.ec before use!

Working directory-

See: Directory (working).

WRDBIB-

An acronym for WRD bibliographic system.

WRDBIB data base-

Compilation of citations and (subject) descriptors of WRD records processed by WRSIC: 1968 to date. The extracted WRD subset resides on Reston Multics and may be accessed by the Multi_trieve application program WRDBIB.

WRDBIB program-

A named custom progran created with Multi_trieve software. (An application program.) Custom features are a data dictionary that describes the WRDBIB input record format, and a selected WRDBIB input file which was used in the compilation process. (See also: Custom program.) The incorporated input file is searched if no other input file is specified during program execution.

WRDBIB system-

A system of custom programs, dictionaries, input files, and response files--taylored to retrieve bibliographic citations and (subject) descriptors from the WRDBIB data base. Retrieval programs will retrieve on desired selection criteria and output data segments which may be reformatted by Report generation programs to create custom reports (in near USGS format), or to prepare various Index reports. An online ready reference segment, WBsum.info, is available for random access of information on WRDBIB files and procedures.

WRSIC-

An acronym denoting the Water Resources Scientific Information Center. U.S. Geological Survey. Department of Interior. 


\section{APPENDIX III}

A WRDBIB RETRIEVAL AND REPORT GENERATION SESSION

IN TEN STEPS:

Step_1: FORMULATE SEARCH STRATEGY

Step_2: FORMULATE RETRIEVAL STATEMENT DATA DICTIONARY

Step_3: SELECT CUSTOM PROGRAM:

CHECK DATA DICTIONARY COMPILED WITH PROGRAM

Step_4: ENTER A CUSTOM PROGRAM STATENENT W/CONTROL ARGUMENTS

FIRST PROGRAM RUN:

Step_5: EXECUTE INITIAL RETRIEVAL RUN (Step 1 of Two-step Procedure)

Step_5A: EXECUTE (OPTIONAL) REPORT GENERATION PROGRAM (Step 2 of Two-step Procedure)

Step_6: EXECUTE ALTERNATE RETRIEVAL \& REPORT-GENERATION PROGRAM (One-step Procedure)

Step_7: EXECUTE (OPTIONAL) AUTHOR INDEX PROGRAM

SECOND PROGRAM RUN:

Step_8: EXECUTE SECOND RETRIEVAL \& REPORT GENERATION PROGRAM (One-step Procedure.)

Step_8A: EXECUTE ALTERNATE REPORT-GENERATION PROGRAM: REFORMAT FINAL REPORT TO INCLUDE DESCRIPTORS

Step_9: EXECUTE FINAL AUTHOR INDEX PROGRAM

Step_10: CHECK WORKING DIRECTORY \& LOGOUT

EXAMPLES: $\quad$ CUSTOM REPORT EXAMPLE AUTHOR INDEX REPORT EXAMPLE 
A WRDBIB RETRIEVAL AND REPORT GENERATION EXERCISE: The following sequence will illustrate the progression of steps taken to provide a data base search and custom-formatted REPORTS in response to the query:

RETRIEVE ALL WRD REPORTS (1968-1979) DEALING WITH

STUDIES OF GROUNDWATER ORGANICS.

\section{PROCEDURE :}

Step 1: FORMULATE SEARCH STRATEGY. (See: Section I-4.)

Your search terms are:

-- GROUNDWATER including all related terms;

-- ORGANICS and its related terms.

NOTE: This retrieval will be carried out on the "descriptor" field. Since MULTI TRIEVE does not provide "AND"-logic within one field, execute two retrieval runs by considering the probable frequency of occurrence of the above terms:

-- "GROUNDWATER" occurrs in about $45 \%$ of all the WRDBIB records: The volume comprises some 3800 records!

-- "ORGANICS" and its related terms occur less frequently.

Begin the retrieval with the term(s) used less frequently which are pertaining to the ORGANICS. 
Step 2: FORMULATE RETRIEVAL STATEMENT:

(See: Section III.A.2. OVERVIEW: RETRIEVAL REQUEST STRUCTURE.)

2.1 Define "ORGANICS" terms:

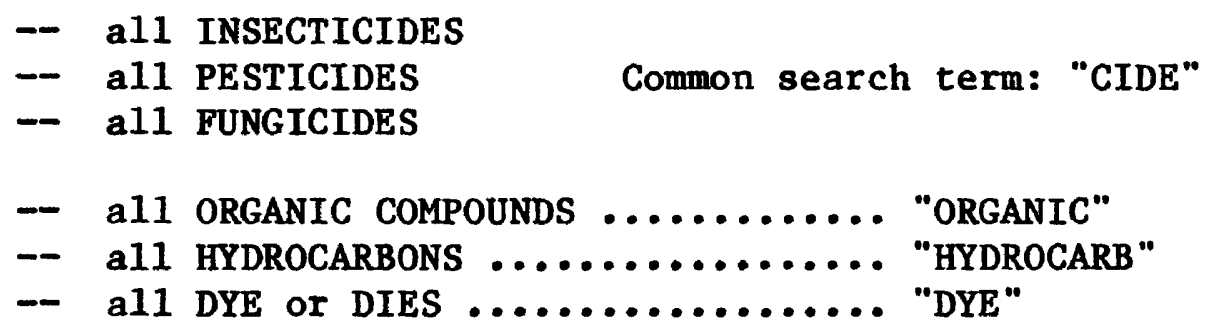

2.2 Select retrieval variable from DATA DICTIONARY:

(See fig. III-1 for DATA DICTIONARY listing.)

-- Search on "descriptor, des" variable to match subject keywords.

-- Use "OR"-logic within the "descriptor" field to combine all related terms, as well as all variant spelling forms:!

-- The RETRIEVAL STATEMENT for the first retrieval run reads:

$$
\text { des=pn"CIDE"ORGANIC"HYDROCARB"DYE" .* }
$$

-- Enter RETRIEVAL STATEMENT in response to PROGRAM prompt: ENTER MATCH CRITERIA FOR RECORD SELECTION.

2.3 Define "GROUNDWATER" terms :

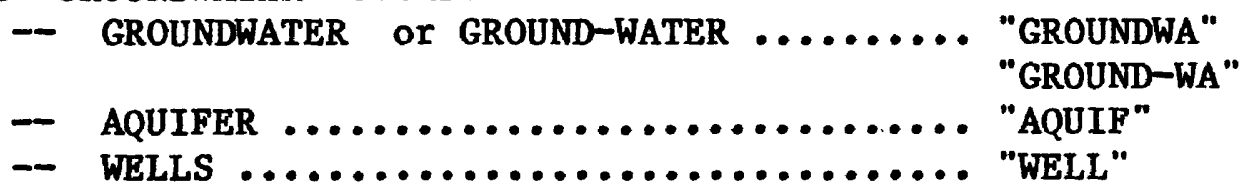

2.4 Select retrieval variable from DATA DICTIONARY. Proceed as in 2.2. Use "OR"-logic to combine all variant forms of "descriptors". The RETRIEVAL STATEMENT for the second retrieval run reads: (See step 8.3.)

$$
\text { des=pn"GROUNDWA"GROUND-WA"AQUIF "WELL" . * }
$$

NOTE: The two consecutive program executions will, in effect, yield records retrieved according to the strategy: 〈ORGANICS> AND 〈GROUNDWATER〉.

* All statement to the system end in a blank and a period on the same line, or with a period on line following statement. 
Step 2: Continued:

DATA DICTIONARY:

The DATA DICTIONARY contains all data elements describing the WRDBIB data files and all input segments derived from it to be used in retrievals. (See Section II.B. DATA DICTIONARY. Online read help WBsum.info unit: DICT.ec.info.)

$\begin{array}{llcc}\text { RETRIEVAL NAME } & \text { PRINT NAME } & \text { START POS } & \text { FIELD LENGTH } \\ \text { wno } & \text { wrsic.no } & 1 & 8 \\ \text { acyr } & \text { acc.yr } & 1 & 2 \\ \text { acno } & \text { acc.no } & 4 & 5 \\ \text { aut } & \text { author } & 9 & 90 \\ \text { sso } & \text { source } & 99 & 120 \\ \text { tit } & \text { title } & 219 & 200 \\ \text { cit } & \text { citation } & 419 & 230 \\ \text { des } & \text { descriptor } & 649 & 380 \\ \text { pub } & \text { pub.yr } & 1029 & 4 \\ \text { idn } & \text { ident } & 1033 & 2\end{array}$

Figure III-1.--DATA DICTIONARY: "extdict" is associated with the PROGRAM, NOVpr.

NOTE: The DATA DICTIONARY does not have to define every character in the input record, only those the user is interested in. The variables can be in any order, overlap one another, or skip characters.

For online reday reference enter: help DICT.ec <-title> 
Step 3: SELECT A CUSTOM PROGRAM AND COMPATIBLE INPUT/DATA FILES: When selecting a WRDBIB PROGRAM, be sure that the DATA DICTIONARY used for its creation adequately describes the INPUT files you plan to search.

3.1 -- Select the INPUT/DATA file you wish to search. The INPUT file must be compatible with the DICTIONARY that has been compiled with your PROGRAM. (For listing procedure see APPENDIX I.) Use list command: (Note: The star convention is allowed!)

$$
\begin{array}{ll}
\text { Is auth* } & \text { for primary files; } \\
\text { ls *.dt } & \text { for previously retrieved } \\
\text { 1s *.data } & \text { data segments; }
\end{array}
$$

3.2 -- Select your custom PROGRAM with its associate DATA DICTIONARY which defines the "Master" file: "auth6880". (Ex.: "wrsdict" describes the old format.)

NOTE: To search the "Master" file we selected the recently compiled program: "AUTpr". When executing retrievals from "Current" files (1978-1982) use: "NOVpr". This PROGRAM is compiled against the DATA DICTIONARY: "extdict". (See step_2: fig. III-1.)*

3.3 -- To check the PROGRAM DICTIONARY enter your 〈PROGRAM NAME) and execute to print DICTIONARY!

3.4 - Enter the RETRIEVAL AND REPORT GENERATION PROGRAM STATEMENT. (See step_4.)

NOTE: For PROGRAM EXECUTION see steps 5,6 and 8 .

* See COMPdict.info: Compiling a custom PROGRAM. 
Step 4: ENTER A CUSTOMIZED PROGRAM STATEMENT USING CONTROL ARGUMENTS.

4.1 TO EXECUTE A WRDBIB RETRIEVAL AND REPORT-GENERATION PROGRAM

enter a customized PROGRAM STATEMENT with CONTROL ARGUMENTS:

$$
\text { 〈PROGRAM_NAME〉 -rsp 〈path> -chg 〈change_1ist> }
$$

-- Use "-response 〈path〉" argument to link to a RESPONSE FILE which has been created during a preceding retrieval and/or report generation session. Such a RESPONSE file provides all the responses necessary to execute a given type of PROGRAM WRDBIB RESPONSE files: "FORM.response" and "newpr. response" include specifications for a custom-formatted REPORT as well as for required output files. (See fig.s III-3 and III-4 for listings.) Note the interactive features specified for your custom-formatted REPORT!

-- Use "-change 〈change list>" arguments to allow the following interactive changes of a given RESPONSE file:

$$
\begin{aligned}
& \text {-chg in } \ldots \ldots \ldots \ldots \ldots \text { change INPUT file (in), } \\
& \text {-chg mc } \ldots \ldots \ldots \ldots \ldots \text { change MATCH citeria (mc), } \\
& \text {-chg sc } \ldots \ldots \ldots \ldots \text { change SORT (sc) }
\end{aligned}
$$

Use one of the following PROGRAM STATEMENTS:

$$
\begin{aligned}
& \text { AUTpr -rsp FORM -chg in,mc ....... retrieval and/or } \\
& \text { NOVpr }- \text { rsp newpr -chg in,sc ........ report generation } \\
& \text { NOVpr }- \text { rsp AUT }- \text { chg in } \ldots \ldots \ldots \text { AUTHOR INDEX }
\end{aligned}
$$

(See: PROGRAM EXECUTION in steps 5 to 9.)

NOTE: The "-change 〈change 1ist>" arguments must be entered with the "-response 〈path〉" argument which they modify.

4.2 SELECT RESPONSE ARGUMENT (RESPONSE FILE):

READ AND EDIT YOUR RESPONSE FILE: When selecting your "-response" argument (RESPONSE file) make sure that you know its specifications. You may check the file as follows:

-- Use the "print,pr" command to print the RESPONSE file online.

- Call the text-editor: Read and edit your RESPONSE file. (See fig. III-3.)

-- Supply "-change 1ist" arguments in your PROGRAM STATEMENT to specify changes in your INPUT, MATCH, and/or SORT criteria interactively: 


\subsection{SELECT RESPONSE ARGUMENT Continued:}

RESPONSE FILE FOR RETRIEVAL AND REPORT GENERATION.

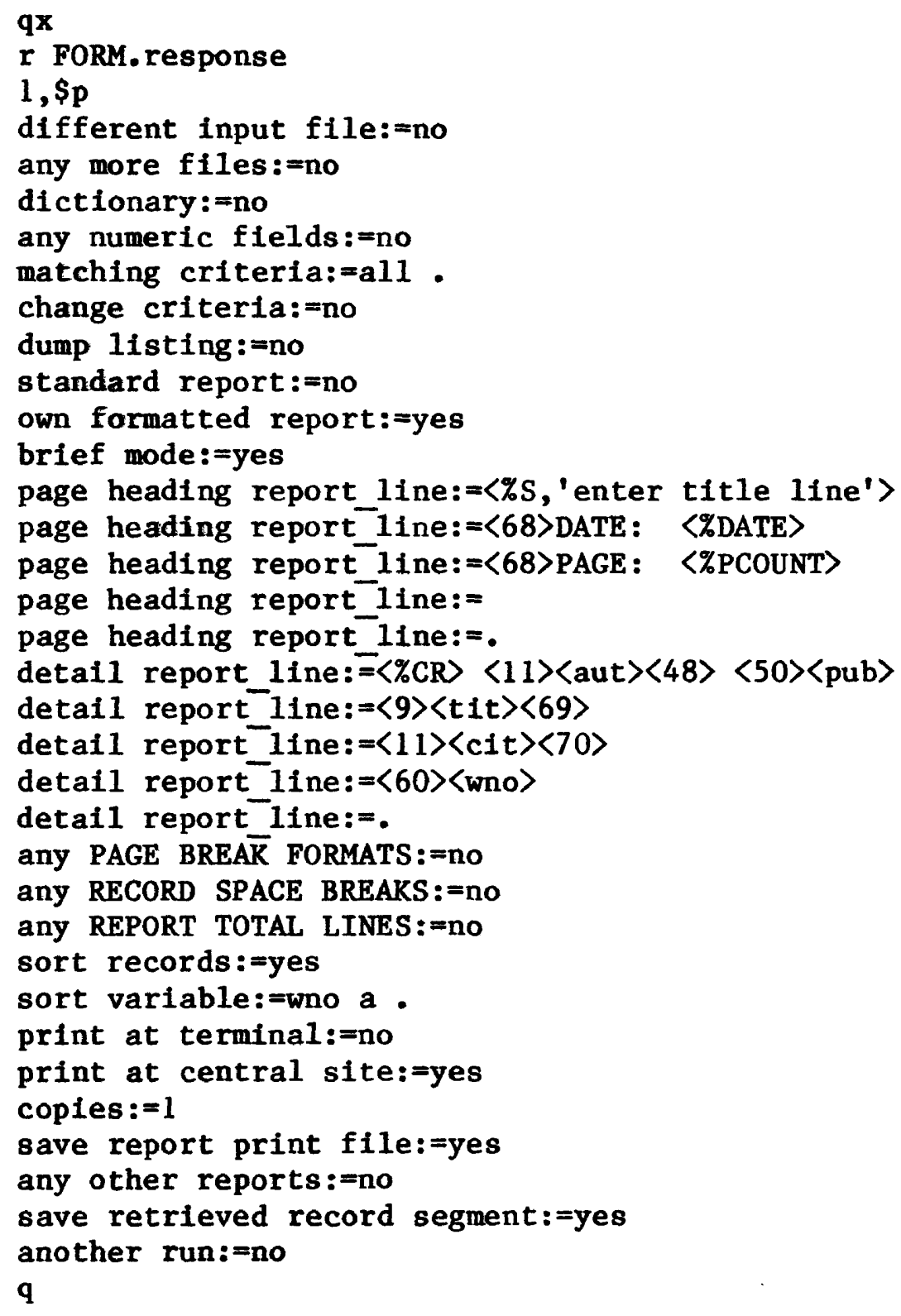

Figure III-2.--RESPONSE FILE: "FORM.response" for custom REPORT generation. 


\subsection{TO EXECUTE AN INDEX (REPORT-GENERATION) PROGRAM:}

-- Use the specially formulated RESPONSE file: "AUT.response" (See listing in fig. III-3; PROGRAM EXECUTION in fig. III-6 and fig. III-10.)

- Enter one of the following PROGRAM STATEMENTS:

$\begin{array}{llll} & \text { 〈PROGRAM_NAME> } & \text {-rsp AUT -chg in } \\ \text { or: } & \text { 〈PROGRAM_NAME> } & \text {-rsp AUT -chg in,mc (to check MATCH criteria) } \\ \text { or: } & \text { 〈PROGRAM_NAME> } & \text { rsp AUT -chg in,sc (to change SORT criteria) }\end{array}$

\subsection{EDIT RESPONSE FILE: "AUT.response". (See fig. III-3.)}

The "AUT.response" file is designed to create an AUTHOR INDEX.

NOTE: Use the "-chg in" argument in your PROGRAM STATEMENT to enter desired INPUT file.

-- Check your MATCH (mc) criteria: When reformatting data segments "al1" records must be retrieved. Your RESPONSE file statement should read:

matching criteria:=al1 .*

-- Check your SORT (sc) criteria: You may want to use the "-chg sc" argument to interactively alter your SORT criteria:

sort variable:=aut a

-- The output data segment (ret XXXXXX.data) is equal to your INPUT file. DO NOT STORE RETRIEVED DATA SEGMENT. Edit your response!

save retrieved record segment:=no

NOTE: If you did not edit the data segment out, use MULTICS systems' command to delete the data upon program execution: (See step_7.)

Enter: (See also step_10: DIRECTORY MANAGEMENT.)

d1 ret_XXXXXX.data

* End statements to the system in a blank and a period. Elements of the statement are separated by blanks. 
4.4 EDIT RESPONSE FILE : "AUT.response" continued:

To generate an INDEX REPORT use RESPONSE file "AUT.response". To read the file enter the "print, pr" command. (To edit the file use editor, qx or ted.)

: pr AUT.response

The system will print at the terminal:

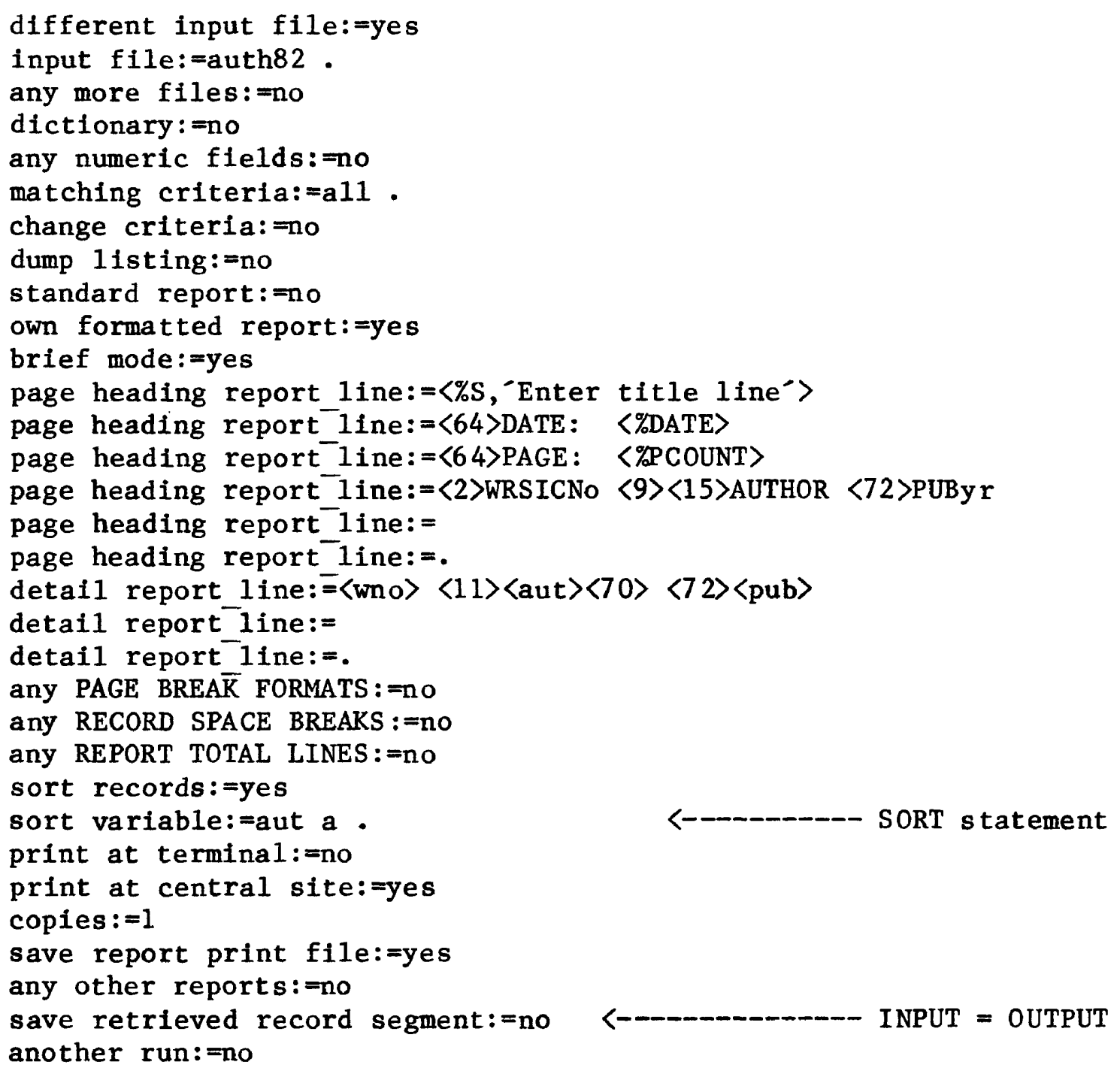

Figure III-3.--RESPONSE File: "AUT.response" creates AUTHOR INDEX. The file is sorted alphabetically by "author, aut" in ascending sequence, "a": A to $\mathrm{Z}$. (See figure III-12.) 
Step 5: EXECUTE INITIAL RETRIEVAL PROGRAM (FIRST RUN).

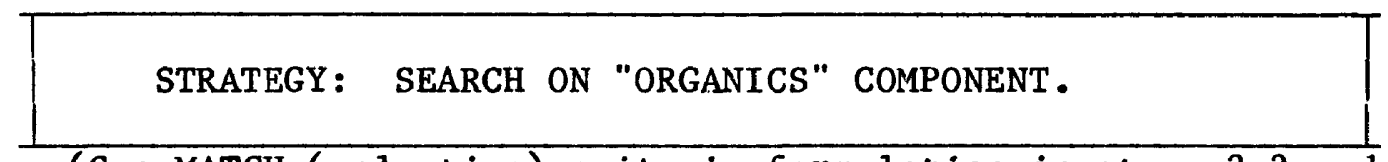

(See MATCH (selection) criteria formulation in steps 2.2 and 2.4.)

NOTE :

Since this is a major RETRIEVAL PROGRAM involving a search of the complete "MASTER" file ( 7417 records), it is prudent to execute a two-step procedure: 1) a RETRIEVAL run to determine the out put volume, and 2) a REPORT GENERATION run using the data segment retrieved during the retrieval run as INPUT file. (see step 5A.) The one-step RETRIEVAL and REPORT GENERATION procedure is shown in fig. III-5 below.

5.1 RETRIEVAL PROCEDURE: Enter selected PROGRAM. DO NOT USE CONTROL ARGUMENTS. Provide your own responses to system's prompts. (Follow procedure in fig. III-4.)

: AUTpr

(System will print path of given INPUT file)

5.2 DO YOU WISH TO USE A DIFFERENT INPUT FILE? Respond "no" if you wish to use the given file and proceed. If you want a "DIFFERENT" file or "ADDITIONAL" files, enter "yes", and be ready to enter your INPUT files as prompted (see fig III-6.).

5.3 DO YOU WANT TO SEE THE DATA DICTIONARY? Enter "yes", if you want to check your DATA DICTIONARY at this point; otherwise enter "no" response to query.

5.4 ... NUMERIC FIELDS? Enter "no" response, if you do not wish to make any numeric comparisons.

5.5 ENTER MATCHING CRITERIA FOR RECORD SELECTION:

Enter your selection criteria as formulated in steps 2.2 and 2.4 .

5.6 The system will perform the search and state the number of records read and the number of records retrieved.

5.7 Should you want a DUMP-LISTING of " $N$ " records $(N=1,2,3)$ at the terminal, respond with "yes" and supply number of records ("N") you want to see after next query.

5.8 Save retrieved record segment for future use as INPUT data for the second run. (See step_8.) Rename your data segment:

: rn ret_182145.data ORG.dt

NOTE: If you wish a custom REPORT at this stage, reformat data segment "ORG.dt" according to step_5A and step_7 (AUTHOR INDEX.) 


\section{TWO-STEP PROGRAM EXECUTION: STEP_1-- RETRIEVAL EXAMPLE}

: $\quad$ AUTpr

YOUR CURRENT INPUT FILE IS >udd>Wrdbib>NTamberg>TEMP>auth6880

DO YOU WISH TO USE A DIFFERENT INPUT FILE?

: no

DO YOU WANT TO SEARCH ADDITIONAL INPUT FILES WHICH CONFORM

TO THE DICTIONARY?

: no

: * no

DO YOU WANT TO SEE THE DATA DICTIONARY?

DO YOU HAVE ANY STRICTLY NUMERIC FIELDS IN YOUR DATA

THAT YOU WANT TREATED AS NUMERIC VARIABLES FOR COMPARISON PURPOSE?

: no

ENTER MATCHING CRITERIA FOR RECORD SELECTION.

: des=pn"CIDE"ORGANIC"HYDROCARB "DYE" .

NAME CONDITION VALUE

des

pn

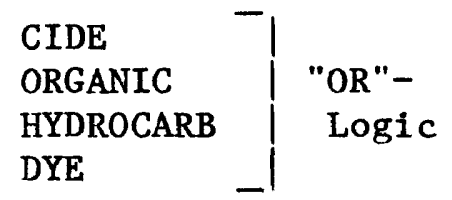

DO YOU WISH TO CHANGE, ADD OR DELETE ANY OF THESE VALUES?

: no

TOTAL NUMBER OF RECORDS READ $=7417$

TOTAL NUMBER OF RECORDS SELECTED $=310$

DO YOU WANT A SIMPLE DUMP LISTING OF SOME OF YOUR RECORDS?

: no

DO YOU WANT THE DUMP PRINTED AT THE CENTRAL SITE?

: no

DO YOU WISH TO CREATE A STANDARD REPORT USING THE SELECTED RECORDS?

: no

DO YOU WISH TO CREATE YOUR OWN FORMATTED REPORT?

: no

DO YOU WANT TO SAVE THE SEGMENT CONTAINING RECORDS JUST RETRIEVED?

: yes

THE NAME OF THE SEGMENT SAVED IS ret_182145.data

DO YOU WISH TO MAKE ANOTHER RUN?

: no

DO YOU WANT TO SAVE YOUR RESPONSES TO RUN THIS SESSION AGAIN?

: no

END OF JOB (Level 2)

r $10: 198 \quad 2459$

: rn ret 182145.data ORG.dt (rename your data segment!)

r $10: 224 \overline{80}$

":" precedes user response.

* See figure III-1 if you wish to see the DATA DICTIONARY !

Figure III-4.--PRELIMINARY RETRIEVAL RUN TO DETERMINE OUTPUT VOLUME: The retrieved data segment is saved for future use. 
TWO-STEP PROGRAM EXECUTION: STEP 2-- REPORT GENERATION PROCEDURE.

Step 5A: EXECUTE OPTIONAL REPORT GENERATION PROGRAM.

Since this is a major RETRIEVAL PROGRAM involving the complete "Master" file the RETRIEVAL and REPORT GENERATION functions are performed in two steps: This step describes the REFORMATTING procedure. (See step 5 for RETRIEVAL procedure.)

NOTE: THIS STEP MAY BE OMITTED, IF NO INTERMEDIATE REPORT IS DESIRED. (See REFORMATTING procedure in step_8A.)

5A.1 - TO REFORMAT A DATA SEGMENT enter a PROGRAM STATEMENT with desired CONTROL ARGUMENTS. (See step 4. Editing RESPONSE file.) For program outline see step_ $\overline{6}$ : Fig. III-5.

: NOVpr -rsp FORM -chg in,mc

$5 \mathrm{~A} .2$-- Enter the data segment retrieved in step 5. in response to the "-chg in" prompt: DO YOU WISH TO USE A DIFFERENT INPUT FILE?

: ORG.dt .

5A.3 -- Check your selection criteria in response to "-chg mc" prompts: ALL RECORDS WILL BE SELECTED. (If you read your RESPONSE file you probably do not need this step. When the "-chg mc" argument has not been entered this step is omitted.)

$5 A .4$-- The system will print out the number of records read: 310 records and the number of records retrieved: 310 records.

5A.5 -- REPORT GENERATION: Enter "Report Title" for your first (intermediate) REPORT in response to program prompt:

"Enter title line" : ORGANICS REPORTS (First Run)

5 A.6 -- The system will print out the labels of your output files. Rename them, for easier access! (See APPENDIX_I.)

$5 \mathrm{~A} .7$-- When the program run has been completed delete your output segment; (Since all records have been retrieved this segment is identical with the INPUT data.)

NOTE: The user may want to generate an alphabetic or numeric AUTHOR INDEX to check on his initial retrieval: Use RESPONSE file "AUT.response" as response argument! (See step-7.) 
6. RETRIEVAL \& REPORT GENERATION PROGRAM:

ONE STEP (ALTERNATE) PROGRAM EXECUTION: RETRIEVAL AND REPORT GENERATION

Step_6: EXECUTE ALTERNATE RETRIEVAL AND REPORT GENERATION PROGRAM.

Use the "one-step" procedure when searching shorter

files, for example, "CURRENT" files. Combine step_5

(RETRIEVAL) and step 5A (REPORT GENERATION) into one

program run. Enter the following PROGRAM STATEMENT:

$$
\text { AUTpr -rsp FORM -chg in,mc }
$$

The procedure is illustrated in fig. III-5.

See specifications of FORM.response in fig. III-2. 
6. RETRIEVAL \& REPORT GENERATION PROGRAM EXAMPLE:

STRATEGY: FIND ALL RECORDS CONTAINING THE TERM "ORGANICS" AND RELATED TERMS IN THE DESCRIPTOR FIELD: USE "OR" LOGIC.

: NOVpr -rsp FORM - chg in,mc MULTI TRIEVE RESPONSES READ FROM FILE

>userdir dir>Wrdbib>NTamberg>TEMP>FORM. response <-- RESPONSE path YOUR CURRENT INPUT FILE IS >user_dir_dir>Wrdbib>NTamberg>auth79 $\overline{80}$ DO YOU WISH TO USE A DIFFERENT INPUT FILE?

:

yes <- - chg in

THE NEW INPUT FILE MUST BE COMPATIBLE WITH DICTIONARY DESCRIBING

THE OLD INPUT FILE.

PLEASE ENTER THE NAMES OF INPUT FILES.

THE NAMES MUST BE SEPARATED BY BLANKS.

THE LAST NAME MUST BE FOLLLOWED BY A BLANK AND A PERIOD.

: auth6880.

(- new INPUT file

ANY MORE FILES TO SEARCH?

: no

INPUT FILES : >user dir dir>Wrdbib>NTamberg>auth6880

ALL RECORDS WILL BE SELECTED.

DO YOU WISH TO CHANGE, AND OR DELETE ANY OF THESE VALUES?

: yes

TO DELETE A VARIABLE ENTER A $d$ AS THE VALUE, SUCH AS $x x=d$

TO ADD OR CHANGE A VARIABLE ENTER AS NORMAL INPUT

SUCH AS $\mathrm{xX}=\mathrm{eq} . .$.

ENTER MATCHING CRITERIA FOR RECORD SELECTION.

: des=pn"CIDE"ORGANIC"HYDROCARB"DYE" .

- - - chg me

$\begin{array}{cll}\text { NAME } & \text { CONDITION } & \text { VALUE } \\ \text { des } & \text { Pn } & \text { CIDE } \\ & \text { ORGANIC } \\ & \text { HYDROCARB } \\ & \text { DYE }\end{array}$

DO YOU WISH TO CHANGE OR DELETE ANY OF THESE VALUES?

$:$ no

TOTAL NUMBER OF RECORDS READ $=7406$

TOTAL NUMBER OF RECORDS SELECTED $=310$

* Enter title line

: ORGANICS IN HYDROLOGICAL STUDIES : 1968-1979

REPORT GENERATION

THE NAME OF SAVED REPORT PRINT FILE IS ret2530.report

SORT \& OUTPUT FILES

THE NAME OF THE SEGMENT SAVED IS ret 182145.data

END OF JOB (Level 2)
r 18:25 366393404
("Ready" message)

: rn ret 182145 .data ORG.dt

(Data segment renamed)

r $18: 2 \overline{5} \quad 0.10950$

("Ready" message)

\footnotetext{
":" precedes user responses

* interactive prompt
}

Figure III-5.--FIRST RETRIEVAL SESSION: SEARCHING THE "MASTER" FILE. Use an one-step retrieval and report generation program with your Report output volume in mind. 
7. PROGRAM EXECUTION PROCEDURE: AUTHOR INDEX

Step 7: EXECUTE AN OPTIONAL AUTHOR INDEX PROGRAM.

Use RESPONSE file "AUT.response" to create this special report.

7.1 -- Check your RESPONSE file "AUT.response": (See step_4.)

7.2 -- Enter the following custom PROGRAM STATEMENT: The "-response" argument will link you to "AUT.response"

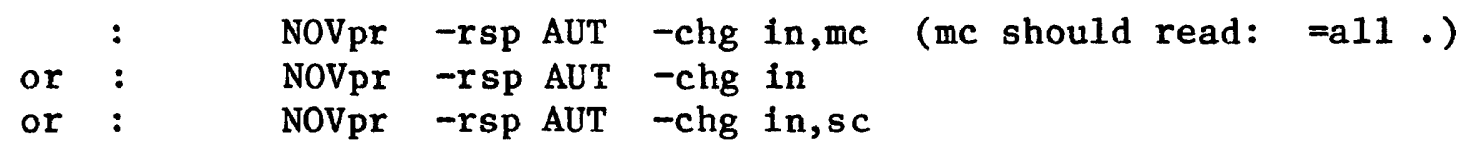

7.3 -- Execute: Use "-chg in" prompts to enter a different INPUT file. Enter data segment retrieved during RETRIEVAL program execution according to either step_5 or step_6.

-- "MATCH CRITERIA" should state: ALL RECORDS WILL BE SELECTED. You may alter your selection criteria interactively, if you supplied the "-chg mc" argument with your PROGRAM!

-- Save only your new REPORT file: The AUTHOR INDEX. (Fig. III-6.) (Delete data segment; it is identical with your INPUT file!) 
GENERATE AN AUTHOR INDEX: Enter--

: NOVpr -rsp AUT -chg in,mc

MULTI TRIEVE RESPONSES READ FROM FILE

$>$ udd $>\bar{W}$ rdbib $>$ NTamberg $>$ TEMP $>$ AUT . response

YOUR CURRENT INPUT FILE IS >udd $>$ Wrdbib>NTamberg $>$ TEMP >auth 81

DO YOU WISH TO USE A DIFFERENT INPUT FILE?

: yes

THE NEW INPUT FILE MUST BE COMPATIBLE WITH THE DICTIONARY DESCRIBING THE

OLD INPUT FILE.

PLEASE ENTER THE NAMES OF INPUT FILES.

THE NAMES MUST BE SEPARATED BY BLANKS.

THE LAST NAME MUST BE FOLLOWED BY A BLANK AND A PERIOD.

: ORG.dt .

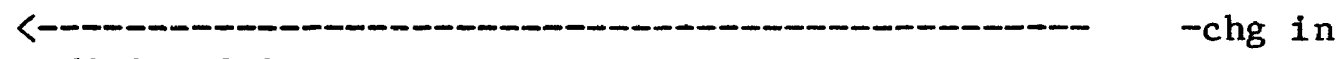

ANY MORE FILES TO SEARCH?

: no

INPUT FILES: >udd>Wrdbib>NTamberg>TEMP>ORG.dt

ALL RECORDS WILL BE SELECTED.

DO YOU WISH TO CHANGE, AND OR DELETE ANY OF THESE VALUES?

: no $<--\mathrm{chg}$

TOTAL NUMBER OF RECORDS READ $=310$

TOTAL NUMBER OF RECORDS RETRIEVED $=310$

"enter title line"

: AUTHOR INDEX

*

THE NAME OF SAVED PRINT FILE IS ret5011.report

END OF JOB (Level 2)

r 18:50 7.028 1278

\footnotetext{
":" precedes user responses

* SORT is specified by AUT.response: aut a * (alpha- by Author)
}

Figure III-6.--PROGRAM EXECUTION: CREATING AN AUTHOR INDEX

(REFORMATTING A DATA SEGMENT.)

NOTE: For INDEX REPORT format see fig. III-12 . 
SECOND AND FINAL RETRIEVAL RUN.

RETRIEVAL STRATEGY: SEARCH "ORGANICS" DATA ON "GROUNDWATER" COMPONENT.

[ORGANICS COMPONENT] * [GROUNDWATER COMPONENT]

Step_8: EXECUTE SECOND RETRIEVAL \& REPORT GENERATION

PROGRAM (One-step Procedure)

Step_8A: GENERATE FINAL REPORT TO INCLUDE DESCRIPTORS:

Step_9: GENERATE FINAL AUTHOR INDEX REPORT

Step_10: CHECK WORKING DIRECTORY \& LOGOUT

CUSTOM REPORT EXAMPLE

AUTHOR INDEX REPORT EXAMPLE 
8. PROGRAM EXECUTION PROCEDURE:

PROGRAM EXECUTION (SECOND RUN): RETRIEVAL AND REPORT GENERATION

Step_8: EXECUTE SECOND RETRIEVAL AND REPORT GENERATION PROGRAM: Use the one-step procedure. Search ORGANICS data segment for the "GROUNDWATER" component: (See step 2.) REPEAT the sequence given in steps 5,6,7 with the following changes:

8.1 -- Enter your second PROGRAM STATEMENT using control arguments . This will be a one-step RETRIEVAL and REPORT GENERATION PROGRAM:

: NOVpr -rsp FORM -chg in,me

8.2 -- Your INPUT file (in) is the DATA segment retrieved in step 5. The first retrieval yielded 310 records. The renamed labe $\overline{1}$ is: ORG.dt . (See figs. III-4 and III-5.)

8.3 -- Your selection criteria (mc) are the GROUNDWATER terms formulated as RETRIEVAL STATEMENT in steps 2.3 and 2.4.:

: des=pn"GROUNDWA"GROUND_WA"GROUND-WA"AQUIF"WELL" •

8.4 -- Enter the desired REPORT TITLE (See figs. III-7 and III-9.)

8.5 -- Rename your saved data segment!

NOTE: If you wish to create an alternate REPORT including "descriptors" proceed according to the sequence outlined in step 8A.: REFORMATTING procedure. 
ONE-STEP RETRIEVAL AND REPORT GENERATION PROGRAM:

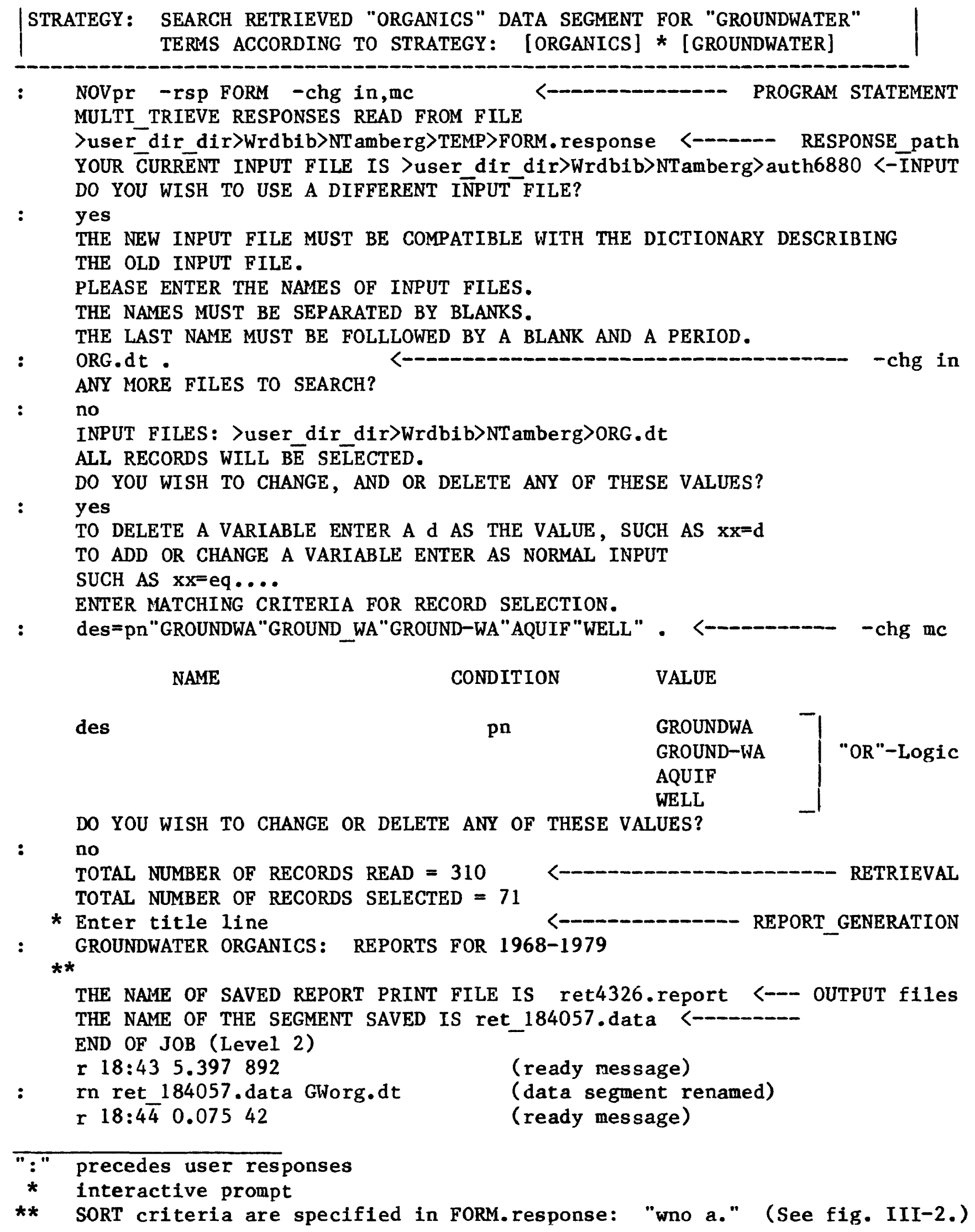
YOUR $\bar{C} U R R \bar{E} N T$ INPUT FILE IS > user dir dir $>$ Wrdbib>NTamberg>auth6880 <- $\overline{\text { INPUT }}$ DO YOU WISH TO USE A DIFFERENT IN $\bar{P}$ UT FILE? 
Step_8A: EXECUTE AN ALTERNATE REPORT GENERATION PROGRAM (Procedure):

Should you wish to create the final REPORT with "descriptors", execute a REPORT GENERATION program using the customized "newpr. response" file as CONTROL ARGUMENT. (See fig. III-8.). This file provides option to interactively specify the printing of an additional variable ("descriptors, des") in your custom REPORT. (See custom REPORT with descriptors in figure III-11.)

Enter--

$$
\text { : NOVpr -rsp newpr -chg in,mc (See fig. III-9.) }
$$

8A.1 -- Enter data segment, GWorg.dt, as your INPUT file

8A.2 -- Check for statement: ALL RECORDS WILL BE SELECTED. If the system states other selection criteria, delete as indicated and enter

: a11.

8A.3 -- Enter REPORT title

8A.4 -- Enter your response to "Enter add. print variable "des ${ }^{-} /$idn $^{-"}$ : des (system will supply descriptors in print REPORT.)

If you enter "idn" - the system will print a blank line!

8A.5 -- SORT sequence: There is no statement unless the "-chg sc" argument was entered in the PROGRAM STATEMENT. RESPONSE file "newpr. response" specifies an alphabetic SORT by "author", in ascending (a) sequence--from A to $Z$. The SORT format is, : aut a.

(See: Fig. III-9 - ALTERNATE REPORT GENERATION: REFORMATTING PROCEDURE. Fig. III-11. Example of custom REPORT format.)

NOTE: The interactive "Add print variable..." feature in RESPONSE file "newpr.response" lends itself to the execution of original RETRIEVAL AND REPORT GENERATION PROGRAMS using "Current" files (less than 2000 records.) If your retrieval volume is not large specify: "des" "descrptors" in your. PRINT REPORT. For large output specify 'idn' ( a blank 1ine).

See: DATA DICTIONARY "extdict" for definitions of data elements. (Use "print, pr" command or the "help DICT .ec" command!) 
RESPONSE FILE "newpr.response":

Use RESPONSE file "newpr.response" as "-response argument to generate a custom REPORT with descriptors. (See fig. III-8 below.)

NOTE: The "newpr.response" file includes two interactive options:

$$
\begin{aligned}
& -\langle \% \text {, string" }\rangle: \begin{array}{l}
\text { Allows to add a print variable from the DICTIONARY } \\
\text { "des" = "descriptors", to your print REPORT. } \\
\text { "idn" = adds a blank line! }
\end{array} \\
& -\langle \% S, \text { string" }\rangle: \text { Allows to enter a suitable REPORT title. }
\end{aligned}
$$

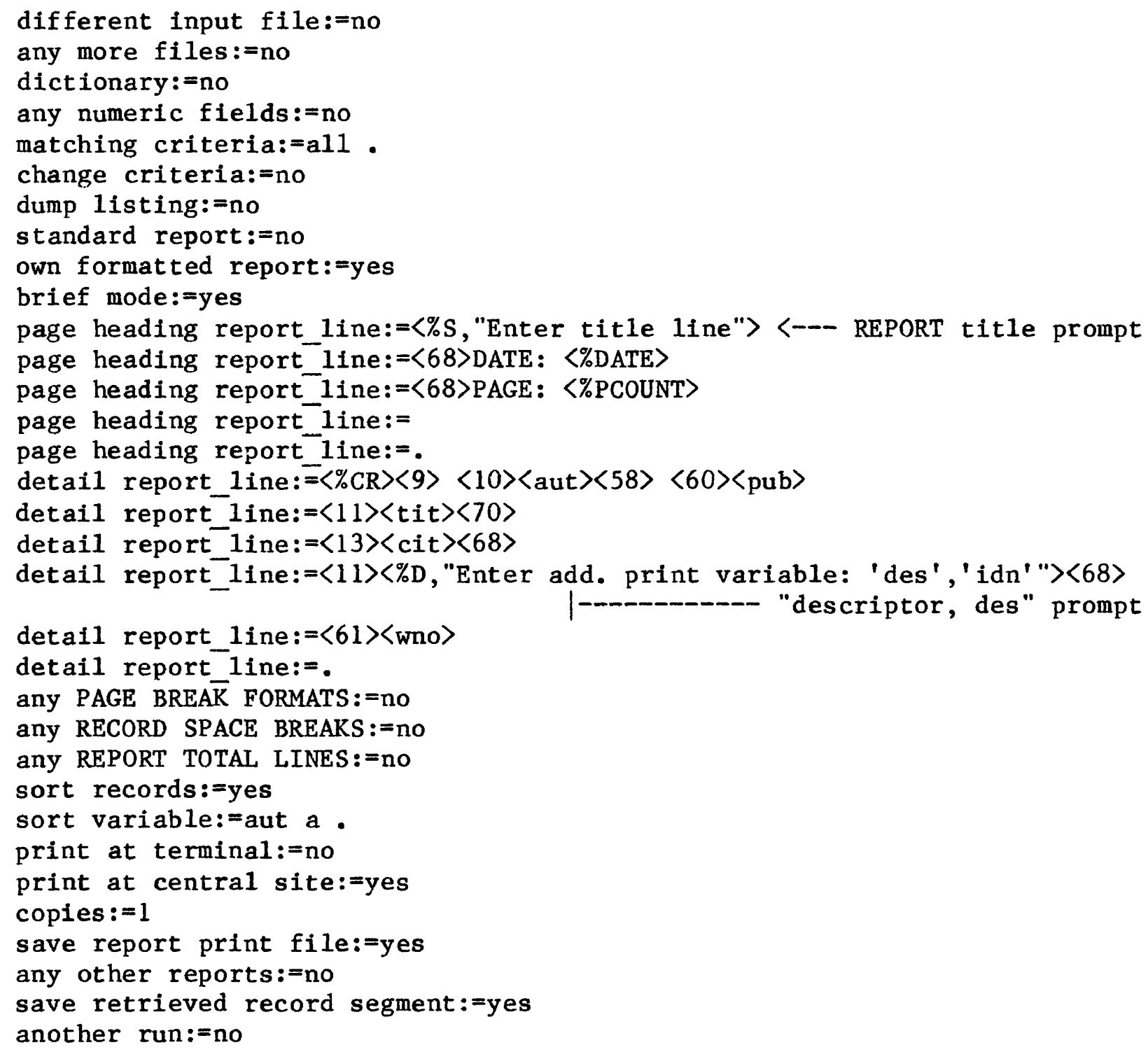

Figure III-8.--WRDBIB RESPONSE FILE: "newpr.response". Provides option to add print variable "descriptors" from Data Dictionary to custom Report. 
REFORMAT FINAL REPORT TO INCLUDE DESCRIPTORS:

-- Use "-response newpr" argument to include descriptors;

"-change in" argument to change the INPUT file.

-- Enter data segment retrieved on second retrieval as INPUT file.

-- ALL RECORDS WILL BE SELECTED. (See "-chg mc" prompt!)

Enter PROGRAM STATEMENT: (Note: User response follows intial ":")

: NOVpr - rsp newpr - chg in,mc PROGRAM STATEMENT

MULTI TRIEVE RESPONSES READ FROM FILE

>user_dir_dir>Wrdbib>NTamberg>TEMP>newpr.response <-- - - RESPONSE path YOUR $\overline{C U R R E} \bar{E}$ T INPUT FILE IS

>user dir dir>Wrdbib>NTamberg>TEMP>auth81 <DO YOŪ WI $\bar{S} H$ TO USE A DIFFERENT INPUT FILE?

: yes

THE NEW INPUT FILE MUST BE COMPATIBLE WITH THE DICTIONARY

DESCRIBING THE OLD INPUT FILE.

PLEASE ENTER THE NAMES OF INPUT FILES.

THE NAMES MUST BE SEPARATED BY BLANKS.

THE LAST NAME MUST BE FOLLLOWED BY A BLANK AND A PERIOD.

: GWorg.dt .

ANY MORE FILES TO SEARCH?

: no

INPUT FILES : >user_dir_dir>Wrdbib>NT amberg>TEMP>GWorg.dt $<---$ new INPUT

ALL RECORDS WILL BE SELECTED.

DO YOU WISH TO CHANGE, AND OR DELETE ANY OF THESE VALUES?

: no

(- no - chg mc

TOTAL NUMBER OF RECORDS READ $=71$

TOTAL NUMBER OF RECORDS SELECTED $=71$

/* Report format is specified by the newpr.response file. */

Enter title line

: GROUNDWATER ORGANICS: REPORTS FOR 1968-1979

Enter add print variable 'des' or 'idn'

: des

/* SORT criteria are specified as by "newpr.response": aut a . */

THE NAME OF SAVED REPORT PRINT FILE IS ret4326. report

THE NAME OF THE SEGMENT SAVED IS ret_184057.data

END OF JOB (Level 2)

r 18:43 5.397892

: d1 ret 184057.data

r $18: 4 \overline{4} 0.07542$
("Ready" message)

(Data segment deleted)

("Ready" message)

Figure III-9.--ALTERNATE REPORT GENERATION: REFORMATTING PROCEDURE. Using "add print variable" option provided by "newpr.response" file to specify "descriptors" in final REPORT. 
Step_9. EXECUTE FINAL AUTHOR INDEX PROGRAM (Procedure).

Enter PROGRAM STATEMENT to generate an AUTHOR INDEX for the second retrieval:

$\begin{array}{llll} & : & \text { NOVpr } & \text { rsp AUT } \\ \text { or } & : & \text { NOVpr in } & \\ & \text { NSp AUT -chg in, sc } & \text { (see above: step 7.) }\end{array}$

9.1 - Your INPUT file is the data segment created during the second retrieval process: GWorg.dt (renamed)

9.2 -- Change your "MATCH CRITERIA" to "all." (this is to reformat al1 (71) records retrieved during the second retrieval run.) Read and, if necessary, edit your RESPONSE file or add the "-chg mc" argument to your PROGRAM STATEMENT. (See step_8A.)

9.3 - Enter your REPORT title: AUTHOR INDEX for...... (Fig. III-10.)

(For PROGRAM EXECUTION see fig. III-10 •)

NOTE: REPORTS depicted in figures III-11 and III-12 are your desired RESULTS! 
INDEX PROGRAM EXECUTION EXAMPLE:

REPORT GENERATION program uses RESPONSE file "AUT.response" to create an AUTHOR INDEX to custom REPORT. (See fig. III-11.)

: NOVpr -rsp AUT - chg in

MULTI TRIEVE RESPONSES READ FROM FILE

(Note: ":" precedes user response)

$>$ udd $>\bar{W}$ r dbib $>$ NTamberg $>$ TEMP $>$ AUT . response

YOUR CURRENT INPUT FILE IS >udd>Wrdbib>NTamberg>auth8 1

DO YOU WISH TO USE A DIFFERENT INPUT FILE?

: yes

THE NEW INPUT FILE MUST BE COMPATIBLE WITH THE DICTIONARY DESCRIBING THE

OLD INPUT FILE.

PLEASE ENTER THE NAMES OF INPUT FILES.

THE NAMES MUST BE SEPARATED BY BLANKS.

THE LAST NAME MUST BE FOLLOWED BY A BLANK AND A PERIOD.

: GWorg.dt • (

ANY MORE FILES TO SEARCH?

: no

INPUT FILES : >udd>Wrdbib>NTamberg $>$ TEMP $>$ GWorg.dt

TOTAL NUMBER OF RECORDS READ $=71$

TOTAL NUMBER OF RECORDS RETRIEVED $=71$

RETRIEVAL

"Enter title line"

REPORT

: AUTHOR INDEX

GENERATION

THE NAME OF SAVED PRINT FILE IS ret5071.report*

END OF JOB (Leve1 2)

r $18: 507.0281278$

* The data segment is equal to the INPUT segment and has not been saved.

Figure III-10.--PROGRAM EXECUTION: CREATING AN AUTHOR INDEX

(Reformatting a previously retrieved data segment.) 
Step_10. CHECK "WORKING DIRECTORY":

-- List the latest $\mathrm{N}=6$ entries in your "Working Directory":

$$
\text { : Is -ft } 6 \quad(1 s \text {-ft } N \text {, where } N=1,2,3 \ldots \ldots)
$$

-- Rename files you wish to store:

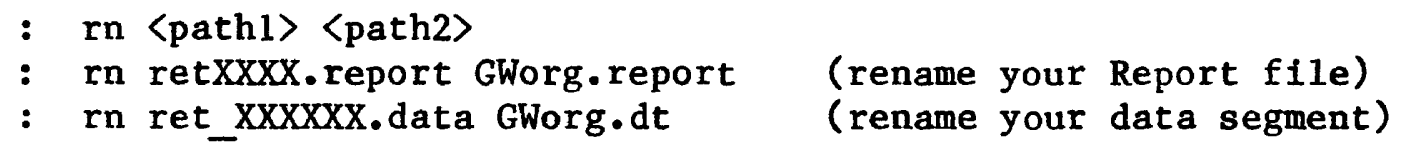

-- Delete (d1 〈path〉) data segments which are no longer needed:

: d1 〈path_1 path_2... path_N〉 (delete 1 to $\mathrm{N}$ segments)

: d1 *.data (System will delete all segments with labels ending in suffix .data)

NOTE: The "star convention" allows you to address all segments in your Working Directory using the common name component ".data". The star stands for any name preceding the common suffix! For the various uses of the star convention see the Multics Manual.

-- Deprint reports:

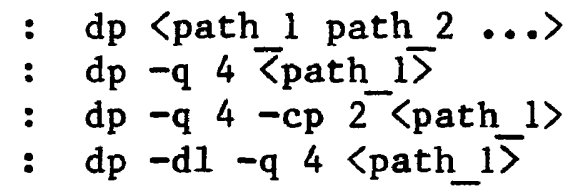

(Deprint long reports in queue 4!) (Deprint 2 copies in queue 4!) (Deprint report in queue 4 and

-- Check cost information (resource units, ru_) month to date:

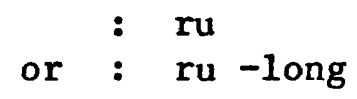

The system will print cost information for all transactions since the monthly closing date; "ru -long" will provide cumulation for the FY. (Note: You must be the project administrator to request "ru" information.)

-- logout

The system will confirm your logout and supply cost information for the current session. 
EXAMPLE: CUSTOM REPORT WITH DESCRIPTORS:

GROUNDWATER ORGANICS (Update)

DATE : $09 / 14 / 82$

PAGE : 1

1 HULL, R. W.; DYSART, J.E. ; AND MANN, W. B., IV; 1981 QUALITY OF SURFACE WATER IN THE SUWANNEE RIVER BASIN, FLORIDA, AUGUST 1968 THROUGH DECEMBER 1977, AVAILABLE FROM THE NATIONAL TECHNICAL INFORMATION SERVICE, SPRINGFIELD, VA 22161 AS PB81-206591, IN PAPER COPY, IN MICROFICHE. GEOLOGICAL SURVEY WATER-RESOURCES INVESTIGATIONS 80-110, 1981. $97 \mathrm{P}, 9$ FIG, 8 TAB, 21 REF. *WATER QUALITY, *STREAMS, *SURFACE-GROUNDWATER RELATIONS, WATER ANALYSIS, SPRINGS, SITES, DATA COLLECTIONS, SAMPLING, TRACE ELEMENTS, WATER PROPERTIES, NUTRIENTS, ORGANIC MATTER, WETLANDS, WASTE WATER, *FLORIDA, *SUWANNEE RIVER BASIN.

81-02992

2 MATTRAW, H. C., JR.; AND ELDER, J.F.;

NUTRIENT YIELD OF THE APALACHICOLA RIVER FLOOD PLAIN, FLORIDA: RIVER-QUALITY ASSESSMENT PLAN,

AVAILABLE FROM THE NATIONAL TECHNICAL INFORMATION SERVICE, SPRINGFIELD, VA 22161 AS PB81-103590, IN PAPER COPY, IN MICROFICHE. GEOLOGICAL SURVEY WATER-RESOURCES

INVESTIGATIONS 80-51, 1980. 21 P, 3 FIG, 1 TAB, 29 REF. *NUTRIENTS, *RIVERS, *FLOOD PLAINS, *WETLANDS, DETRITUS, RIVER FLOW, SAMPLING, MEASUREMENT, VEGETATION, TREES, DISTRIBUTION PATTERNS, DECOMPOSING ORGANIC MATTER, SURFACE-GROUNDWATER RELATIONSHIPS, TRACE ELEMENTS, PESTICIDES, *FLORIDA, REMOTE SENSING, *APALACHICOLA RIVER(FL), *RIVER QUALITY.

3 RIMA, D. R.; SUSCEPTIBILITY OF THE MEMPHIS WATER SUPPLY TO CONTAMINATION FROM THE PESTICIDE WASTE DISPOSAL SITE IN NORTHEASTERN HARDEMAN COUNTY, TENNESSEE, GEOLOGICAL SURVEY OPEN-FILE REPORT 79-750, 1979. 5 P, 1 FIG, 3 REF. *WATER POLLUTION, *PESTICIDES, *WASTE DUMPS, *WATER SUPPLY, *TENNESSEE, WASTE DISPOSAL, LEACHATE, GROUNDWATER MOVEMENT, PATH OF POLLUTANTS, WATER POLLUTION SOURCES, *HARDEMAN COUNTY(TN), MEMPHIS(TN).

$81-01192$

Figure III-11.--EDITED GROUND-WATER ORGANICS REPORT WITH DESCRIPTORS. 
EXAMPLE: AUTHOR INDEX REPORT:

INPUT FILES: >user_dir_dir $>$ Wrdbib $>$ NTamberg $>$ TEMP $>$ GWorg.dt

AUTHOR INDEX (Update)

DATE: $09 / 14 / 82$

PAGE : 1

\author{
WRSICNO AUTHOR \\ PUByr \\ 81-02992 HULL, R. W.; DYSART, J.E. ; AND MANN, W. B., IV; \\ 1981 \\ 81-04322 KAMMERER, P. A., JR.; \\ 1981 \\ 81-00350 MATTRAW, H. C., JR.; AND ELDER, J. F.; \\ 1980 \\ 81-01192 RIMA, D. R.; \\ 1979 \\ 81-00154 SIMMONS, C. E.; AND ALDRIDGE, M. C.; \\ 1980 \\ end of report
}

Figure III-12.--AUTHOR INDEX FOR GROUND-WATER ORGANICS REPORT. (In alphabetical sort sequence.) 